\title{
Evolution of MRI features of cerebral small vessel disease
}

Citation for published version (APA):

Loos, C. M. J. (2018). Evolution of MRI features of cerebral small vessel disease. [Doctoral Thesis, Maastricht University]. Datawyse / Universitaire Pers Maastricht. https://doi.org/10.26481/dis.20180928cl

Document status and date:

Published: 01/01/2018

DOI:

$10.26481 /$ dis.20180928cl

Document Version:

Publisher's PDF, also known as Version of record

\section{Please check the document version of this publication:}

- A submitted manuscript is the version of the article upon submission and before peer-review. There can be important differences between the submitted version and the official published version of record.

People interested in the research are advised to contact the author for the final version of the publication, or visit the DOI to the publisher's website.

- The final author version and the galley proof are versions of the publication after peer review.

- The final published version features the final layout of the paper including the volume, issue and page numbers.

Link to publication

\footnotetext{
General rights rights.

- You may freely distribute the URL identifying the publication in the public portal. please follow below link for the End User Agreement:

www.umlib.nl/taverne-license

Take down policy

If you believe that this document breaches copyright please contact us at:

repository@maastrichtuniversity.nl

providing details and we will investigate your claim.
}

Copyright and moral rights for the publications made accessible in the public portal are retained by the authors and/or other copyright owners and it is a condition of accessing publications that users recognise and abide by the legal requirements associated with these

- Users may download and print one copy of any publication from the public portal for the purpose of private study or research.

- You may not further distribute the material or use it for any profit-making activity or commercial gain

If the publication is distributed under the terms of Article $25 \mathrm{fa}$ of the Dutch Copyright Act, indicated by the "Taverne" license above, 


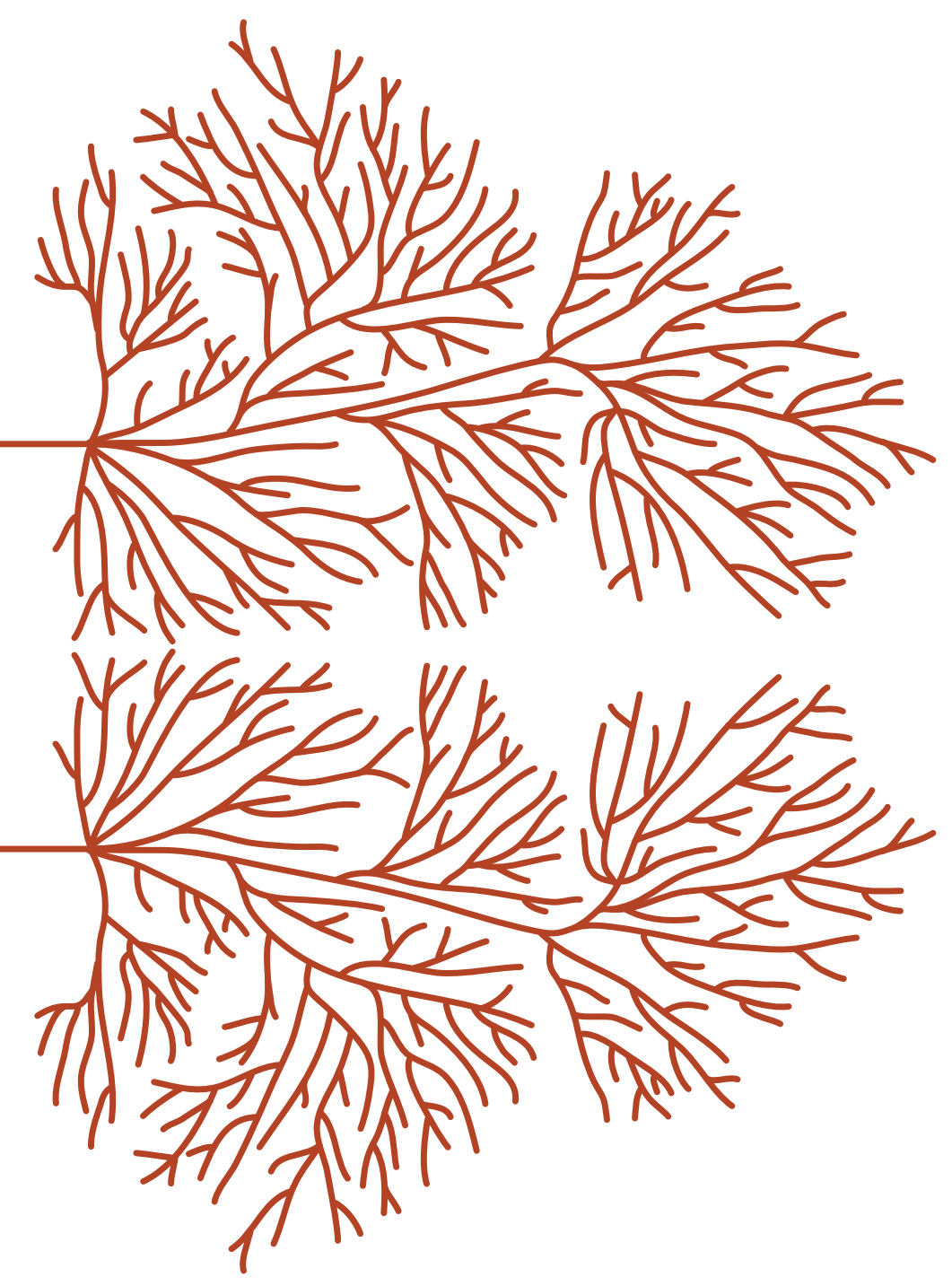

EVOLUTION OF MRI FEATURES OF CEREBRAL SMALL VESSEL DISEASE

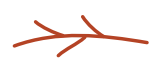

CAROLINE M.J. LOOS 
C) copyright Caroline Loos, Maastricht 2018

Cover by Christine Loos, 2018

Printing: Datawyse | Universitaire Pers Maastricht

ISBN 9789493019584

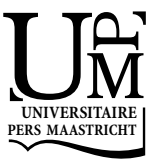




\title{
Evolution of MRI features of cerebral small vessel disease.
}

\author{
PROEFSCHRIFT
}

ter verkrijging van de graad van doctor aan de Universiteit Maastricht, op gezag van de Rector Magnificus, Prof. dr. Rianne M. Letschert volgens het besluit van het College van Decanen, in het openbaar te verdedigen op vrijdag 28 september 2018 om 12.00 uur

door

Caroline Maria Jozef Loos 
Promotor

Prof. dr. R.J. van Oostenbrugge

Copromotor

Dr. J.E.A. Staals

Beoordelingscommissie

Prof. dr. W. H. Mess (voorzitter)

Prof. dr. P.A.M. Hofman

Prof. dr. C.J.M. Klijn (Radboud UMC)

Dr. M.L. Kuijf

Prof. dr. P.M. Parizel (Universitair Ziekenhuis Antwerpen)

The research described in this thesis was performed at the Department of Neurology, Maastricht University Medical Centre, and at the Brain Research Imaging Centre and Centre for Clinical Brain Sciences at The University of Edinburgh, and within Cardiovascular Research Institute Maastricht (CARIM) of Maastricht University. Financial support by the Dutch String-of-Pearls Stroke Initiative and Dutch Alzheimer Foundation. 
Voor Maria Van Assche 


\section{Abbreviations}

24-h DBP 24-hour ambulatory Diastolic Blood Pressure levels

24-h SBP 24-hour ambulatory Systolic Blood Pressure levels

BBB Blood-Brain Barrier

BP Blood Pressure

CADASIL Cerebral Autosomal Dominant Arteriopathy with Subcortical Infarcts and Leukoencephalopathy

CBF Cerebral Blood Flow

CMB Cerebral Microbleeds

CI Confidence Interval

CSF Cerebrospinal Fluid

cSVD cerebral Small Vessel Disease

DWI Diffusion-Weighted Imaging

FLAIR Fluid Attenuated Inversion Recovery

GRE Gradient Echo

MR(I) Magnetic Resonance (Imaging)

mRS modified Rankin Scale

NIHSS National Institute of Health Stroke Scale

OR Odds Ratio

PVS Perivascular Spaces

SD Standard Deviation

SIS Stroke Impact Scale

SPSS Statistical Package for the Social Sciences

STRIVE Standards for Reporting Vascular Changes on Neuroimaging

$\mathrm{T} \quad$ Tesla

TUG(T) Timed-Up-and-Go (Test)

WMH White Matter Hyperintensity 


\section{Table of contents}

Abbreviations $\quad 6$

Chapter 1 Introduction and outline of thesis. 9

Chapter 2 Cavitation of deep lacunar infarcts in first-ever lacunar stroke patients: a two-year follow-up study with MR.

Chapter 3 The appearance of a new white matter hyperintensity just adjacent to the old infarct in first-ever lacunar stroke patients: a 2-year follow-up study with MR.

Chapter 4 Long-term morphological changes of symptomatic lacunar infarcts and surrounding white matter on structural MRI.

Chapter 5 Association between perivascular spaces and progression of white matter hyperintensities in lacunar stroke patients.

Chapter 6 The relation between total cerebral small vessel disease burden and gait impairment in patients with minor stroke.

Chapter 7 General discussion and future perspectives.

Summary.

Nederlandse samenvatting.

Valorisation.

Dankwoord.

List of publications.

Curriculum Vitae. 



\section{CHAPTER 1}

Introduction and outline of thesis. 



\section{INTRODUCTION AND OUTLINE OF THESIS}

\section{Lacunar stroke and cerebral small vessel disease}

Stroke is the third leading cause of death in most Western countries and one of the leading causes of long-term disability worldwide. Therefore, stroke puts a major burden on the healthcare system and society in general.

Stroke can be divided into ischemic stroke $( \pm 80 \%)$ and haemorrhagic stroke $( \pm$ $20 \%$ ). Ischemic stroke can be further subtyped into (cardio-)embolic stroke $( \pm 25 \%$ ), large vessel atherosclerotic stroke $( \pm 25 \%)$, lacunar stroke $( \pm 25 \%)$, stroke with rare causes $( \pm 5 \%)$ and stroke with undetermined cause $( \pm 20 \%)^{1}$. Lacunar stroke is characterized by one of the clinical lacunar syndromes with a compatible lacunar infarct - also called small subcortical infarct - on brain imaging ${ }^{2}$. Lacunar infarcts are small infarcts located in the territory of a small artery or arteriole penetrating the deep parts of the brain $^{2}$. The underlying pathology causing lacunar infarcts is cerebral small vessel disease (cSVD). This is an umbrella term covering all pathological processes involving the small perforating vessels in the brain, including the most prevalent form which is age- and cardiovascular risk factor associated cSVD (arteriolosclerosis).

Cerebral SVD results in brain damage in the cerebral white and deep grey matter, which is radiologically not only represented by lacunar infarcts (small subcortical infarcts), but also by lacunes, white matter hyperintensities (WMH), cerebral microbleeds (CMB) and perivascular spaces (PVS) ${ }^{2-3}$. These are called "MRI markers of cSVD" on which we will elaborate later on in this chapter.

\section{Clinical features of cerebral small vessel disease}

Clinically, cSVD can present with acute symptoms, such as an acute lacunar stroke syndrome $^{4}$, and with symptoms that have a more protracted course, such as vascular cognitive impairment ${ }^{3,5}$, mood and behavioral disorders ${ }^{6}$, gait and balance impairment ${ }^{7}$, urinary symptoms ${ }^{8}$ and general functional disability ${ }^{9-10}$. In the early stage of cSVD, these subacute symptoms can be mild. However, cSVD is a progressive disease and in the late stage of cSVD, symptoms may progress to vascular dementia, which is the second most common type of dementia after Alzheimer's disease ${ }^{2-3}$, gait impairment with frequent falls, resembling lower body parkinsonism, and prominent depressive symptoms or even apathy ${ }^{3}$.

The prognosis of lacunar stroke is not more benign than other ischemic stroke types regarding stroke recurrence, long term disability and mortality ${ }^{11-12}$. Furthermore, "silent" or background cSVD at the time of an index stroke has prognostic implications: functional recovery after stroke is worse in patients with coexisting MRI features of cSVD 9 10,13-14. Taken all together, cSVD is not an innocent disease of aging.

Most research on the subacute clinical consequences of cSVD has been focusing on cognitive impairment. Studies have shown associations between severity of individual MRI markers and cognitive decline ${ }^{3,5}$. Lacunes, extensive WMH and CMB have been 
independently associated with worse cognitive function ${ }^{5,15}$ and PVS in the basal ganglia are also associated with cognitive impairment, independent of $\mathrm{WMH}^{16}$. Gait impairment in cSVD has gained far less research attention than cognitive function, although it is a serious consequence of cSVD that is associated with increased morbidity and mortality ${ }^{7}$ Studies in patients with clinical cSVD, showed that $\mathrm{WMH}^{7,17}$, the number of lacunes ${ }^{7}$ and $\mathrm{CMB}^{18}$ are independently associated with concurrent gait impairment. Furthermore, there is evidence that cSVD contributes to gait disturbances even at a preclinical level ${ }^{7}$.

\section{Pathogenesis of cerebral small vessel disease}

The exact pathogenesis of cSVD is still largely unknown. There is increasing evidence that activation of the cerebral microvascular endothelium might be one of the primary steps in the pathogenesis of cSVD, subsequently leading to increased permeability of the blood-brain barrier (BBB) ${ }^{19-20}$. The $\mathrm{BBB}$, formed by the brain capillary endothelium, is a highly selective semipermeable membrane barrier, which protects neural tissue from variations in blood composition, pathogens and toxins. An intact BBB is essential for maintaining a micro-environment that allows neuronal circuits to function properly. Compromised BBB integrity manifests mainly as increased barrier permeability, which allows blood products to cross the vessel wall and perivascular space. It leads to dilatation of perivascular spaces and causes vascular, as well as neural inflammation, resulting in progressively impaired vascular function, including decreased cerebrovascular reactiv$i^{21}$. In the end stages, these pathological processes result in luminal narrowing and occlusion, precipitating discrete focal brain parenchymal ischemic lesions (lacunes and WMH) and vessel wall rupture, leading to cerebral microbleeds and even major deep hemorrhages $^{2-3}$.

\section{Etiology of cerebral small vessel disease}

Cerebral SVD is significantly associated with vascular risk factors. Age indisputably is the most important vascular risk factor for cSVD. The incidence of lacunar stroke increases with age and age is also strongly related to MRI markers of cSVD ${ }^{22}$. Furthermore, the cerebrovascular endothelium becomes increasingly permeable with age ${ }^{23}$.

Hypertension is the second most important risk factor for cSVD ${ }^{2}$. Studies have shown that hypertension could lead to endothelial dysfunction and BBB breakdown 2,24 . However, hypertension is not a unique risk factor for cSVD. Hypertension, and other vascular risk factors, including hypercholesterolemia, (current) smoking and diabetes mellitus, are equally common in patients with non-lacunar stroke as they are in patients with lacunar stroke ${ }^{25}$.

Furthermore, not all patients with cSVD have hypertension and/or vascular risk factors, so other factors must be involved. A positive family history of stroke is an independent risk factor for lacunar stroke, especially in young patients and in patients with concomitant extensive WMH, which suggests a significant genetic contribution to cSVD $^{26}$. This is probably a polygenetic contribution. Rarely, cSVD is caused by a 
monogenetic disease, with CADASIL (cerebral autosomal dominant arteriopathy with subcortical ischaemic strokes and leukoencephalopathy) and Fabry's disease as the most common inherited cSVD ${ }^{27}$.

\section{MRI features of cerebral small vessel disease}

Several features of cSVD can been seen on imaging, preferably magnetic resonance imaging (MRI). These imaging features include recent small subcortical infarcts (lacunar infarcts), WMH, lacunes, PVS, CMB and brain atrophy ${ }^{28}$. These MRI features are used in many studies as markers for presence and extent of cSVD. Furthermore, these different MRI markers are often used as surrogate outcome measures in therapeutic studies with cSVD patients (for example therapies to slow down WMH progression instead of reducing cognitive decline). Therefore, it is important that we understand the radiological evolution of these MRI features. However, patterns of progression of these imaging features have been studied little in patients with cSVD.

\section{MRI features: recent small subcortical infarct}

A recent lacunar infarct - also called small subcortical infarct - is defined as an ovoid or round lesion (with axial diameter $<20 \mathrm{~mm}$ ) in the basal ganglia, internal capsule, centrum semiovale or brainstem (Figure 1.1) ${ }^{28}$.
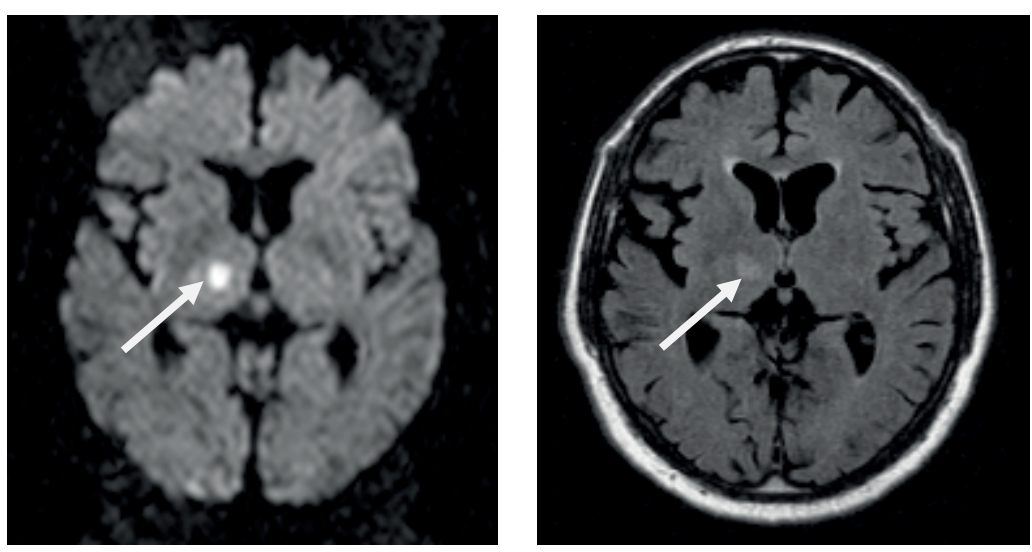

Figure 1.1 Recent lacunar infarct in the right thalamus (MRI, DWI and FLAIR).

The typical MRI signal characteristics are a hyperintense area on diffusion-weighted imaging (DWI) with corresponding reduced signal on apparent diffusion coefficient imaging, with or without increased signal on T2-weighted or fluid-attenuated inversion recovery imaging (FLAIR), reduced signal on T1-weighted imaging, corresponding with a typical small vessel territory ${ }^{29}$ and can be carefully distinguished from $\mathrm{WMH}^{30}$. These may evolve into a cavitated lacune, although few studies studied their evolution over time ${ }^{31-32}$. 
Sporadically, a recent asymptomatic small subcortical infarct is identified by coincidence on brain MRI and is referred to as a silent recent lacunar infarct ${ }^{28,33}$. Furthermore, in up to $30 \%$ of symptomatic lacunar stroke patients, no visible small subcortical infarct is seen on brain MRI imaging ${ }^{34}$.

\section{MRI features: lacunes}

Lacunes - formerly called asymptomatic lacunar infarcts - are defined as round or ovoid lesions ( $<20 \mathrm{~mm}$ axial diameter) of cerebrospinal fluid (CSF) signal intensity on T2 and FLAIR, generally with a hyperintense rim on FLAIR and no increased signal on DWI, in the basal ganglia, internal capsule, centrum semiovale or brainstem ${ }^{28}$ (Figure 1.2). They are cavitated lesions, evolved from symptomatic or silent lacunar infarcts.
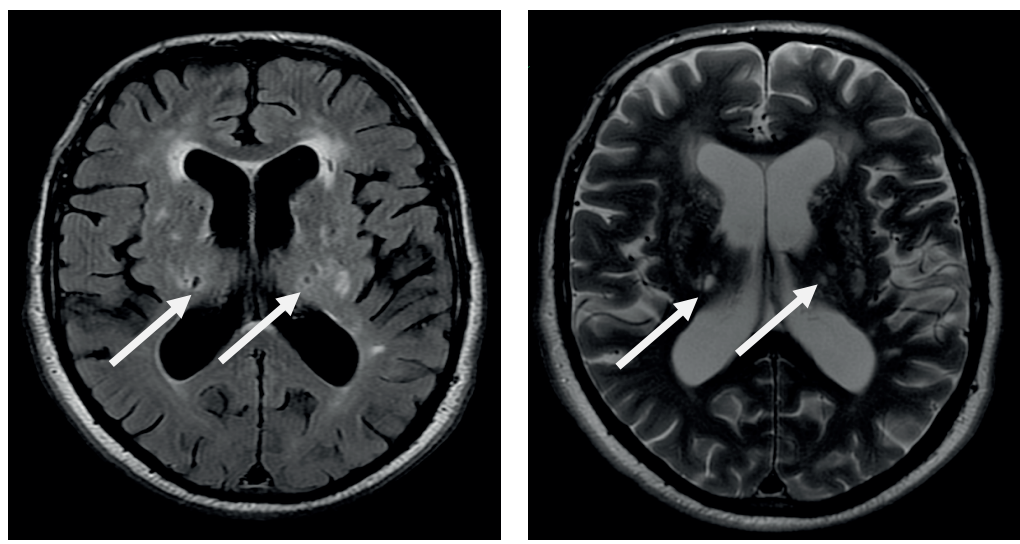

Figure 1.2 Bilateral lacunes in thalamus and posterior leg of internal capsule (MRI, FLAIR and T2).

\section{MRI features: white matter hyperintensities}

White matter hyperintensities of presumed vascular origin are bilateral, mostly symmetrical hyperintensities on FLAIR and T2-weighted MR imaging, located in the periventricular and deep white matter of the brain ${ }^{28}$ (Figure 1.3). The extent can be visually rated using the Fazekas' scale ${ }^{35}$. 

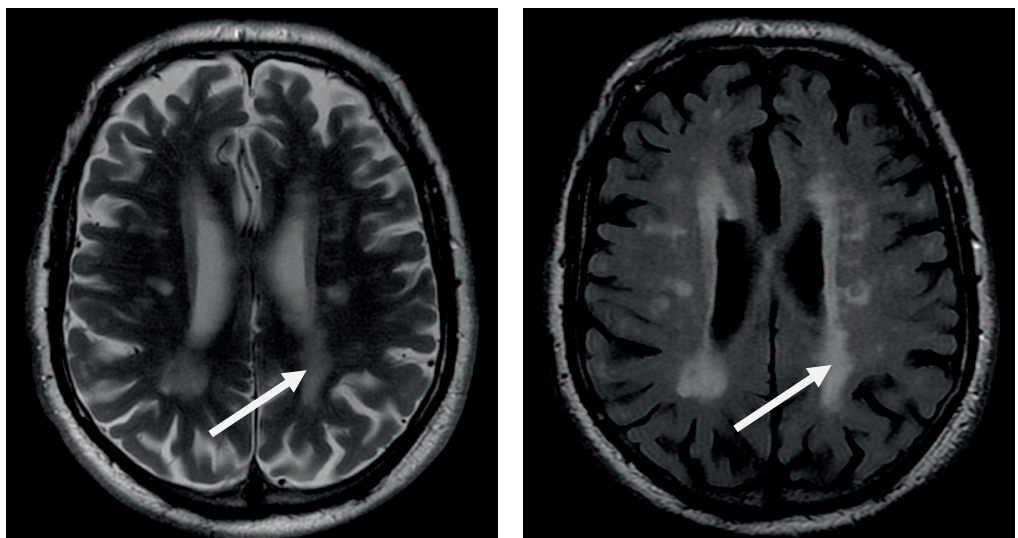

Figure 1.3 Bilateral periventricular white matter hyperintensities (MRI, T2 and FLAIR).

\section{MRI features: perivascular spaces}

Perivascular spaces (PVS) - also known as enlarged Virchow-Robin spaces - are dilated cerebrospinal fluid (CSF)-filled spaces surrounding the small penetrating cerebral vessels in the basal ganglia and centrum semiovale 28 (Figure 1.4). On MRI PVS are defined as round, oval or linear-shaped lesions with a smooth margin, absence of mass effect and with CSF signal intensity on T2-weighted images, and (if visible) hypointense on FLAIR without a hyperintense rim to distinguish them from lacunes ${ }^{28}$. PVS are considered an early imaging feature of $\mathrm{cSVD}^{28}$.
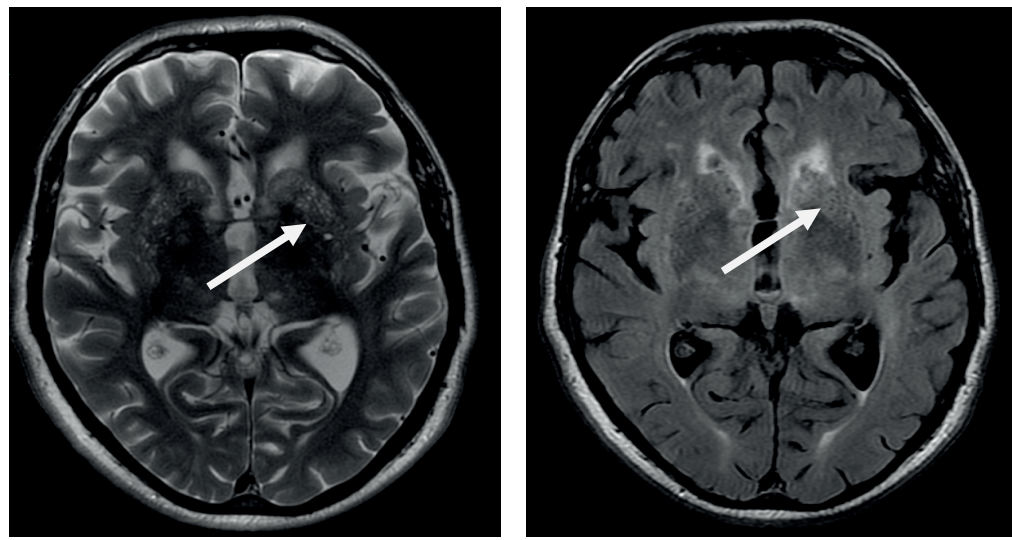

Figure 1.4 Bilateral extensive perivascular spaces in the basal ganglia (MRI, T2 and FLAIR).

\section{MRI features: cerebral microbleeds}

Cerebral microbleeds (CMB) are old micro-hemorrhages, consistent with vascular leakage of blood cells through the vessel wall. On MRI CMB are defined as small homogeneous, round foci of low signal intensity on T2*-weighted gradient echo (GRE) in the white matter, basal ganglia, brainstem, cerebellum or cortico-subcortical junction, with 


\section{Chapter 1}

a diameter $<5 \mathrm{~mm}$, and are differentiated from vessel flow voids and mineral depositions in the basal ganglia 28 (Figure 1.5).

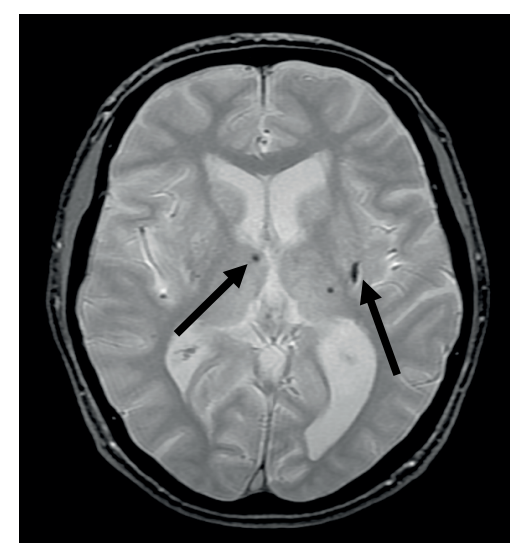

Figure 1.5 Bilateral cerebral microbleeds in the thalamus and left lenticular nucleus (MRI, GRE).

\section{MRI features: brain atrophy}

Brain atrophy in context of cSVD is defined as a lower brain volume in relation to intracranial volume that is not related to a specific macroscopic focal injury such as infarction, and which is assumed from the enlargement of peripheral (sulcal) and central (ventricular) CSF spaces $^{28}$.

\section{Total cerebral small vessel disease burden}

One of the causes for the lack of knowledge about pathogenesis of cSVD is that most research has focused on individual MRI features of cSVD rather than recognizing the combined components as one whole. The MRI markers of cSVD do not occur in isolation. To capture the overall effect of cSVD on the brain, a total cSVD MRI burden score, based on visual MRI feature recognition, was developed ${ }^{36-39}$. The total cSVD burden score (with a range of $0-4$ ) is an ordinal score, which counts the presence of 4 MRI features of cSVD: one point is awarded when one or more lacunes are present, one point for presence of one or more CMB, one point in case of (early) confluent deep WMH and/or irregular periventricular WMH extending into the deep white matter and one point for presence of moderate to severe PVS at the basal ganglia ${ }^{36-37}$.

The total cSVD MRI burden score might represent better the overall severity of cSVD. It comprehends better the relation between risk factors and brain injury ${ }^{37-38}$ and the overall effect of cSVD on cognitive function ${ }^{36,39}$. 


\section{General aim and objectives}

The general aim of this thesis is to gain more insights into the natural disease course of cSVD, by assessing radiological evolution and progression of MRI features of cSVD.

Research objective 1 - To assess the MR imaging evolution (cavitation) of symptomatic lacunar infarcts over two years of follow-up in patients with first-ever lacunar stroke (Chapter 2).

Few studies have assessed the evolution of symptomatic lacunar infarcts over time. It is unclear whether they always cavitate and evolve into a lacunar cavity ${ }^{31}$. They may also disappear leaving no visible lesion on MR imaging ${ }^{31}$, or stay as a hyperintensity without apparent cavitation on T2-weighted sequences and resemble a $\mathrm{WMH}^{28}$. Estimates of the proportion of recent small subcortical infarcts that cavitate and become a lacune range from $28 \% \%^{31}$ to $60 \% 0^{32}$. However, these neuroimaging studies included patients over a wide range of times to follow-up imaging, partly used CT for imaging and had relative small sample sizes ${ }^{31-32}$. Therefore, in chapter 2 , we assess evolution of symptomatic lacunar infarcts over two years of follow-up on MR imaging in a first-ever lacunar stroke population. We also determine which patient-related and imaging-related variables are associated with cavitation over time.

Research objective 2 - To describe a MR imaging observation of occurrence of new WMH "capped" on the symptomatic lacunar infarct during two years of follow-up in patients with first-ever lacunar stroke (Chapter 3).

To gain more insights into the evolution of symptomatic lacunar infarcts, we performed a longitudinal neuro-imaging study over two years of follow-up in first-ever lacunar stroke patients. During the assessment of these imaging results, we noticed the occurrence of new WMH "capped" (WMH “caps") on (adjacent to) the symptomatic lacunar lesion. We describe our thoughts on this observation in chapter 3.

Research objective 3 - To confirm our MR imaging observation of secondary white matter changes adjacent to lacunar infarcts in a different lacunar stroke patient cohort with 1 to 5-year follow-up imaging (Chapter 4).

In chapter 3, we observed new WMH distally from the index lacunar infarct. Other neuroimaging studies showed that lacunes tend to develop at the edge of WMH and that there is often a spread of WMH around incident lacunes ${ }^{40}$. These studies suggest a spatial relationship in progression of WMH and lacunes. In chapter 4, we investigate the natural disease course of sporadic cSVD by assessing the long-term changes in imaging appearance of symptomatic lacunar infarcts and the adjacent white matter in a (different) lacunar stroke cohort. We describe WMH "caps" and "tracks". 
Research objective 4 - To determine the association between severity of PVS and progression of WMH over two years in first-ever lacunar stroke patients (Chapter 5).

PVS are associated with other MRI markers of cSVD, especially WMH ${ }^{41}$. They seem to appear early in the course of cSVD and the amount of PVS might be an early MR marker of brain damage related to cSVD. However, it is unknown whether PVS predate and are related with further progression of cSVD, especially progression of WMH. Therefore, in chapter 5, we determine if PVS are associated with progression of WMH over two years in first-ever lacunar stroke patients.

Research objective 5 - To determine if the overall cSVD-related brain damage, measured by the total cSVD burden score, is associated with gait disturbances after three years in patients with minor stroke (Chapter 6).

There is increasing evidence that a total cSVD MRI burden score, which summarizes individual cSVD markers, might better reflect the overall effect of cSVD on the brain. Whether total cSVD-related brain damage is associated with one of the less recognized clinical features of cSVD, namely gait impairment, is unknown. In chapter 6, we determine if the total burden of cSVD is related with mobility impairment in minor stroke patients.

\section{Outline of the thesis}

Chapter 1 presents an introduction and the general aim of this thesis. The research objectives are addressed in chapter 2-6. In chapter 7, a general discussion regarding the findings of this thesis is presented, also considering the strengths and weaknesses of the studies. Directions for future research are pointed out. 


\section{References}

1. Sudlow CLM, Warlow CP. Comparable studies of the incidence of stroke and its pathological types. Results from an international collaboration. Stroke 1997;28:491-499.

2. Wardlaw JM, Smith C, Dichgans M. Mechanisms of sporadic cerebral small vessel: insights from neuroimaging. Lancet Neurol 2013;12:483-497.

3. Pantoni L. Cerebral small vessel disease: from pathogenesis and clinical characteristics to therapeutic challenges. Lancet Neurol 2010;9:689-701.

4. Fisher CM. Lacunar strokes and infarcts: a review. Neurology 1982;32:871-876.

5. van der Flier WM, van Straaten EC, Barkhof F, Verdelho A, Madureira S, Pantoni L, et al. Small vessel disease and general cognitive function in nondisabled elderly: the LADIS study. Stroke 2005;36:2116-2120.

6. White CL, McClure LA, Wallace PM, Braimah J, Liskay A, Roldan A, et al. The correlates and course of depression in patients with lacunar stroke: results from the Secondary Prevention of Small Subcortical Strokes (SPS3) study. Cerebrovasc Dis 2011;32:354-360.

7. de Laat KF, van Norden AG, Gons RA, van Oudheusden LJ, van Uden IW, Bloem BR, et al. Gait in elderly with cerebral small vessel disease. Stroke 2010;41:1652-1658.

8. Poggesi A, Pracucci G, Chabriat H, Erkinjuntti T, Fazekas F, Verdelho A, et al. Urinary complaints in nondisabled elderly people with age-related white matter changes: the Leukoaraiosis And DISability (LADIS) Study. J Am Geriatr Soc 2008;56:1638-1643.

9. Leonards CO, Ipsen N, Malzahn U, Fiebach JB, Endres M, Ebinger M. White matter lesion severity in mild acute ischemic stroke patients and functional outcome after 1 year. Stroke 2012;43:3046-3051.

10. Kim BJ, Leeb SH. Prognostic Impact of Cerebral Small Vessel Disease on Stroke Outcome. J Stroke 2015;17:101-110.

11. Sacco S, Marini C, Totaro R, Russo T, Cerone D, Carolei A. A population-based study of the incidence and prognosis of lacunar stroke. Neurology 2006;66:1335-1338.

12. Norrving B. Lacunar infarcts: no black holes in the brain are benign. Pract Neurol 2008;8:222-228.

13. de Jong G, Kessels F, Lodder J. Two types of lacunar infarcts, further arguments from a study on prognosis. Stroke 2002;33:2072-2076.

14. Debette S, Markus HS. The clinical importance of white matter hyperintensities on brain magnetic resonance imaging: systematic review and meta-analysis. BMJ 2010;341:c3666.

15. Charidimou A, Werring DJ. Cerebral microbleeds and cognition in cerebrovascular disease: an update. J Neurol Sci 2012;322:50-55.

16. Huijts M, Duits A, Staals J, Kroon AA, de Leeuw PW, van Oostenbrugge RJ. Basal ganglia enlarged perivascular spaces are linked to cognitive function in patients with cerebral small vessel disease. Curr Neurovasc Res 2014;11:136-141.

17. Baezner H, Blahak C, Poggesi A, Pantoni L, Inzitari D, Chabriat H, et al. Association of gait and balance disorders with age-related white matter changes: the LADIS study. Neurology 2008;70:935-942.

18. de Laat KF, van den Berg HA, van Norden AG, Gons RA, Olde Rikkert MG, de Leeuw FE. Microbleeds are independently related to gait disturbances in elderly individuals with cerebral small vessel disease. Stroke 2011;42:494-497.

19. Wardlaw JM, Sandercock PA, Dennis MS, Starr J. Is breakdown of the blood-brain barrier responsible for lacunar stroke, leukoaraiosis, and dementia? Stroke 2003;34:806-812.

20. Knottnerus ILH, Ten Cate H, Lodder J, Kessels F, van Oostenbrugge RJ. Endothelial dysfunction in lacunar stroke: A systematic review. Cerebrovasc Dis 2009;27:519-526.

21. Obermeier B, Daneman R, Ransohoff RM. Development, maintenance and distuption of the blood-brain barrier. Nat Med 2013;19:1584-1596.

22. Bamford J, Sandercock P, Jones L and Warlow C. The natural history of lacunar infarction: the Oxfordshire Community Stroke Project. Stroke 1987;18:545-551.

23. Farrall AJ, Wardlaw JM. Blood brain barrier: ageing and microvascular disease: systemic review and metaanalysis. Neurobiol Aging 2007;30:337-352.

24. Dharmashankar K, Widlansky ME. Vascular endothelial function and hypertension: insights and directions. Curr Hypertens Rep 2010;12:448-455.

25. Jackson CA, Hutchison A, Dennis MS, Wardlaw JM, Lindgren A, Norrving B, et al. Differing risk factor profiles of ischemic stroke subtypes: evidence for a distinct lacunar arteriopathy? Stroke 2010;41:624-629. 


\section{Chapter 1}

26. Knottnerus IL, Gielen M, Lodder J, Rouhl RP, Staals J, Vlietinck R, et al. Family history of stroke is an independent risk factor for lacunar stroke subtype with asymptomatic lacunar infarcts at younger ages. Stroke 2011;42:1196-1200.

27. Dichgans M. Genetics of ischaemic stroke. Lancet Neurol 2007;6:149-161.

28. Wardlaw JM, Smith EE, Biessels GJ, Cordonnier C, Fazekas F, Frayne R, et al. Neuroimaging standards for research into small vessel disease and its contribution to ageing and neurodegeneration. Lancet Neurol 2013;12:822-838.

29. Warlow C, van Gijn J, Dennis M, et al. Is it a vascular event and where is the lesion? Identifying and interpreting the symptoms and signs of cerebrovascular disease. In: Warlow C, van Gijn J, Dennis M, et al. Stroke: Practical Management, 3rd ed. Malden, MA: Blackwell Publishing 2008:35-130.

30. Wang X, Valdés Hernández MC, Doubal F, Chappell FM, Wardlaw JM. How much do focal infarcts distort white matter lesions and global cerebral atrophy measures? Cerebrovasc Dis 2012;34:336-342.

31. Potter GM, Marlborough FJ, Wardlaw JM. Wide variation in Definition, Detection, and Description of Lacunar Lesions on Imaging. Stroke 2011;42:359-366.

32. Koch S, McClendon MS, Bhatia R. Imaging evolution of acute lacunar infarction. Leukoaraiosis or lacune? Neurology 2011;77:1091-1095.

33. Chowdhury D, Wardlaw JM, Dennis MS. Are multiple acute small subcortical infarctions caused by embolic mechanisms? J Neurol Neurosurg Psychiatry 2004;75:1416-1420.

34. Doubal FN, Dennis MS, Wardlaw JM. Characteristics of patients with minor ischaemic strokes and negative MRI: a cross sectional study. J Neurol Neurosurg Psychiatry 2011;82:540-542.

35. Fazekas F, Chawluk JB, Alavi A, Hurtig HI, Zimmerman RA. MR signal abnormalities at 1.5 T in Alzheimer's dementia and normal aging. Am J Roentgenol. 1987;149:351-356.

36. Huijts M, Duits A, Van Oostenbrugge RJ, Kroon AA, de Leeuw PW, Staals J. Accumulation of MRI markers of cerebral small vessel disease is associated with decreased cognitive function. A study in first-ever lacunar stroke and hypertensive patients. Front. Aging Neurosci 2013;5:72.

37. Klarenbeek P, Van Oostenbrugge RJ, Rouhl RP, Knottnerus, ILH, Staals J. Ambulatory blood pressure in patients with lacunar stroke: association with total MRI burden of cerebral small vessel disease. Stroke 2013;44:2995-2999.

38. Staals J, Makin S, Doubal FN, Dennis MS, Wardlaw JM. Stroke subtype, vascular risk factors and total MRI brain small-vessel disease burden. Neurology 2014;83:1228-1234.

39. Staals J, Booth T, Morris Z, Bastin ME, Gowd AJ, Corley J, et al. Total MRI load of cerebral small vessel disease and cognitive ability in older people. Neurobiology of Aging 2015;36:2806-2811.

40. Duering M, Csanadi E, Gesierich B, Jouvent E, Hervé D, Seiler S, et al. Incident lacunes preferentially localize to the edge of white matter hyperintensities: insights into the pathophysiology of cerebral small vessel disease. Brain 2013;136:2717-2726.

41. Doubal FN, MacLullich AM, Ferguson KJ, Dennis MS, Wardlaw JM. Enlarged perivascular spaces on MRI are a feature of cerebral small vessel disease. Stroke 2010;41:450-454. 


\section{CHAPTER 2}

\section{Cavitation of deep lacunar infarcts in first-ever lacunar stroke patients: a two-year follow-up study with MR.}

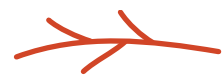

Loos CM, Staals J, Wardlaw JM, van Oostenbrugge RJ.

Cavitation of deep lacunar infarcts in first ever lacunar stroke patients: a two year follow-up study with MR.

Stroke 2012;43:2245-2247. 


\section{Abstract}

Background Studies in lacunar stroke patients often assess the number of lacunes. However, data on how many symptomatic lacunar infarcts cavitate into a lacune are limited. We assessed the evolution of symptomatic lacunar infarcts over 2-year followup.

Methods In 82 first-ever lacunar stroke patients with a lacunar infarct in the deep brain regions (excluding the centrum semiovale) we performed a brain MRI at presentation and 2 years later. We classified cavitation of lacunar infarcts at baseline and on followup MRI as absent, incomplete or complete. We recorded time to imaging, infarct size and vascular risk factors.

Results On baseline MRI, 38 (46\%) index infarcts showed complete or incomplete cavitation. Median time to imaging was 8 (0-73) days in non-cavitated and 63 (1-184) days in cavitated lesions $(\mathrm{p}<0.05)$. On follow-up imaging, $94 \%$ of the lacunar infarcts were completely or incompletely cavitated, most had reduced in diameter and $5(6 \%)$ had disappeared. Vascular risk factors were not associated with cavitation.

Conclusion Cavitation and lesion shrinkage was seen in almost all symptomatic lacunar infarcts in the deep brain regions over two year follow-up. Counting lacunes in these specific regions at a random moment might slightly, however not substantially, underestimate the burden of deep lacunar infarction. 


\section{Introduction}

Lacunar stroke is characterized by one of the clinical lacunar syndromes with a compatible lacunar infarct on brain imaging-1. Lacunar infarcts are small infarcts located deep within the brain, caused by occlusion of a single perforating artery due to cerebral small vessel disease ${ }^{2}$. Radiologically, old lacunar infarcts are considered to be represented by lacunes, which are focal cavities in the brain ${ }^{2}$.

Lacunes on brain imaging are often used as markers of cSVD. However, precise data on the proportion of lacunar infarcts that cavitate and become a lacune are limited. Former MRI studies found that only $28 \% 0^{3}$ to $60 \% 0^{4}$ of the symptomatic lacunar infarcts progress to definite cavitation, leading to the conclusion that many lacunar infarcts stay noncavitated WMH. However, these studies included patients over a wide range of times to follow-up imaging and symptomatic lacunar infarcts in all subcortical brain regions. There is some evidence that, while lacunar infarcts in the deep brain regions are caused by cSVD, lacunar infarcts in the centrum semiovale have different causes ${ }^{5-7}$.

We studied cavitation of symptomatic lacunar infarcts in the basal ganglia, pons and internal capsule, for which there was no other cause than intrinsic cerebral small vessel disease, in first-ever lacunar stroke patients, all of whom had a 2-year follow-up MRI.

\section{Subjects and Methods}

\section{Study Population}

From a lacunar stroke project with first-ever lacunar stroke patients presenting at Maastricht University Medical Centre or Orbis Medical Centre Sittard, the Netherlands, we selected all first-ever lacunar stroke patients who had a baseline brain MR between 2004 and 2007 and a two-year follow-up brain MRI ${ }^{8}$. All patients participated with informed consent, in this on-going research project, which has been approved by the local Medical Ethical Committee. Lacunar stroke was defined as one of the recognized lacunar stroke syndromes with a lacunar lesion in the deep grey matter, pons or internal capsule, compatible with occlusion of a single deep perforating artery. Patients with symptomatic centrum semiovale infarcts were not included, as the cause of these may differ from deep grey matter, pons and internal capsule lesions in the territory of the deep perforators arising from the proximal arteries of the circle of Willis. Patients with potential cardio-embolic sources or $>50 \%$ carotid stenosis in at least one carotid artery were not included.

Of the original cohort of 138 included first-ever lacunar stroke patients, we excluded 35 patients $(25 \%)$ that had a clinical diagnosis of lacunar stroke, but did not show a symptomatic lesion at baseline. Twenty-one patients did not participate in follow-up imaging, leaving 82 patients, who had a two-year follow-up brain MR. Thirty-four patients $(41 \%)$ presented with a pure motor lacunar syndrome, 22 patients $(27 \%)$ with a sensorimotor stroke, 13 patients $(16 \%)$ with a pure sensory stroke, 8 patients $(10 \%)$ with 
a dysarthria-clumsy hand syndrome and 5 cases $(6 \%)$ with other lacunar syndromes. Age at stroke onset, gender and vascular risk factors were recorded as defined earlier ${ }^{8}$. The baseline characteristics of our follow-up study population did not differ from those that did not participate on follow-up ${ }^{8}$.

\section{MR scoring}

MR images (1,5 or 3T MRI scanner, Philips) were obtained as soon as possible and within 6 months after stroke onset. The MR protocol consisted of standard axial T2weighted fast spin echo [TR shortest; TE $100 \mathrm{~ms}$; flip angle 90॰; field of view (FOV) 230 $\mathrm{mm}$; matrix 512x512] and fluid attenuated inversion recovery (FLAIR) sequences [TR 8000 ms; TE 120 ms; inversion time 2000 ms; FOV 230 mm; matrix 256x256 reconstructed to $512 \times 512$ ], with slice thickness of $5 \mathrm{~mm}$ and gaps $0.5 \mathrm{~mm}$. Forty-eight of 82 patients (59\%) also had DWI at baseline. Two vascular neurologists independently assessed the location of the acute lacunar infarct at baseline. An acute lacunar infarct was defined as round lesion ( 3 to $20 \mathrm{~mm}$ in diameter) ${ }^{9-10}$ of hyperintense signal on T2weighted imaging with, if DWI was present, a compatible diffusion restriction lesion on DWI, located in the basal ganglia, internal capsule, thalamus or pons, and compatible with clinical findings. The interobserver agreement for presence of a symptomatic infarct, determined before this study, was 0.89 (Cohen's kappa) ${ }^{11}$.

Cavitation at baseline imaging was classified by consensus into three groups: absent cavitation, incompletely or completely cavitated (Figure 2.1). In case of uncertainty or no consensus, images were reviewed by an experienced third party. Absent cavitation was defined as a lesion without any evidence of cavitation. Incomplete cavitation was defined as a lesion with hypointense core on FLAIR and the presence of one or more of the following characteristics: an irregular gliotic border, a spongiform appearance with areas of marked hypointensity in the core of the lesion or a hypointense core with a different signal intensity compared to CSF. Complete cavitation (lacune) was defined as a small cavity with hypointense signal intensity comparable to CSF, with a thin surrounding hyperintense halo (gliosis) on FLAIR 3 . The total diameter (hypointense core and gliotic rim) of each index lacunar infarct was measured, in three directions, and we report maximum diameter.

Patients had a follow-up brain MR (1.5T or 3T MRI scanner), with T2-weighted imaging and FLAIR sequences, two years after the first MRI. The MRI protocol was similar to the baseline protocol. The appearance of the lacunar infarct on T2-weighted and FLAIR was classified into four groups: absent cavitation, incompletely and completely cavitated lesions, or disappearance of the lesion, using the same imaging criteria as baseline imaging. The total diameter of the lacunar infarct was again assessed on follow-up imaging. The presence of extensive deep and periventricular WMH according to Fazekas' scale and the number of asymptomatic lacunes elsewhere in the brain were assessed, as defined earlier ${ }^{8}$. 

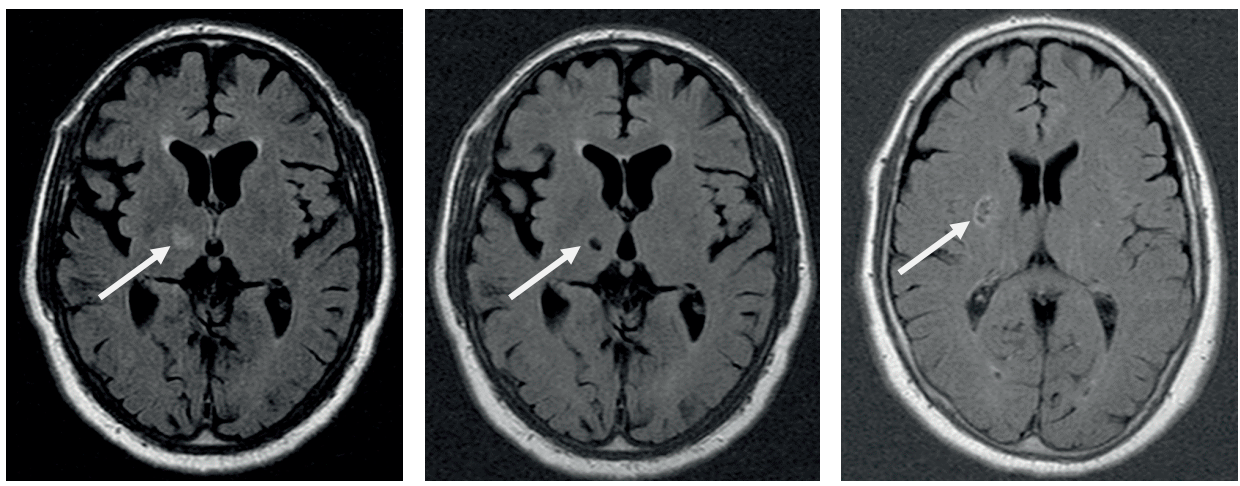

Figure 2.1 FLAIR sequences. Left image: Lacunar infarct in the right thalamus without cavitation. Time to baseline imaging was 10 days. Middle image: At follow-up, the lesion has completely cavitated. Right image: Incompletely cavitated lacunar infarct, with a spongiform appearance, in the right internal capsule.

\section{Statistical analysis}

Categorical variables are presented as $\mathrm{N}$ with frequencies (\%). Data are presented as mean \pm standard deviation (SD) for normally distributed data and as medians with range for non-parametric data. Differences between groups were tested using independentsample t-test or ANOVA for normally distributed variables and Mann-Whitney $\mathrm{U}$ test and Kruskal-Wallis test for variables with skewed distributions. Categorical variables were explored by Pearson $\chi 2$ and Fisher test. Diameter at baseline and after 2 years were compared with paired t-test. Statistical significance was set at $\mathrm{p}<0.05$ (2-tailed). Analyses were performed using SPSS statistical software package (version SPSS 18.0; SPSS Inc).

\section{Results}

\section{Cavitation at baseline MR}

Table 2.1 shows baseline measurements. Median time between stroke onset and baseline MR was 22 days (0-184 days). 
Table 2.1 Clinical and imaging parameters at baseline.

\begin{tabular}{|c|c|c|c|c|c|}
\hline & \multirow[b]{3}{*}{$\mathrm{N}=82$} & \multicolumn{3}{|l|}{ Cavitation } & \multirow[b]{3}{*}{$p$} \\
\hline & & no & incomplete & complete & \\
\hline & & $\mathrm{N}=44$ & $\mathrm{~N}=27$ & $\mathrm{~N}=11$ & \\
\hline \multicolumn{6}{|l|}{ Demographics } \\
\hline Age (years $\pm \mathrm{SD}$ ) & $63 \pm 11$ & $61 \pm 12$ & $66 \pm 9$ & $62 \pm 12$ & 0.15 \\
\hline \multicolumn{6}{|l|}{ Imaging parameters } \\
\hline Onset to baseline MR, days (range) & $22(0-184)$ & $8(0-73)$ & $54(1-62)$ & $78(15-184)$ & 0 \\
\hline Diameter infarct, $\mathrm{mm}($ mean $\pm \mathrm{SD})$ & $11.0 \pm 4.0$ & $11.5 \pm 3.7$ & $11.2 \pm 4.3$ & $8.8 \pm 4.0$ & 0.12 \\
\hline Asymptomatic lacunes $(\%)$ & $53(65)$ & $29(66)$ & $16(59)$ & $8(73)$ & 0.71 \\
\hline Extensive periventricular WMH (\%) & $31(38)$ & $16(36)$ & $11(41)$ & $4(37)$ & 0.93 \\
\hline Extensive deep WMH (\%) & $28(34)$ & $14(32)$ & $11(41)$ & $3(27)$ & 0.65 \\
\hline \multicolumn{6}{|l|}{ Vascular risk factors } \\
\hline Hypertension (\%) & $60(73)$ & $31(71)$ & $20(74)$ & $9(83)$ & 0.74 \\
\hline Diabetes $(\%)$ & $13(16)$ & $6(14)$ & $4(15)$ & $3(27)$ & 0.53 \\
\hline Hypercholesterolemia (\%) & $65(79)$ & $35(76)$ & $22(82)$ & $8(73)$ & 0.83 \\
\hline Smoking $(\%)$ & $33(40)$ & $20(46)$ & $8(30)$ & $5(46)$ & 0.63 \\
\hline
\end{tabular}

SD: standard deviation; WMH: white matter hyperintensity

At baseline, 44 of the 82 lacunar infarcts (53\%) showed no cavitation, $27(33 \%)$ were incompletely cavitated and $11(13 \%)$ were completely cavitated. Longer time interval between stroke onset and baseline imaging was significantly associated with cavitation. No other patient-related or imaging-related variables (WMH or asymptomatic lacunes) were associated with cavitation.

\section{Cavitation on follow-up MR}

Results are shown in Table 2.2. The follow-up brain MRI was performed at mean 759 \pm 58 days after the baseline MRI. In the group without cavitation at baseline $(n=44), 16$ $(36 \%)$ showed incomplete cavitation, $24(55 \%)$ were completely cavitated and in 4 cases $(9 \%)$ no lesion was seen on follow-up imaging. In the group with incomplete cavitation at baseline ( $\mathrm{n}=27), 5(19 \%)$ were still incompletely cavitated, $21(78 \%)$ showed complete cavitation and in 1 case no lesion was seen on follow-up. There was no association between vascular risk factors and cavitation on follow-up.

\section{Infarct size}

The total diameter of the non-cavitated lesions at baseline $(11.5 \pm 3.7 \mathrm{~mm})$ reduced to $6.5 \pm 3.4 \mathrm{~mm}$ on follow-up imaging $(\mathrm{p}<0.05)$. Infarct size in the group of 11 completely cavitated lesions at baseline was $8.8 \pm 4.0 \mathrm{~mm}$ and showed a significant reduction (6.6 $\pm 3.7 \mathrm{~mm} ; \mathrm{p}<0.05)$ on follow-up. 
Table 2.2 Clinical and imaging parameters on follow-up MR.

\begin{tabular}{|c|c|c|c|c|c|}
\hline & \multirow[b]{3}{*}{$\mathrm{N}=82$} & \multicolumn{3}{|l|}{ Cavitation } & \multirow[b]{3}{*}{$p$} \\
\hline & & incomplete & complete & lost & \\
\hline & & $\mathrm{N}=21$ & $N=56$ & $\mathrm{~N}=5$ & \\
\hline \multicolumn{6}{|l|}{ Imaging parameters } \\
\hline Onset to FU, days (range) & $\begin{array}{l}794 \\
(619-1016)\end{array}$ & $\begin{array}{l}778 \\
(638-858)\end{array}$ & $\begin{array}{l}794 \\
(619-1002)\end{array}$ & $\begin{array}{l}780 \\
(769-1016)\end{array}$ & 0.43 \\
\hline Diameter infarct, mm (mean $\pm \mathrm{SD})$ & $7.3 \pm 2.8^{*}$ & $7.3 \pm 2.6$ & $7.2 \pm 3.0$ & & 0.95 \\
\hline \multicolumn{6}{|l|}{ Vascular risk factors } \\
\hline Hypertension $(\%)$ & $58(75)^{*}$ & $16(76)$ & $42(75)$ & & 1.00 \\
\hline Diabetes $(\%)$ & $13(17)^{*}$ & $4(19)$ & $9(16)$ & & 0.74 \\
\hline Hypercholesterolemia (\%) & $61(79)^{*}$ & $17(81)$ & $44(79)$ & & 1.00 \\
\hline Smoking $(\%)$ & $6(8)^{*}$ & $2(10)$ & $4(7)$ & & 0.67 \\
\hline
\end{tabular}

SD: standard deviation; FU: follow-up; ${ }^{*} \mathrm{n}=77$, lost lesions were excluded.

\section{Discussion}

We assessed the evolution of symptomatic lacunar infarcts in the basal ganglia and internal capsule, due to presumed cSVD, over a period of 2 years. We found that all symptomatic lacunar infarcts, except those no longer visible, cavitate over time and that longer time interval between stroke onset and imaging is the sole predictor of cavitation. Furthermore, we found a significant reduction of infarct size on follow-up.

Potter $^{3}$ et al. found definitive cavitation in one fifth of symptomatic lacunar stroke patients and concluded that many lacunar infarcts long term may resemble WMH. However, they included symptomatic lacunar infarcts both in the centrum semiovale and the basal ganglia, their time interval to follow-up imaging was generally shorter, they partly used CT for imaging and their MR scoring methods might not completely correspond with ours. $\mathrm{Koch}^{4}$ et al. found that cavitation occurred in $61 \%$ of lacunar stroke patients, but their follow-up time interval was wide-spread and their patient sample with MRI follow-up was relatively small. As there is a shortage of data on long term appearances of symptomatic lacunar infarcts, our data almost doubles the number of the total published MRI cases so far, even if there are limitations such as the restricted definition of location of lacunar infarcts in our study.

We did not include lacunar infarcts in the centrum semiovale in contrast to these two studies, because the centrum semiovale is generally supplied by medullary branches of the cortical arteries and these infarcts may have different causes than those arising in the territory of the deep perforators ${ }^{5-7}$. It may also be that the deep grey and white matter respond differently to lacunar damage, grey matter being more likely to cavitate than white matter. It would be interesting to directly compare cavitation rates between small deep and centrum semiovale infarcts.

Even when cavitation has been reached, it seems that the lacune is still in a dynamic process as we showed reduction in size over time. In five cases the lesion even disappeared on follow-up MR. Although it is possible that the brain tissue healed without the formation of a lacune, it seems more likely that these infarcts have progressed into small, 
collapsed lacunes that can be missed by brain imaging, possibly corresponding to microinfarcts $^{12}$.

The main strengths of our study are a relatively fixed long follow-up time and MR imaging in all patients, which is superior to CT for the detection of lacunar infarcts ${ }^{13}$. A limitation is that we did not use the same MRI field strength in all patients, due to the clinical setting of this study, however other MRI settings were standardized. Furthermore, not all patients had DWI, which could have caused that the wrong lesion was counted for the symptomatic lacunar infarct. However, we only included patients with a definitive clinical diagnosis of first-ever lacunar stroke and the lesion had to be compatible with clinical signs.

\section{Conclusion}

In conclusion, cavitation of symptomatic lacunar infarcts was present in all, except for those that disappeared over time. Cavitation seems to be a dynamic process with a reduction in size over time, and with a definitive lacune as final result. Because it takes time to cavitate, counting lacunes at a random moment might slightly, however not substantially, underestimate the burden of deep lacunar infarcts, but these results cannot be applied to lacunar infarcts in the centrum semiovale. 


\section{References}

1. Donnan GA, Norring B, Bammer R, Bogousslavsky J. Classification of subcortical infarcts. In: Donnan GA, Norring B, Bamford J, Bogousslavsky J, eds. Subcortical stroke. New York: Oxford University Press;2002:2734.

2. Fisher CM. Lacunar strokes and infarcts: A review. Stroke 1982;32:871-876.

3. Potter GM, Doubal FN, Jackson CA, Chappell FM, Sudlow CL, Dennis MS, Wardlaw JM. Counting cavitating lacunes underestimates the burden of lacunar infarction. Stroke 2011;41:267-272.

4. Koch S, McClendon MS, Bhatia R. Imaging evolution of acute lacunar infarction. Leukoariosis or lacune? Neurology 2011;77:1091-1095.

5. Lammie GA, Wardlaw JM. Small centrum ovale infarcts - a pathological study. Cerebrovasc Dis 1999;9:8290.

6. Bogousslavsky J, Regli F. Centrum ovale infarcts: Subcortical infarction in the superficial territory of the middle cerebral artery. Neurology 1992;42:1992-1998.

7. Uehara T, Tabuchi M, Mori E. Risk factors for silent infarcts in subcortical white matter and basal ganglia. Stroke 1999;30:378-382.

8. Staals J, van Oostenbrugge RJ, Knottnerus ILH, Rouhl RPW, Henkens LHG, Lodder J. Brain microbleeds relate to higher ambulatory blood pressure levels in first-ever lacunar stroke patients. Stroke 2009;40:32643268 .

9. Lodder J. Size criterion for lacunar infarction. Cerebrovasc Dis 2007;24:156-157.

10. Potter GM, Marlborough FJ, Wardlaw JM. Wide variation in Definition, Detection, and Description of Lacunar Lesions on Imaging. Stroke 2011;42:359-366.

11. Rouhl RP, van Oostenbrugge RJ, Knottnerus ILH, Staals J, Lodder J. Virchow-Robin spaces relate to cerebral small vessel disease severity. J Neurol 2008;255:692-696.

12. White L, Petrovitch H, Hardman J, Nelson J, Davis DG, Ross GW, et al. Cerebrovascular pathology and dementia in autopsied Honolulu-Asia aging study participants. Ann N Y Acad Sci 2002;977:9-23.

13. Lövblad KO, Baird AE. Computed tomography in acute ischemic stroke. Neuroradiology 2010;52:175-187. 



\section{CHAPTER 3}

The appearance of a new white matter hyperintensity just adjacent to the old infarct in first-ever lacunar stroke patients: a 2-year follow-up study with MR.

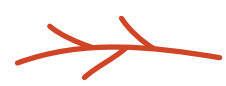

Loos CM, van Oostenbrugge RJ, Staals J.

The appearance of a new white matter lesion adjacent to the old infarct in first-ever lacunar stroke patients: a two-year follow-up study with MRI.

Cerebrovasc Dis 2012;34:443-445. 


\section{Abstract}

Background White matter hyperintensities are often seen on brain MRI in lacunar stroke patients. In a follow-up MRI study in first-ever lacunar stroke patients, we observed in several cases a distinct new WMH in the zone adjacent to and just distal from the old infarct. We describe this particular imaging feature and discuss the possible mechanism for these new WMH.

Methods From an ongoing lacunar stroke research project, we selected all first-ever lacunar stroke patients who had a baseline brain MRI and a 2-year follow-up brain MRI. Presence of vascular risk factors and ambulatory blood pressure measurements at baseline were recorded. We reviewed all follow-up MRI scans and recorded the presence of a new WMH in the zone adjacent to and distal from the symptomatic lacunar infarct. We also assessed the presence of diffuse WMH at baseline, according to Fazekas' scale, and the progression of WMH after 2 years, according to the modified Rotterdam progression scale, disregarding the new WMH in the zone distal to the old lacunar infarct.

Results In 15 (18\%) of 82 first-ever lacunar stroke patients, we observed on 2-year follow-up MRI a new WMH in the zone adjacent to and just distal from the old lacunar infarct. These WMH were mostly round with indistinct margins, with a mean diameter $13.1 \pm 2.0 \mathrm{~mm}$ and could be clearly outlined from diffuse WMH (if present). The presence of these WMH was not associated with vascular risk factors, nor with presence of diffuse WMH at baseline, nor the progression of diffuse WMH on follow-up. The mean ambulatory blood pressure at baseline was significantly lower in the group with a new WMH adjacent to and distal from the old infarct (100 \pm 11 vs. $107 \pm 12 \mathrm{mmHg}$; $<0.05)$.

Conclusion We described the occurrence of a distinct WMH in a zone adjacent to and distal from the old lacunar infarct on 2-year follow-up brain MRI in first-ever lacunar stroke patients. We hypothesize that this particular distal zone, at the end of the vascular territory of the deep perforators, might be vulnerable for regionally impaired vascular autoregulation and chronic hypoperfusion, resulting in a new, single WMH. Larger prospective studies are necessary to confirm our findings. 


\section{Introduction}

Lacunar stroke is characterized by one of the clinical lacunar syndromes with a compatible lacunar infarct on brain imaging ${ }^{1}$. Lacunar infarcts are small deep brain infarcts, presumed to be caused by occlusion of a single deep perforating artery ${ }^{2}$. White matter hyperintensities are lesions of increased signal intensity in the white matter on T2weighted and FLAIR MRI sequences, which might be caused by chronic hypoperfusion leading to ischemia or blood-brain barrier damage ${ }^{3-6}$.

We observed in a follow-up MR study in first-ever lacunar stroke patients in some cases a substantial new WMH in the zone adjacent to and just distal (in the vascular territory) from the old infarct. We reviewed all 2-year follow-up scans of our lacunar stroke patient-cohort for this particular imaging feature 7 . We describe this imaging feature here and discuss the possible mechanisms for these $\mathrm{WMH}$.

\section{Subjects and Methods}

\section{Study Population}

From a lacunar stroke project with first-ever lacunar stroke patients, we selected all firstever lacunar stroke patients who had a baseline brain MRI between 2004 and 2007 and a 2-year follow-up MRI ${ }^{7}$. The project has been approved by the local Medical Ethical Committee, and all patients gave written informed consent. Of the included baseline cohort of 138 lacunar stroke patients, 82 patients agreed to follow-up MR imaging. Lacunar stroke was defined as one of the recognized lacunar stroke syndromes with a lacunar lesion in the basal ganglia, pons or internal capsule, compatible with occlusion of a single deep perforating artery. All patients with potential cardiac embolic sources or with carotid stenosis were excluded. Baseline characteristics, including age at stroke onset, vascular risk factors and 24-hour ambulatory blood pressure monitoring were present ${ }^{7}$.

\section{MR scoring}

MR images (1.5 or 3T, Philips) at baseline consisted of axial T2-weighted fast spin echo and FLAIR sequences ${ }^{7}$. An acute lacunar infarct was defined as a round T2-weighted hyperintense lesion $(<20 \mathrm{~mm})$ with, if DWI was performed, restricted diffusion, located in the basal ganglia, internal capsule, thalamus or pons, and compatible with clinical findings. We also assessed the presence of extensive deep WMH (grade 3 according to Fazekas' scale), extensive periventricular WMH (grade 2 or 3 according to Fazekas' scale) and the presence of asymptomatic lacunes. Patients had a follow-up brain MRI (1.5 or 3T), with T2-weighted and FLAIR sequences, two years after the first MRI. The MRI protocol was similar to the baseline protocol. We assessed the presence of a new WMH in the zone distal to the old lacunar infarct. We also assessed the presence of diffuse 
WMH progression, defined as progression in one or more brain areas according to the modified Rotterdam progression scale ${ }^{8}$, but disregarding the new WMH in the zone distal to the old lacunar infarct. An example is given in Figure 3.1.
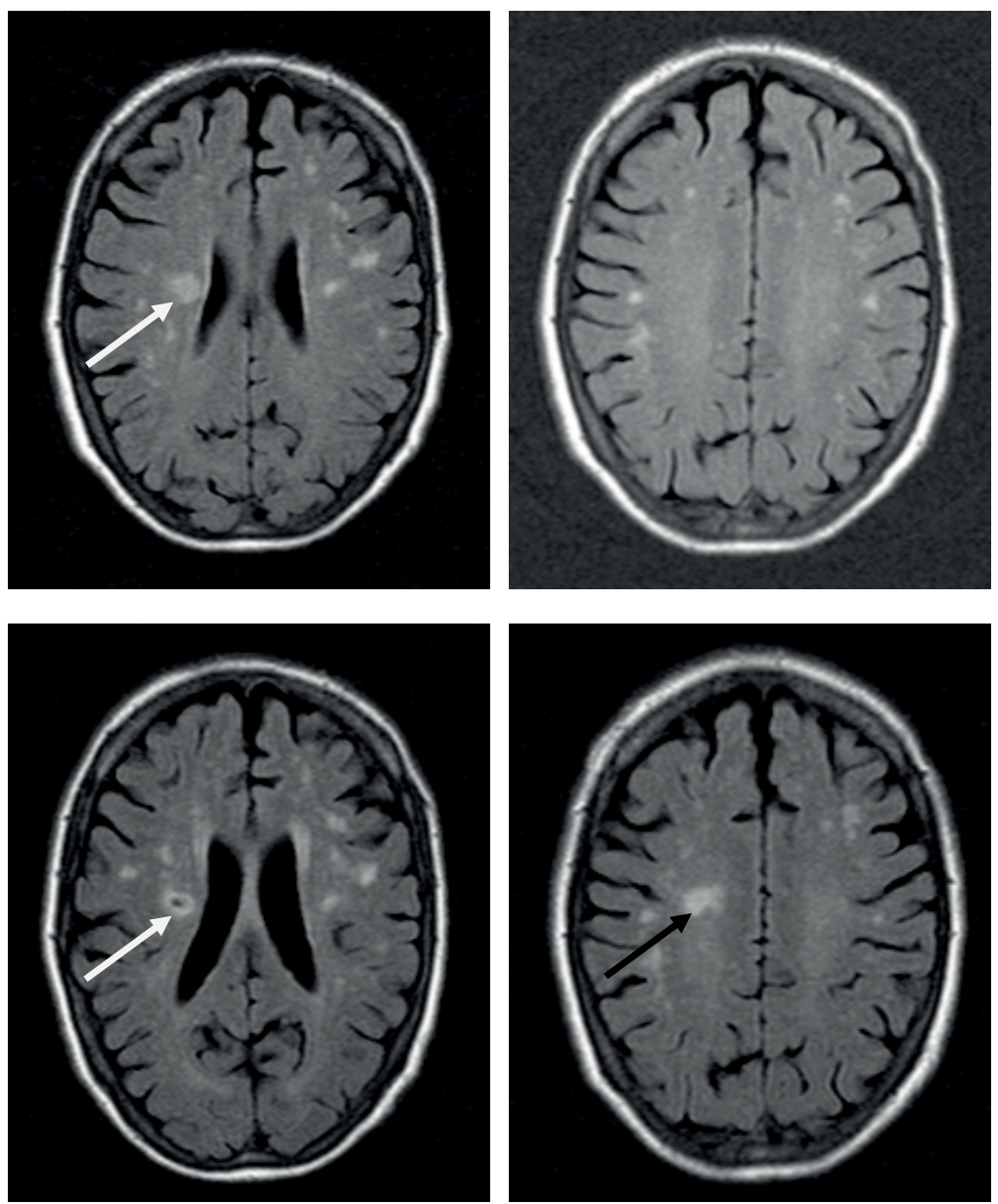

Figure 3.1 FLAIR-images. Left upper image: Right-sided periventricular symptomatic lacunar infarct at baseline (MRI was performed 94 days after stroke onset). Right upper image: MRI-slice distal (cranial) to the lacunar infarct at baseline. Left bottom image: Lacunar infarct after 2-year follow-up imaging. Right bottom image: Although scan levels do not completely correspond between baseline and follow-up imaging, a new WMH "cap" can be seen just distal to the old infarct.

\section{Statistical analysis}

Differences between groups were tested using independent-sample t-test for normally distributed variables and Mann-Whitney $U$ for variables with skewed distributions. Categorical variables were explored by $X^{2}$ and Fisher test. Statistical significance was set at $\mathrm{p}<0.05$ (2-tailed). 


\section{Results}

Results are shown in Table 3.1. On 2-years follow-up MRI, we observed in 15 cases $(18 \%)$ a new WMH in the zone distal to the old lacunar infarct.

Table 3.1 Clinical and imaging characteristics.

\begin{tabular}{|c|c|c|c|c|}
\hline & \multirow[b]{3}{*}{$\mathrm{N}=82$} & \multicolumn{2}{|c|}{ new WMH } & \multirow[b]{3}{*}{$p$} \\
\hline & & absent & present & \\
\hline & & $\mathrm{N}=67$ & $\mathrm{~N}=15$ & \\
\hline \multicolumn{5}{|l|}{ Demographics at baseline } \\
\hline Age at stroke onset(year) & $63 \pm 11$ & $62 \pm 11$ & $65 \pm 12$ & 0.38 \\
\hline Male $(\%)$ & $48(58)$ & $40(60)$ & $8(53)$ & 0.65 \\
\hline Hypertension (\%) & $60(73)$ & $49(73)$ & $11(73)$ & 0.99 \\
\hline Diabetes $(\%)$ & $13(16)$ & $12(18)$ & $1(7)$ & 0.28 \\
\hline Hypercholesterolemia (\%) & $65(79)$ & $54(81)$ & $11(73)$ & 0.53 \\
\hline Smoking $(\%)$ & $33(40)$ & $27(40)$ & $6(40)$ & 0.59 \\
\hline \multicolumn{5}{|l|}{ BP monitoring at baseline } \\
\hline Systolic 24h BP (mmHg) & $140 \pm 17$ & $140 \pm 17$ & $135 \pm 18$ & 0.18 \\
\hline Diastolic 24h BP (mmHg) & $84 \pm 11$ & $84 \pm 11$ & $75 \pm 9$ & 0.00 \\
\hline 24h MAP (mmHg) & $107 \pm 12$ & $107 \pm 12$ & $100 \pm 11$ & 0.03 \\
\hline \multicolumn{5}{|l|}{ MR Imaging at baseline } \\
\hline Asymptomatic lacunes (\%) & $53(65)$ & $44(66)$ & $9(60)$ & 0.68 \\
\hline Extensive periventricular WMH (\%) & $31(38)$ & $25(37)$ & $6(40)$ & 0.85 \\
\hline Extensive deep WMH (\%) & $28(34)$ & $23(34)$ & $5(34)$ & 0.94 \\
\hline \multicolumn{5}{|l|}{ MR Imaging at FU } \\
\hline Progression of diffuse WMH (\%) & $40(49)$ & $31(46)$ & $9(60)$ & 0.37 \\
\hline
\end{tabular}

Numbers (\%) or mean \pm standard deviation (SD); FU: follow-up; MAP: mean arterial pressure; BP: blood pressure.

These lesions were single and mostly round with indistinct margins, but could be clearly outlined from diffuse WMH (if present), with a mean diameter $13.1 \pm 2.0 \mathrm{~mm}$. They were all located adjacent to and just distal from the lacunar infarct in the vascular territory of the deep perforators. The occurrence of these WMH was not associated with vascular risk factors, including diabetes, nor the presence of diffuse WMH at baseline or progression of WMH at follow-up. The mean diastolic ambulatory blood pressure and mean ambulatory blood pressure were significant lower in the group with a new WMH, respectively $75 \pm 9$ vs. $84 \pm 11 \mathrm{mmHg}$ and $100 \pm 11$ vs. $107 \pm 12 \mathrm{mmHg}(\mathrm{p}<0.05)$.

\section{Discussion}

On 2-years follow-up MRI, we observed in 18\% (15 cases) of first-ever lacunar stroke patients a new WMH in a zone adjacent to and just distal (in the vascular territory) from the old infarct. These WMH were not seen on baseline MRI. The occurrence of these 
new WMH was independent of vascular risk factors, presence at baseline or progression on follow-up MR of diffuse WMH.

Endothelial dysfunction and altered permeability of the blood-brain barrier are thought to be involved in the pathogenesis of $\mathrm{WMH}^{3-6}$. However, considering the location (always distal to the lacunar infarct), the imaging appearance and the occurrence of these lesions, independent of overall WMH progression, we hypothesize that these particular distal zone WMH might be the consequence of regionally impaired vascular autoregulation and chronic hypoperfusion in the internal border zone, at the end of the vascular territory of the deep perforator. This assumption is supported by the fact that cSVD has also been described as a frequent cause of internal border zone ischemia due to impaired vascular autoregulation ${ }^{9}$. As one side of the internal border zone is locally struck by occlusion of a deep perforator, resulting in a lacunar infarct, the other side is more vulnerable for reduction in perfusion pressure and chronic ischemia, resulting in a WMH. Furthermore, patients with a new WMH in the zone distal to the old lacunar infarct, had lower diastolic and mean arterial blood pressures, which further compromises perfusion pressure. However, it should be noticed that the blood pressure was measured only at one moment within the first 6 months after stroke onset.

A limitation is that we did not use the same MRI field strength in all patients due to the clinical setting of this study, however other MRI settings were standardized. Another limitation is that not all patients had DWI at baseline, therefore we cannot exclude that in some patients the original ischemic zone was larger at the acute onset. However, these new WMH were always distal from and adjacent to the original lacunar infarct, not surrounding it, and were never seen at baseline imaging; therefore, it seems unlikely that the new WMH is just a part of the original lacunar infarct.

\section{CONCLUSION}

We observed on 2-years follow-up brain MRI in 18\% of first-ever lacunar stroke patients a new WMH in a zone adjacent to the old infarct. We postulate that the region distal from a lacunar infarct might be vulnerable for chronic hypoperfusion. Larger prospective studies in a cohort independent from our study population are necessary to ground this hypothesis. 


\section{References}

1. Donnan GA, BN, Bammer R, Bogousslavsky J. Classification of subcortical infarcts. In: Donnan GA, Norring B, Bamford J, Bogousslavsky J, eds. Subcortical stroke. New York: Oxford University Press;2002:27-34.

2. Fisher CM. Lacunar strokes and infarcts: A review. Stroke 1982;32:871-876.

3. Pantoni L. Cerebrall smell vessel disease: from pathogenesis and clinical characteristics to therapeutic challenges. Lancet Neurol 2010;9:689-701.

4. Kawamura J, Meyer JS, Terayama Y, Weathers S. Leukoaraiosis correlates with cerebral hypoperfusion in vascular dementia. Stroke 1991;22:609-614.

5. Wardlaw JM, Sandercock PAG, Dennis MS, Starr J. Is breakdown of the blood-brain barrier responsible for lacunar stroke, leukoaraiosis, and dementia? Stroke 2003;34:806-812.

6. Ovbiagele B, Saver JL. Cerebral white matter hyperintensities on MRI: current concepts and therapeutic implications. Cerebrovasc Dis 2006;22:83-90.

7. Staals J, van Oostenbrugge RJ, Knottnerus ILH, Rouhl RPW, Henkens LHG and Lodder J. Brain microbleeds relate to higher ambulatory blood pressure levels in first-ever lacunar stroke patients. Stroke 2009;40:32643268 .

8. Gouw AA, van der Flier WM, van Straaten ECW, Pantoni L, Bastos-Leite AJ, Inzitari D, et al. Reliability and sensitivity of visual scales versus volumetry for evaluating white matter hyperintensity progression. Cerebrovasc Dis 2008;25:247-253.

9. Immink RV, van Montfrans GA, Stam J, Karemaker JM, Diamant M, van Lieshout JJ. Dynamic cerebral autoregulation in acute lacunar stroke and middle cerebral artery territory ischemic stroke. Stroke 2005;36:2595-2600. 



\section{CHAPTER 4}

\section{Long-term morphological changes of symptomatic lacunar infarcts and surrounding white matter on structural MRI.}

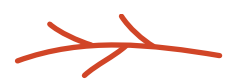

Loos CMJ, Makin SDJ, Staals J, Dennis MS, van Oostenbrugge RJ, Wardlaw JM. Long-term morphological changes of symptomatic lacunar infarcts and surrounding white matter on structural MRI.

Stroke 2018;49:1183-1188. 


\section{ABSTRACT}

Background Insights into evolution of cerebral small vessel disease (cSVD) on neuroimaging might advance knowledge of the natural disease course. Data on evolution of sporadic symptomatic lacunar infarcts are limited. We investigated long-term changes of symptomatic lacunar infarcts and surrounding white matter on structural MRI.

Methods From two non-overlapping single centre, prospective observational stroke studies, we selected patients presenting with lacunar stroke symptoms with a recent small subcortical (lacunar) infarct on baseline structural MRI and with follow-up MRI available at one to five years. We assessed changes in imaging characteristics of symptomatic lacunar infarcts and surrounding white matter.

Results We included 79 patients of whom 32/79 (41\%) had complete and 40/79 (51\%) had partial cavitation of the index lesion at median follow-up of 403 (range 315-1781) days. In 42/79 (53\%) patients, we observed a new white matter hyperintensity (WMH) adjacent to the index infarct, either distally (WMH "cap", $n=17$ ), proximally (WMH "track", $n=13)$, or both ( $\mathrm{n}=12)$.

Conclusion Half of sporadic symptomatic lacunar infarcts developed secondary changes in adjacent white matter distally and/or proximally. These WMH "caps" and "tracks" may reflect another aspect of cSVD-related disease progression. The clinical and prognostic value remain to be determined. 


\section{Introduction}

Cerebral small vessel disease (cSVD) is a pathological process involving small perforating vessels in the brain ${ }^{1}$. It may cause symptomatic lacunar infarcts, but also "silent" brain damage that is visible on structural MRI, including white matter hyperintensities $(\mathrm{WMH})$ and lacunes 2 . Insights into the radiological evolution of cSVD features are important as they might increase our knowledge of vascular disease and neurodegeneration and could be used as surrogate markers for therapeutic studies.

However, there is limited information on long-term tissue damage in sporadic cSVD. Although central cavitation (lacune formation) of the sporadic symptomatic lacunar infarct has been reported in several studies ${ }^{3-6}$, only one study investigated long-term perilesion morphological changes of sporadic symptomatic lacunar infarcts, finding new WMH ("caps") lateral and/or superior to $18 \%(15 / 82)$ of sporadic symptomatic lacunar infarcts ${ }^{7}$. Other studies have suggested that sporadic symptomatic infarcts are associated with widespread secondary degeneration in adjacent white matter tracts 8 .

In contrast, in patients with CADASIL (cerebral autosomal dominant arteriopathy with subcortical infarcts and leukoencephalopathy), a genetic cSVD, several studies document long-term perilesional and remote morphological changes of cSVD lesions, including development of new lacunes at the edge of WMH, or spread of WMH around incident lacunes ${ }^{910}$.

The aim of the present study was to investigate further the natural disease course of sporadic cSVD by assessing the long-term morphological lesional and perilesional changes in symptomatic lacunar infarcts and adjacent white matter on structural MRI.

\section{SUBJECTS and Methods}

\section{Study Population and Recruitment}

We used longitudinal data from two non-overlapping, prospective, observational studies in patients with minor (i.e. non-disabling) ischaemic stroke who were all scanned on one researched-dedicated MRI scanner (Mild Stroke Study-1, 2003-2007; Mild Stroke Study2, 2010-2012).

The design of both studies has been described before ${ }^{11-13}$. Briefly, both studies recruited patients who presented with minor ischaemic stroke, including symptoms of lacunar stroke, to the regional stroke service. Patients with contra-indications to MRI and unstable medical conditions were excluded. For the present study, we selected all patients with: a) a clinical diagnosis of lacunar stroke and a relevant (to symptoms) acute small subcortical infarct (lacunar infarct; index lesion) on diffusion MRI at presentation and b) a follow-up structural MRI between one and five years after the index stroke. We recorded age at stroke onset, gender and vascular risk factors, as defined earlier ${ }^{11}$. Both studies were approved by the Scotland and Lothian Research Ethics Committee and all patients gave written informed consent. 


\section{MR imaging}

All patients had a brain MRI at baseline (median 4, range 0-57, days after stroke onset) on a research-dedicated 1.5 Tesla MR scanner (Signa LX; General Electric, Milwaukee, WI). Sequences included axial diffusion-weighted imaging (DWI), fluid-attenuated inversion recovery (FLAIR), T2-weighted, and T2*-imaging and sagittal T1-weighted sequences (details were described elsewhere ${ }^{11,13}$ ). An experienced neuroradiologist (JMW) assessed the MR images for presence of the acute small subcortical (lacunar) infarct, cSVD lesions and brain atrophy, all according to the STRIVE criteria ${ }^{2}$. We defined an acute small subcortical (lacunar) infarct as a round or ovoid (axial diameter $<20 \mathrm{~mm}$ ) lesion in the basal ganglia, internal capsule, centrum semiovale, or brainstem, that was hyperintense on DWI, had reduced signal on apparent diffusion coefficient imaging, with or without increased signal on FLAIR or T2-weighted imaging ${ }^{2}$. We refer to this symptomatic acute lesion as the "index" lacunar lesion. The diameter of each index lacunar infarct was measured in three directions on FLAIR (we report maximum diameter). Baseline MRI was also rated separately and blind to the index lesion progression for presence of lacunes (number, location), WMH (periventricular and deep; Fazekas score ${ }^{14}$ ), cerebral microbleeds (CMB; location, number; modified BOMBS score ${ }^{15}$ ) and perivascular spaces (PVS; 5-point score in basal ganglia and centrum semiovale separately $\left.{ }^{11}\right)$.

We selected those patients, who had a follow-up brain MRI at one to five years after index stroke (median 403, range 315-1781, days after index stroke) as part of the original studies. The follow-up MR protocol was the same as the baseline MR protocol and performed at the same MR scanner. We visually scored the follow-up appearance of the index lacunar lesion and adjacent white matter on MRI, blind to the other cSVD features, by examining the index lesion and at least three MRI slices distal to (superior/lateral) and three MRI slices proximal to (inferior) the index lacunar infarct. We assessed the appearance of the index lacunar lesion itself by measuring the diameter in three planes as at baseline (we report on maximum diameter) and the appearance, including different degrees of cavitation (no cavitation, partial cavitation or complete cavitation), as defined previously 3,5 . Definitions and imaging characteristics of different degrees of cavitation are in Supplemental Methods.

Proximally and distally, adjacent to the index lacunar lesion, we assessed the presence of new WMH (respectively WMH "track" and WMH "cap"). Figure 4.1 shows an example of a WMH "cap" adjacent to the index lesion. These WMH "caps" were single, mostly round or ovoid with indistinct margins, were not visible at baseline and could be clearly outlined from diffuse WMH (if present). 

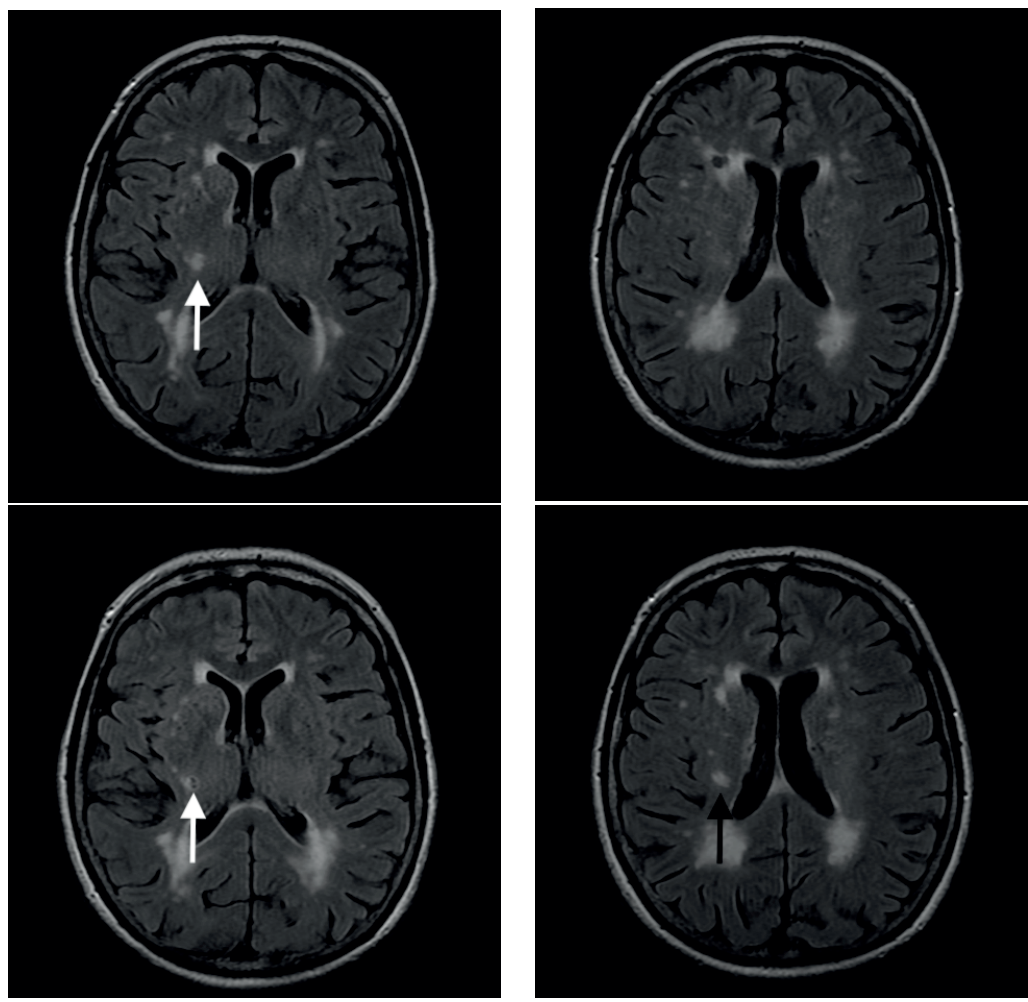

Figure 4.1 Left upper image: Baseline MRI, performed 1 day after stroke onset, sporadic symptomatic lacunar infarct in the right internal capsule (FLAIR); Right upper image: Baseline FLAIR image one MRI slice superior to the index lesion; Left bottom image: Follow-up MRI at 1 year (353 days) after index stroke, partial cavitated lesion (lacey-like appearance) on FLAIR; Right bottom image: Follow-up FLAIR image one MRI slice superior to the cavitated index lesion, showing a WMH "cap" adjacent to the index lacunar lesion (black arrow).

Figure 4.2 shows an example of a WMH "track" located proximal (inferior) from the index lacunar infarct. WMH "tracks" were round and small (often narrower than "caps"), elongated (visible up to two or three MRI slices inferior to the index lacunar lesion) and followed the descending white matter tract, similar to Wallerian degeneration, that is common after larger territorial infarcts. WMH "tracks" could be clearly outlined from extensive WMH (if present) and were not present at baseline. WMH progression was assessed by using a validated visual WMH change scale (The modified Rotterdam Progression Scale ${ }^{16}$ ), not including the WMH "cap" and/or "track" in this assessment. 

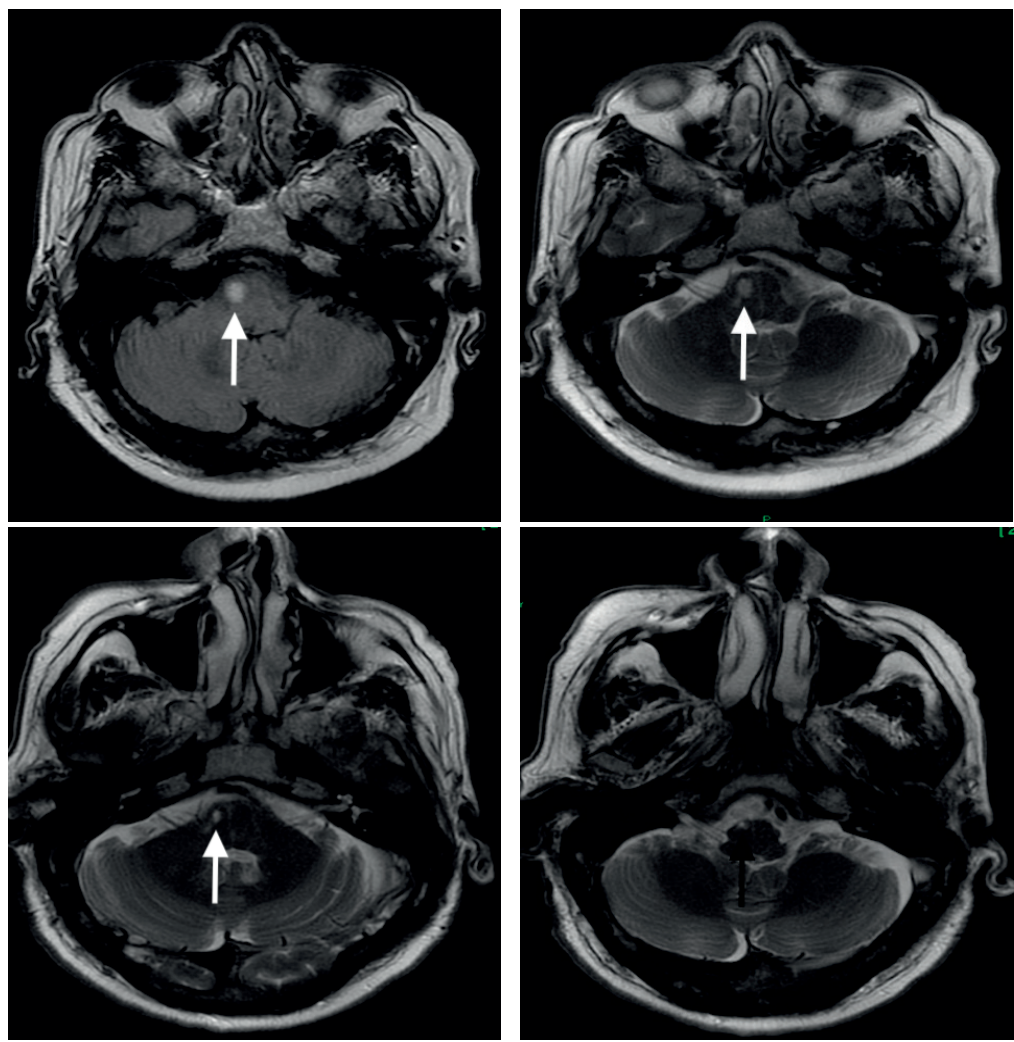

Figure 4.2 Left and right upper image: Baseline MRI, performed 11 days after stroke onset, sporadic symptomatic lacunar infarct in the right pons (FLAIR; T2-weighted imaging); Left bottom image: Follow-up MRI at 1 year (412 days) after index stroke, cavitated lacunar lesion in the right pons on T2-weighted imaging; Right bottom image: Follow-up MRI, WMH “track" proximal to index lacunar lesion in the right pons (black arrow), visible on more than two MRI slices inferior to the index lacunar lesion (T2-weighted imaging).

\section{Statistical Analysis}

Data differences between groups were tested using independent samples t-test (normally distributed variables), Mann-Whitney $U$ test (nonparametric data) and Pearson $\chi^{2}$ and Fisher test (categorical variables). Associations with occurrence of WMH "caps" and "tracks" were tested by univariable and multivariable logistic regression analysis, adjusted for key variables, including age, gender, vascular risk factors (hypertension, smoking, diabetes mellitus and hypercholesterolemia), baseline MRI features (extensive basal ganglia PVS (grade 2-4); extensive WMH (Fazekas' periventricular grade 3 and/or deep grade 2 or 3)) and follow-up MRI features (time between index stroke and follow-up MRI; WMH progression). Statistical significance was set at $\mathrm{p}<0.05$ (2-tailed). Analyses were performed using SPSS statistical software package (SPSS version 23.0; SPSS Inc, Chicago, IL). 


\section{Results}

Of 517 stroke patients in the original studies, 169 (33\%) had a lacunar stroke with an acute symptomatic (index) small subcortical (lacunar) infarct on MRI. Of these, 79 patients had a one to five-year follow-up MRI and met the inclusion criteria for the present study. Recruitment details are shown in Figure 4.3.

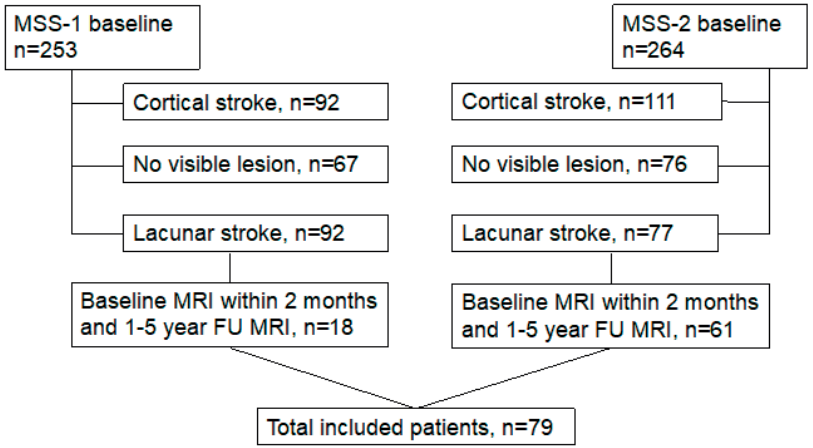

Figure 4.3 Patients recruitment characteristics.

Table 4.1 shows baseline patient characteristics. Five (6\%) patients had a recurrent stroke during follow-up; three were lacunar stroke (all in the contralateral hemisphere) and two were cortical stroke (one in the ipsilateral hemisphere). Twenty-two $(28 \%)$ patients had WMH progression ( $\geq 1$ point on Rotterdam Progression Scale).

Table 4.1 Baseline characteristics

\begin{tabular}{ll}
\hline & $\mathrm{N}=79$ \\
\hline Patient characteristics & \\
Age, mean \pm SD & $65 \pm 11$ \\
Male (\%) & $50(63)$ \\
Vascular risk factors & \\
Hypertension (\%) & $57(72)$ \\
Hyperlipidaemia (\%) & $45(57)$ \\
Smoking (\%) & $28(35)$ \\
Diabetes mellitus (\%) & $9(11)$ \\
Baseline imaging characteristics & \\
Stroke onset to baseline MR, in days (range) & $4(0-57)$ \\
DWI lesion present (\%) & $76(96)$ \\
Diameter acute lesion in mm (on FLAIR), mean \pm SD & $11.5 \pm 4.5$ \\
Presence of lacunes (\%) & $31(39)$ \\
Presence of microbleeds (\%) & $19(24)$ \\
Moderate-extensive PVS in basal ganglia (\%) & $48(61)$ \\
Extensive WMH (\%) & $33(42)$ \\
\hline
\end{tabular}

SD: standard deviation; PVS: perivascular spaces; WMH: white matter hyperintensity; FLAIR: fluid-attenuated inversion recovery. Extensive WMH: periventricular WMH Fazekas 3 and/or deep WMH Fazekas 2-3. 


\section{Evolution of the index lacunar infarct on follow-up imaging}

On follow-up imaging some degree of cavitation was seen in $72 / 79(91 \%)$ of index lacunar infarcts, partial in 40/79 (51\%) and complete in 32/79 (41\%) of index lacunar infarcts. Five of $79(6 \%)$ index lesions had disappeared during follow-up, although one of these had developed a WMH "cap" (see below). Two (3\%) index lacunar lesions resembled a non-cavitated WMH on follow-up imaging. No patient-related or imagingrelated variables were associated with any degree of cavitation.

\section{WMH adjacent to index lacunar infarct on follow-up imaging}

We observed a new WMH adjacent to the index lacunar infarct in 42/79 (53\%) patients: in $17 / 79(22 \%)$ patients the new WMH was distal (WMH “cap"), in 13/79 (16\%) patients the new WMH was proximal (WMH "track") and in 12/79 (15\%) patients it was both proximal and distal to the index lacunar infarct. Table 4.2 shows characteristics of patients with WMH "caps" and "tracks".

WMH "caps" were most frequent on index lesions in the centrum semiovale (62\%), but were also present in the internal and external capsule or nucleus lentiformis $(24 \%)$, thalamus $(10 \%)$ and brainstem (4\%). We observed WMH "tracks" mostly in the centrum semiovale (64\%), but also in the brainstem (16\%), in the internal and external capsule and nucleus lentiformis $(20 \%)$.

WMH "caps" were associated with presence of extensive deep WMH at baseline on univariable (OR 3.31; 95\% CI 1.27-8.59, $\mathrm{p}<0.05)$ and multivariable analysis (OR 6.31; $95 \%$ CI 1.21-32.88, $\mathrm{p}<0.05$ ); and with overall WMH progression on univariable (OR 3.83; 95\% CI 1.33-11.02, $\mathrm{p}<0.05$ ) and multivariable analysis (OR 3.77; 95\% CI: 1.0912.98; $\mathrm{p}<0.05)$. WMH "tracks" were associated with moderate-extensive basal ganglia PVS at baseline on univariable analysis (OR 3.71; 95\% CI 1.22-11.34, p<0.05), but on multivariable analysis, this association lost significance (OR 3.64; 95\% CI: 1.00-13.30; $\mathrm{p}=0.05)$. No other patient-related or imaging-related variables, including index lacunar infarct cavitation, were associated with occurrence of WMH "caps" or "tracks". 
Table 4.2 The occurrence of WMH “caps" and "tracks" adjacent to index lacunar lesions.

\begin{tabular}{|c|c|c|c|c|}
\hline & $\begin{array}{l}\text { no WMH } \\
\text { "cap" } \\
\mathrm{N}=50\end{array}$ & $\begin{array}{l}\text { WMH } \\
\text { "cap" } \\
\mathrm{N}=29\end{array}$ & $\begin{array}{l}\text { no WMH } \\
\text { "track" } \\
\mathrm{N}=54\end{array}$ & $\begin{array}{l}\text { WMH } \\
\text { "track" } \\
\mathrm{N}=25\end{array}$ \\
\hline \multicolumn{5}{|l|}{ Patient characteristics } \\
\hline Age, mean \pm SD & $63 \pm 12$ & $67 \pm 8$ & $64 \pm 12$ & $66 \pm 8$ \\
\hline Male $(\%)$ & $35(70)$ & $15(52)$ & $35(65)$ & $15(60)$ \\
\hline \multicolumn{5}{|l|}{ Vascular risk factors } \\
\hline Hypertension (\%) & $37(74)$ & $20(70)$ & $40(74)$ & $17(68)$ \\
\hline Hypercholesterolemia (\%) & $31(62)$ & $14(48)$ & $32(59)$ & $13(52)$ \\
\hline Smoking $(\%)$ & $19(38)$ & $9(31)$ & $20(38)$ & $8(32)$ \\
\hline Diabetes mellitus (\%) & $7(14)$ & $2(7)$ & $6(11)$ & $3(12)$ \\
\hline \multicolumn{5}{|l|}{ Baseline imaging parameters } \\
\hline $\begin{array}{l}\text { Diameter symptomatic lesion on FLAIR }(\mathrm{mm}) \\
\text { mean } \pm \text { SD }\end{array}$ & $11.3 \pm 4.7$ & $12.0 \pm 4.3$ & $11.5 \pm 5.0$ & $11.7 \pm 3.3$ \\
\hline Presence of lacunes $(\%)$ & $18(36)$ & $13(45)$ & $22(41)$ & $9(36)$ \\
\hline Presence of cerebral microbleeds (\%) & $11(22)$ & $8(28)$ & $13(24)$ & $6(24)$ \\
\hline Moderate-extensive basal ganglia PVS (\%) & $31(62)$ & $17(59)$ & $28(52)$ & $20(80)^{*}$ \\
\hline Extensive perivascular WMH (Fazekas 3) (\%) & $9(18)$ & $7(24)$ & $10(19)$ & $6(24)$ \\
\hline Extensive deep WMH (Fazekas 2- 3) (\%) & $15(30)$ & $17(59)^{*}$ & $18(33)$ & $14(56)$ \\
\hline \multicolumn{5}{|l|}{ Follow-up imaging parameters } \\
\hline Onset to follow-up MRI, days (range) & $\begin{array}{l}401 \\
(315-1781)\end{array}$ & $\begin{array}{l}403 \\
(341-1270)\end{array}$ & $\begin{array}{l}407 \\
(314-1871)\end{array}$ & $\begin{array}{l}392 \\
(341-1286)\end{array}$ \\
\hline $\begin{array}{l}\text { Diameter symptomatic lesion FLAIR }(\mathrm{mm}) \\
\text { mean } \pm \mathrm{SD}\end{array}$ & $7.8 \pm 3.4$ & $9.2 \pm 3.5$ & $8.0 \pm 3.5$ & $8.9 \pm 3.3$ \\
\hline (Partial) cavitation symptomatic lesion $(\%)^{\dagger}$ & $44(88)$ & $28(97)$ & $47(87)$ & $25(100)$ \\
\hline $\begin{array}{l}\text { Overall WMH progression, without "cap" and } \\
\text { "track" (\%) }\end{array}$ & $25(50)$ & $23(79)^{*}$ & $32(59)$ & $16(64)$ \\
\hline
\end{tabular}

*<0.05; analysis between no WMH “cap" versus WMH "cap" and between no WMH "track" versus WMH "track". SD: standard deviation, PVS: perivascular spaces, WMH: white matter hyperintensity. $†$ Five lesions disappeared on follow-up imaging.

\section{Discussion}

We assessed the long-term radiological evolution of sporadic symptomatic lacunar infarcts and perilesional white matter tissue on structural MRI. We demonstrate that, during follow-up of between one and five years, more than half of these sporadic symptomatic lacunar infarcts showed secondary perilesional morphological changes (WMH "caps" and "tracks).

WMH "caps" were associated with baseline deep WMH and WMH progression. Since severe WMH at baseline is the strongest predictor of WMH progression, similar risk factors might also be linked to the development of these WMH "caps", although we could not find any association with conventional risk factors, such as age and hypertension. The present study confirms results of a prior longitudinal MRI study that reported new WMH "caps" distally from sporadic symptomatic lacunar infarcts in 15 of 82 patients during 2-year follow-up? 
The new WMH "tracks" that appeared proximal to the index lacunar lesion seemed to be following a descending white matter tract similar to Wallerian degeneration. Wallerian degeneration of descending tracts is a well-known phenomenon after territorial stroke and reflects a pathological process with disintegration of axons, macrophages infiltration, degradation of myelin and finally gliosis and atrophy of the affected tracts ${ }^{17-18}$. Although we found that many index lacunar infarcts also underwent some degree of central cavitation, there was no association between progressive perilesional (WMH "caps" or "tracks") and central lesion tissue damage.

We suggest that secondary changes in white matter surrounding a sporadic index lacunar infarct should be considered a separate MRI feature of worsening brain damage, and so disease progression. Their possible clinical and prognostic value requires further study. Wallerian degeneration has been associated with poor motor function recovery after territorial stroke ${ }^{19}$. Longitudinal MRI studies with tractography have shown that subcortical infarcts in patients with CADASIL cause focal thinning in the remote cortex by degeneration of connected white matter tracts ${ }^{9,20}$. Further, diffusion tensor studies (DTI) studies have shown secondary tract degeneration in white matter tracts, remote from sporadic symptomatic lacunar infarcts, the severity of which were independently related to worse cognitive functioning ${ }^{8}$.

Several studies have assessed long-term cavitation of sporadic symptomatic lacunar infarcts ${ }^{3-6}$. As in two former studies ${ }^{5-6}$, we found a high partial or complete cavitation rate. While some of the apparent difference in cavitation rates between studies likely reflects differences in definitions or interpretation of cavitation, the formation of even a partial cavity over time, could reflect more interruption to white matter connectivity and might lead to worse clinical outcome. Therefore, it could be worthwhile to compare connectivity of white matter tracts (with DTI) in cavitated versus non-cavitated lesions. Some symptomatic lacunar lesions disappear, at least macroscopically, which could imply that conventional MRI underestimates the total cSVD-related brain damage.

The main strengths of our study are a relatively long follow-up time, standardized MRI protocols and use of one carefully monitored MRI scanner. We used standardized international consensus criteria ${ }^{2}$ to describe cSVD imaging findings and all assessments were blinded. However, our study has also limitations. Although this is one of the largest neuroimaging follow-up studies on this topic, our sample is relatively small for a common disease like lacunar stroke. We only included patients with a follow-up MRI at one to five years after stroke, which could have introduced bias. Our study describes imaging findings, and is too small to correlate these with clinical features like cognition or stroke recovery. Larger prospective studies in an independent cohort are necessary to confirm our findings.

\section{CONCLUSION}

In conclusion, many sporadic symptomatic lacunar infarcts developed secondary changes in the adjacent proximal and/or distal white matter during follow-up and show 
some degree of cavitation over time. Adjacent WMH "caps" and "tracks" may reflect another aspect of cSVD-related disease progression and neurodegeneration, with possible clinical and prognostic value. Larger prospective studies are necessary to confirm this hypothesis.

\section{Funding}

The contributing studies were funded by the Chief Scientist Office of the Scottish Executive (grant 217 NTU R37933), the Wellcome Trust (grants 075611 and WT088134/Z/09/A) and Row Fogo Charitable Trust. The imaging was performed at the Brain Research Imaging Centre Edinburgh, which is supported by the SINAPSE (Scottish Imaging Network A Platform for Scientific Excellence) collaboration and the Chief Scientist Office of the Scottish Government (http://www.bric.ed.ac.uk/). The work was supported by European Union Horizon 2020 (EU H2020), PHC- 03-15, project No 666881, 'SVDs@Target', and the Fondation Leducq Transatlantic Network of Excellence for Study of Perivascular Spaces in Small Vessel Disease, ref no. 16 CVD 05. The work reflects the views of the authors and not of the funders. CMJL was supported by the Dutch Alzheimer Foundation. 


\section{References}

1. Wardlaw JM, Smith C, Dichgans M: Mechanisms of sporadic cerebral small vessel disease: insights from neuroimaging. Lancet Neurol 2013;12:483-497.

2. Wardlaw JM, Smith EE, Biessels GJ, Cordonnier C, Fazekas F, Frayne R, et al. Neuroimaging standards for research into small vessel disease and its contribution to ageing and neurodegeneration. Lancet Neurol 2013;12:822-838.

3. Potter GM, Doubal FN, Jackson CA, Chappell FM, Sudlow CL, Dennis MS, et al. Counting cavitating lacunes underestimates the burden of lacunar infarction. Stroke 2010;41:267-272.

4. Koch S, McClendon MS, Bhatia R. Imaging evolution of acute lacunar infarc- tion: leukoariosis or lacune? Neurology 2011;77:1091-1095.

5. Loos CM, Staals J, Wardlaw JM, van Oostenbrugge RJ. Cavitation of deep lacunar infarcts in patients with first-ever lacunar stroke: a 2-year follow-up study with MR. Stroke 2012;43:2245-2247.

6. Moreau F, Patel S, Lauzon ML, McCreary CR, Goyal M, Frayne R, et al. Cavitation after acute symptomatic lacunar stroke depends on time, location, and MRI sequence. Stroke 2012;43:1837-1842.

7. Loos CM, van Oostenbrugge RJ, Staals J. The appearance of a new white matter lesion adjacent to the old infarct in first-ever lacunar stroke patients: a two-year follow-up study with MRI. Cerebrovasc Dis 2012;34:443-445.

8. Reijmer YD, Freeze WM, Leemans A, Biessels GJ; Utrecht Vascular Cognitive Impairment Study Group. The effect of lacunar infarcts on white matter tract integrity. Stroke 2013;44:2019-2021.

9. Duering M, Righart R, Csanadi E, Jouvent E, Hervé D, Chabriat H, et al. Incident subcortical infarcts induce focal thinning in connected cortical regions. Neurology 2012;79:2025-2028.

10. Duering M, Csanadi E, Gesierich B, Jouvent E, Hervé D, Seiler S, et al. Incident lacunes preferentially localize to the edge of white matter hyperintensities: insights into the pathophysiology of cerebral small vessel disease. Brain 2013;136:2717-2726.

11. Doubal FN, MacLullich AM, Ferguson KJ, Dennis MS, Wardlaw JM. Enlarged perivascular spaces on MRI are a feature of cerebral small vessel disease. Stroke 2010;41:450-454.

12. Makin SD, Doubal FN, Dennis MS, Wardlaw JM. Clinically Confirmed Stroke With Negative DiffusionWeighted Imaging Magnetic Resonance Imaging: Longitudinal Study of Clinical Outcomes, Stroke Recurrence, and Systematic Review. Stroke 2015;46:3142-3148.

13. Valdés Hernández Mdel C, Armitage PA, Thrippleton MJ, Chappell F, Sandeman E, Muñoz Maniega S, et al. Rationale, design and methodology of the image analysis protocol for studies of patients with cerebral small vessel disease and mild stroke. Brain Behav 2015;5:e00415.

14. Fazekas F, Chawluk JB, Alavi A, Hurtig HI, Zimmerman RA. MR signal abnormalities at 1.5 T in Alzheimer's dementia and normal aging. Am J Roentgenol 1987;149:351-356.

15. Cordonnier C, Potter GM, Jackson CA, Doubal F, Keir S, Sudlow CL, et al. Improving interrater agreement about brain microbleeds: development of the Brain Observer MicroBleed Scale (BOMBS). Stroke 2009;40:9499.

16. Prins ND, van Straaten EC, van Dijk EJ, Simoni M, van Schijndel RA, Vrooman HA, et al. Measuring progression of cerebral white matter lesions on MRI: visual rating and volumetrics. Neurology 2004;62:1533-1539.

17. Thomalla G, Glauche V, Weiller C, Rother J. Time course of wallerian degeneration after ischaemic stroke revealed by diffusion tensor imagingJ Neurol Neurosurg Psychiatry 2005;76:266-268.

18. Matsusue E, Sugihara S, Fujii S, Kinoshita T, Ohama E, Ogawa T: Wallerian degeneration of the corticospinal tracts: postmortem MR-pathologic correlations. Acta Radiol 2007;48:690-694.

19. Watanabe T, Honda Y, Fujii Y, Koyama M, Matsuzawa H, Tanaka R: Three-dimension- al anisotropy contrast magnetic resonance axonography to predict the prognosis for motor function in patients suffering from stroke. J Neurosurg 2001;94:955-960.

20. Duering M, Righart R, Wollenweber FA, Zietemann V, Gesierich B, Dichgans M. Acute infarcts cause focal thinning in remote cortex via degeneration of connecting fiber tracts. Neurology 2015;84:1685-1692. 


\section{Supplemental Methods}

\section{Cavitation on MRI}

We visually assessed the appearance of the index lacunar lesion, including different degrees of cavitation. Figure 4.4 shows the imaging characteristics of different degrees of cavitation.

Absent cavitation was defined as a lesion without any evidence of cavitation. Partial cavitation was defined as a lesion with one of the following characteristics: a lacey-like or spongiform appearance with areas of marked hypointensity in the core of the lesion on FLAIR; a lesion with a core with equivalent to cerebrospinal fluid (CSF) signal on T2, but which is not visible on FLAIR; a lesion with a core with equivalent to CSF signal on T2, but with presence of a hypointensity, not as dark as CSF, on FLAIR; a lesion with a core with equivalent to CSF signal on T2, but with presence of a non-cavitated WMH on FLAIR; and a lesion were only a small core in part of the lesion is visible, both on T2 and FLAIR. Complete cavitation (lacune) was defined as a cavity with signal intensity comparable to CSF on FLAIR and T2, with a thin surrounding hyperintense halo (gliosis) on FLAIR.

Figure 4.4 Imaging characteristics of different degrees of cavitation.

\begin{tabular}{lll}
\hline MRI feature & MRI characteristics \\
\hline $\begin{array}{l}\text { No cavitation } \\
\text { No cavitation }\end{array}$ & $\begin{array}{l}\text { Hyperintense on FLAIR and T2 } \\
\text { imaging, without any evidence } \\
\text { of cavitation. }\end{array}$
\end{tabular}

Partial cavitation

Lacey-like FLAIR

Lacey-like appearance with areas of marked hypo-intensity in the core (often with septa) on FLAIR, and a core with the equivalent to CSF signal on T2 imaging.

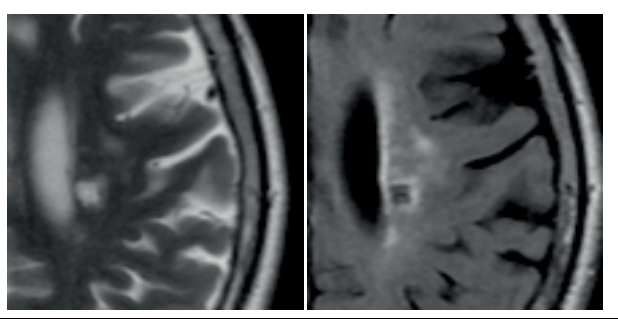




\begin{tabular}{ll}
\hline MRI feature & MRI characteristics \\
\hline $\begin{array}{l}\text { T2 hole like, FLAIR } \\
\text { Lesion has a core with the } \\
\text { equivalent to CSF signal on T2, } \\
\text { but is not visible on FLAIR } \\
\text { imaging. }\end{array}$ \\
$\begin{array}{ll}\text { T2 hole like, FLAIR } \\
\text { not as dark as CSF }\end{array}$ & $\begin{array}{l}\text { Lesion has a core with the } \\
\text { equivalent to CSF signal on T2, } \\
\text { and a hypointensity in the core, } \\
\text { which is not as dark as CSF, on } \\
\text { FLAIR imaging. }\end{array}$
\end{tabular}

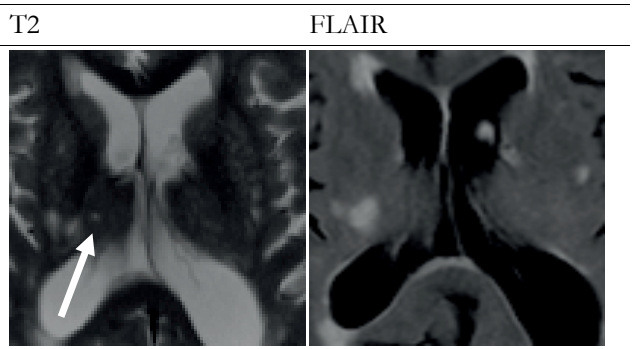

T2 hole like, FLAIR Lesion has a core with the WMH equivalent to CSF signal on T2, and resembles a (non-cavitated) WMH on FLAIR imaging.
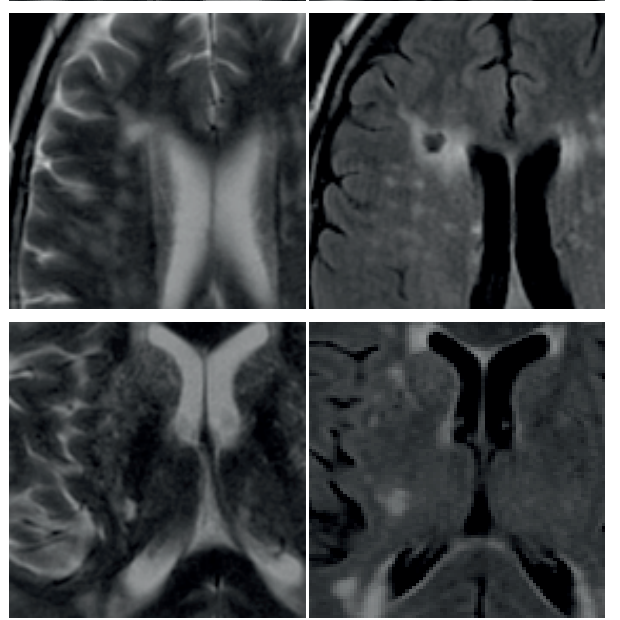

Small hole in part of lesion both $\mathrm{T} 2$ and FLAIR

Only a small core in part of the lesion is cavitated (with the equivalent to CSF signal) on T2 and FLAIR imaging.

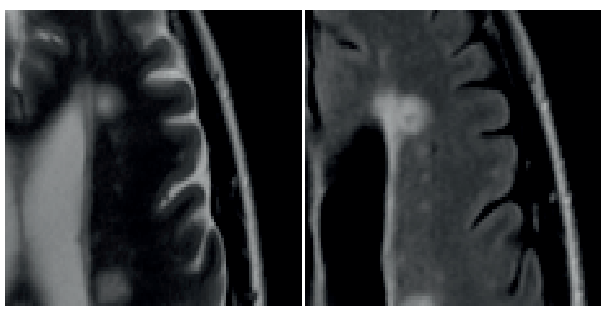

Complete cavitation

Complete cavitation Hyperintense (equivalent to CSF signal) core on $\mathrm{T} 2$, with hypointense signal intensity comparable to CSF and with a thin surrounding hyperintense halo (gliosis) on FLAIR imaging.
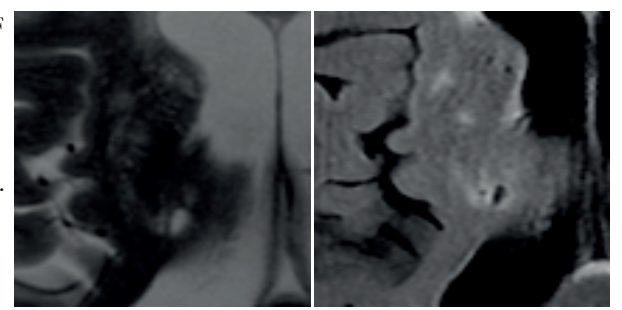

WMH: white matter hyperintensity; CSF: cerebrospinal fluid. 




\section{CHAPTER 5}

\section{Association between perivascular spaces and progression of white matter hyperintensities in lacunar stroke patients.}

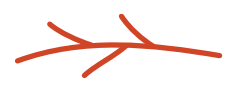

Loos CM, Klarenbeek P, van Oostenbrugge RJ, Staals J.

Association between basal ganglia perivascular spaces and progression of white matter hyperintensities in lacunar stroke patients.

PLoS One 2015;10:e0137323. 


\section{Abstract}

Background Perivascular spaces (PVS) are associated with MRI markers of cerebral small vessel disease (cSVD), including white matter hyperintensities (WMH). Although PVS are considered to be an early MRI marker of cSVD, it is unknown whether they are associated with further progression of MRI markers, especially WMH. We determined the association between PVS and progression of WMH after 2-year follow-up in lacunar stroke patients.

Methods In 118 lacunar stroke patients we obtained brain MRI and 24-hour ambulatory blood pressure measurements at baseline, and a follow-up brain MRI 2 years later. We visually graded PVS and WMH at baseline. Progression of WMH was assessed using a visual WMH change scale. Associations with WMH progression were tested with binary logistic regression analysis.

Results Extensive basal ganglia PVS were associated with progression of WMH (OR 4.29; 95\% CI: 1.28-14.32; $\mathrm{p}<0.05$ ), after adjustment for age, gender, 24-hour blood pressure and vascular risk factors. This association lost significance after additional adjustment for baseline WMH. Centrum semiovale PVS were not associated with progression of WMH.

Conclusion Our study shows that extensive basal ganglia PVS are associated with progression of WMH in cSVD. However, this association was not independent of baseline WMH. Therefore, presence of WMH at baseline remains an important determinant of further progression of WMH in cSVD. 


\section{Introduction}

Perivascular spaces are cerebrospinal fluid-filled spaces surrounding the small penetrating cerebral vessels in the basal ganglia and centrum semiovale. Magnetic resonance imaging visible PVS are associated with risk factors for CSVD, such as age and hypertension ${ }^{2,3}$. They are also cross-sectionally associated with severity of other MRI markers of cSVD, especially $\mathrm{WMH}^{4}$. Therefore, PVS are considered to be an early MRI marker of cSVD. The location of PVS may indicate different types of underlying cSVD: basal ganglia PVS are more strongly associated with blood pressure-related arteriopathy, whereas centrum semiovale PVS are associated with cerebral amyloid angiopathy ${ }^{5}$. Perivascular spaces in these two regions are also anatomically different: two leptomeningeal layers surround the basal ganglia small vessels, and superficial perforating small vessels in the centrum semiovale are only surrounded by one layer ${ }^{2}$.

There is increasing evidence that blood-brain barrier (BBB) breakdown 4,6 is one of the primary steps in the pathogenesis of blood pressure-related cSVD. Derangement of the BBB leads to leakage of plasma components over the BBB into the vessel wall and perivascular space, and it is thought that this leads to enlargement of PVS 4,6 . Hypertension may cause BBB dysfunction through effects on the endothelium 7 . Previous studies have shown that elevated BP levels are related with MRI markers of cSVD, including PVS and WMH ${ }^{3,8-13}$, and that high BP levels are associated with WMH progression over time $^{14-15}$. Furthermore, there is evidence that basal ganglia PVS are more strongly associated with hypertension and WMH than PVS in the centrum semiovale ${ }^{4,16-17}$.

Although PVS are considered to be an early MRI marker of cSVD, it is unknown whether PVS, mainly in the basal ganglia, are related with progression of cSVD, and particularly with progression of WMH. Therefore, we aimed to determine the association between severity of PVS in the basal ganglia and centrum semiovale at baseline and progression of WMH after 2-year follow-up in lacunar stroke patients. We studied a patient cohort with highly prevalent MRI features of cSVD, namely lacunar stroke patients, and we included 24-hour BP levels in our analysis.

\section{SUBJECTS and Methods}

\section{Study Population}

From a lacunar stroke research project with first-ever lacunar stroke patients presenting at Maastricht University Medical Centre or Orbis Medical Centre Sittard, the Netherlands, between 2003 and 2008, we selected all first-ever lacunar stroke patients who had a baseline brain MRI and 24-hour ambulatory BP monitoring, and a two-year follow-up brain $\mathrm{MRI}^{3},{ }^{12}$. All patients participated with written informed consent in this research project, which has been approved by the local Medical Ethical Committee (Maastricht University Medical Centre). Lacunar stroke was defined as one of the recognized lacunar stroke syndromes ${ }^{18}$ with a small $(<20 \mathrm{~mm})$ lacunar lesion in the deep grey matter, pons 
or internal capsule, compatible with occlusion of a single deep perforating artery. In absence of such a lesion on baseline MRI, we used established clinical criteria for lacunar stroke syndromes ${ }^{18}$. Patients with potential cardio-embolic sources or $>50 \%$ carotid stenosis in at least one carotid artery were not included. Age, gender and vascular risk factors (hypertension, hypercholesterolemia, diabetes mellitus and smoking) were recorded as defined earlier ${ }^{12}$.

\section{BP measurements}

Ambulatory BP monitoring during a 24-hour period was performed after the acute stroke phase, between 1 and 6 months after stroke (mean $101 \pm 42$ days). Patients continued their prescribed medication, and we registered the use of antihypertensive drugs. We calculated 24-hour ambulatory systolic blood pressure levels (24-h SBP) and 24-hour ambulatory diastolic blood pressure levels (24-h DBP). Details were described elsewhere $^{12}$.

\section{MRI scoring}

Baseline MRI images (at 1,5 or 3T MRI scanner, Philips) were obtained as soon as possible and within 6 months after stroke onset. The MRI protocol consisted of axial T2weighted fast spin echo and FLAIR sequences, with slice thickness of $5 \mathrm{~mm}$, gaps 0.5 $\mathrm{mm}$ and in-plane resolution $0.45 \times 0.45 \mathrm{~mm}$. The MRI protocol at two-year follow-up was similar to the baseline protocol. Two vascular neurologists independently assessed baseline and follow-up imaging.

Perivascular spaces were defined as round, oval, or linear-shaped lesions with a smooth margin, absence of mass effect and with signal intensity equal to cerebrospinal fluid on T2-weighted images, and (if visible) hypointense on fluid-attenuated inversion recovery images (FLAIR) without a hyperintense rim to distinguish them from old lacunar infarcts ${ }^{1}$. We distinguished PVS at the level of basal ganglia and centrum semiovale. We visually graded PVS on the slide with the highest number in one hemisphere, using a formerly described semi-quantitative three-category severity scale (none-to-mild, moderate and extensive) ${ }^{3}$ (Figure 5.1). The inter-observer agreement was fair to good; weighted Cohen's kappa 0.73 for basal ganglia PVS and 0.71 for centrum semiovale PVS 3 . We graded deep and periventricular WMH at baseline according to Fazekas' scale $^{19}$. The inter-observer agreement was good to excellent; weighted Cohen's kappa 0.77 for periventricular WMH, and 0.84 for deep $\mathrm{WMH}^{16}$. 

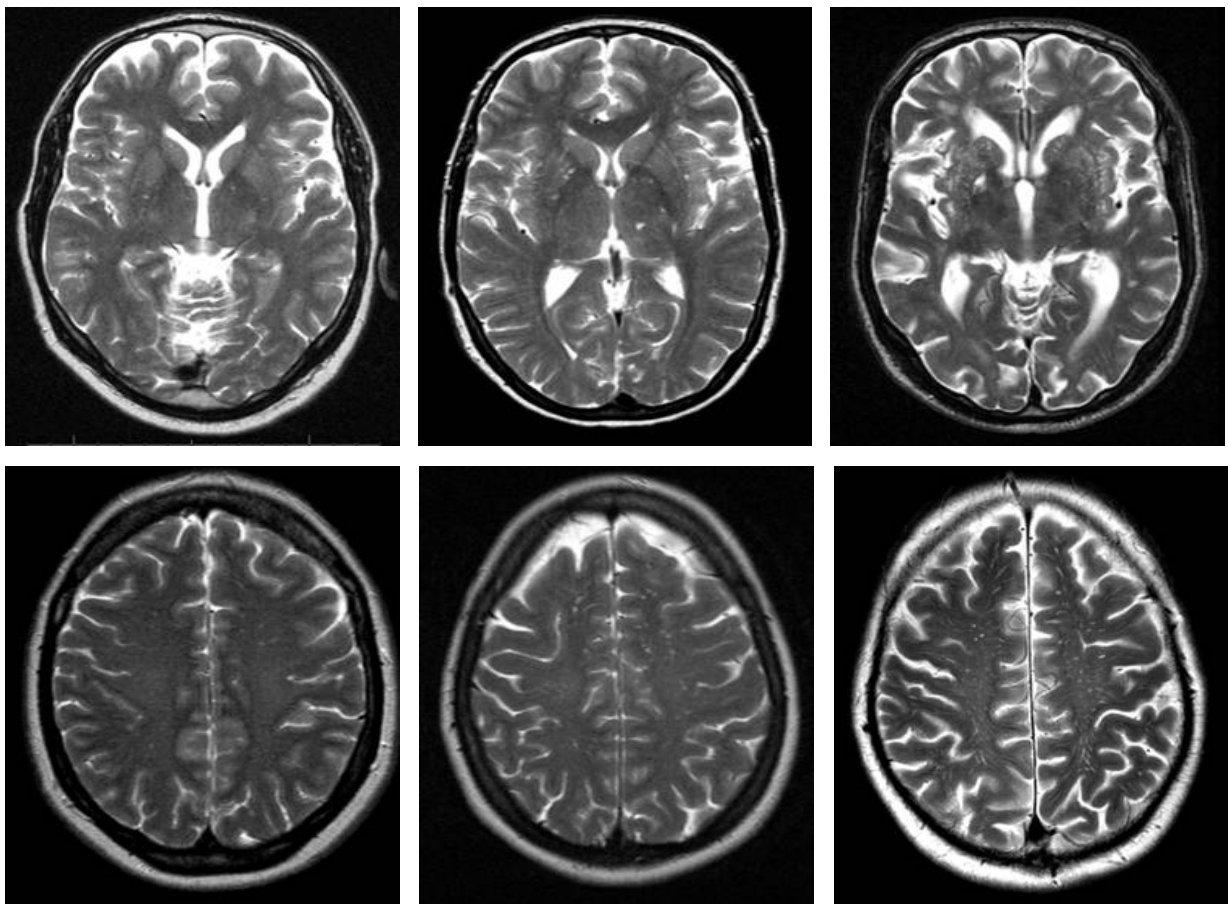

Figure 5.1 Examples of the categories of perivascular spaces (PVS) by using a semi-quantitative three-category severity scale. Upper image, left to right: PVS in the basal ganglia; respectively none-to-mild, moderate and extensive. Bottom image, left to right: PVS in the centrum semiovale; respectively none-to-mild, moderate and extensive.

At follow-up imaging, progression of WMH was assessed by a validated visual WMH change scale (The modified Rotterdam Progression Scale) ${ }^{20}$. This scale (range -7 to 7 ) measures a decrease, no change, or increase $(-1,0,1$ respectively) of WMH in three different periventricular and four different subcortical regions. We defined progression of WMH as an increase of WMH in one or more periventricular and/or subcortical regions. The inter-observer agreement was good; weighted Cohen's kappa 0.79 for progression of WMH.

\section{Statistical analysis}

Statistical analysis was performed using SPSS version 21.0 (Chicago, IL). Data are presented as $\mathrm{n}(\%)$ for categorical variables or as mean \pm SD for parametric data. We determined the association between PVS categories and presence or absence of progression of WMH by binary logistic regression analysis. We corrected for age, gender, 24hour SBP and 24-hour DBP. Next, we performed two models in which we additionally corrected for other vascular risk factors (including hypercholesterolemia, diabetes mellitus and smoking), or for baseline deep and periventricular WMH. Second, we also performed a binary logistic regression analysis to determine the possible relation between 24-hour ambulatory BP levels and progression of WMH. We performed two models in 
which we first corrected for age, gender and vascular risk factors (including hypercholesterolemia, diabetes mellitus and smoking), and second for age, gender and deep and periventricular WMH at baseline imaging. Statistical significance was considered at $\mathrm{p}<0.05$.

\section{Results}

\section{Patients and Baseline Characteristics}

Of 281 first-ever lacunar stroke patients who presented at Maastricht University Medical Centre, 35 patients were excluded because of presence of a carotid artery stenosis or possible cardio-embolic source (most commonly atrial fibrillation). In total 116 patients refused to participate or had absolute contra-indications for MR imaging. Of the remaining 130 patients, we excluded 16 patients because of an inadequate baseline MRI and/or inadequate BP monitoring data, leaving 114 patients at baseline. By applying the same inclusion and exclusion criteria we recruited 29 patients from Orbis Medical Centre Sittard (number and characteristics of non-included patients were not listed), which totals 143 included patients at baseline. Patients were offered a clinical follow-up MRI after 2 years. Twenty patients were lost to follow up ( 5 patients died and 15 refused follow-up or could not be contacted), leaving 123 patients. To avoid overestimation of WMH progression, we excluded an additional 5 patients who had follow-up MRI at higher field strength than baseline MRI. Of the finally included 118 patients, 95 patients had baseline and follow-up MRI at $1.5 \mathrm{~T}, 20$ patients had baseline MRI at $3.0 \mathrm{~T}$ with follow-up MRI at $1.5 \mathrm{~T}$ and 3 patients had baseline and follow-up MRI at 3.0 T. Table 5.1 shows baseline patient characteristics of these 118 patients.

Table 5.1 Baseline patient characteristics.

\begin{tabular}{ll}
\hline & $\mathrm{N}=118$ \\
\hline Demographics & $63 \pm 12$ \\
Age at stroke onset (years), mean \pm SD & $72(61)$ \\
Male (\%) & $79(67)$ \\
Vascular risk factors & $16(14)$ \\
Hypertension (\%) & $93(79)$ \\
Diabetes (\%) & $49(42)$ \\
Hypercholesterolemia (\%) & \\
Smoking (\%) & $139 \pm 18$ \\
BP measurements & $83 \pm 12$ \\
24-h SBP (mmHg), mean \pm SD & \\
24-h DBP (mmHg), mean \pm SD & \\
\hline
\end{tabular}

Numbers (\%) or means \pm SD (standard deviation); 24-h SBP: 24-hour ambulatory systolic blood pressure; 24-h DBP: 24-hour ambulatory diastolic blood pressure. 
Table 5.2 shows baseline and follow-up MRI characteristics. On baseline imaging, 34 (28\%) patients had extensive basal ganglia PVS and $41(35 \%)$ patients had extensive centrum semiovale PVS. On 2 year follow-up imaging, 54 (46\%) patients had progression of WMH.

Table 5.2 MRI characteristics.

\begin{tabular}{ll}
\hline & $\mathrm{N}=118$ \\
\hline Baseline MRI & \\
Periventricular WMH (\%) & $46(39)$ \\
Fazekas grade 0 & $33(28)$ \\
Fazekas grade 1 & $8(7)$ \\
Fazekas grade 2 & $31(26)$ \\
Fazekas grade 3 & \\
Deep WMH (\%) & $33(28)$ \\
Fazekas grade 0 & $50(42)$ \\
Fazekas grade 1 & $14(12)$ \\
Fazekas grade 2 & $21(18)$ \\
Fazekas grade 3 & \\
PVS at basal ganglia (\%) & $42(36)$ \\
none-to-mild & $42(36)$ \\
moderate & $34(28)$ \\
extensive & \\
PVS at centrum semiovale (\%) & $27(23)$ \\
none-to-mild & $50(42)$ \\
moderate & $41(35)$ \\
extensive & \\
Follow-up MRI & $54(46)$ \\
\hline
\end{tabular}

WMH: white matter hyperintensities; PVS: perivascular spaces.

\section{Association between baseline PVS and progression of WMH}

Table 5.3 shows the association between baseline PVS and progression of WMH after 2 years of follow-up. Extensive basal ganglia PVS were associated with progression of WMH after 2 years (OR 5.23; 95\% CI: 1.96-13.96; $\mathrm{p}<0.01$ ). After adjusting for age, gender, 24-h SBP and 24-h DBP this association remained significant (OR 3.98; 95\% CI: $1.23-12.88 ; \mathrm{p}<0.05)$ and also with additional adjustment for other vascular risk factors (OR 4.29; 95\% CI: 1.28-14.32; $\mathrm{p}<0.05$ ). However, with additional adjustment for periventricular and deep WMH at baseline, the association between extensive PVS and WMH progression lost statistical significance (OR 1.49; 95\% CI: 0.37-6.07; $\mathrm{p}=0.58$ ). No association was found between centrum semiovale PVS and WMH progression. 
Table 5.3 Association between baseline PVS and progression of WMH by binary logistic regression analysis.

\begin{tabular}{|c|c|c|c|c|}
\hline & \multicolumn{4}{|c|}{$\begin{array}{l}\text { Progression of WMH } \\
\text { OR }(95 \% \text { CI })\end{array}$} \\
\hline & unadjusted & model 1 & model 2 & model 3 \\
\hline \multicolumn{5}{|c|}{ Basal ganglia PVS } \\
\hline None to mild & 1.00 & 1.00 & 1.00 & 1.00 \\
\hline Moderate & $2.07(0.84-5.10)$ & $1.85(0.67-5.11)$ & $1.70(0.60-4.83)$ & $1.22(0.37-3.99)$ \\
\hline Extensive & $5.23(1.96-13.96)^{* *}$ & $3.98(1.23-12.88)^{*}$ & $4.29(1.28-14.32)^{*}$ & $1.49(0.37-6.07)$ \\
\hline \multicolumn{5}{|c|}{ Centrum semiovale PVS } \\
\hline None to mild & 1.00 & 1.00 & 1.00 & 1.00 \\
\hline Moderate & $0.89(0.34-2.32)$ & $0.99(0.36-2.75)$ & $0.82(0.29-2.37)$ & $1.15(0.34-3.88)$ \\
\hline Extensive & $2.05(0.77-5.51)$ & $2.05(0.72-5.87)$ & $1.88(0.65-5.49)$ & $2.42(0.64-9.14)$ \\
\hline
\end{tabular}

Model 1 adjusted for age, gender, 24-h systolic blood pressure (24-h SBP) and 24-h diastolic blood pressure (24-h DBP). Model 2 adjusted for age, gender, 24-h SBP, 24-h DBP and vascular risk factors (diabetes mellitus, hypercholesterolemia and smoking). Model 3 adjusted for age, gender, 24-h SBP, 24-h DBP and baseline white matter hyperintensities (WMH). OR: odds ratio; CI: confidence interval; PVS: perivascular spaces. ${ }^{*} \mathrm{p}<0.05$; ${ }^{* *} \mathrm{p}<0.01$.

\section{Association between BP and progression of WMH}

Table 5.4 shows the associations between baseline 24-hour ambulatory BP levels and progression of WMH after 2 year of follow-up. We did not find a significant association between baseline 24-h SBP and progression of WMH after 2 years. Twenty-four hour DBP levels seemed to be negatively associated with progression of WMH (OR 0.83; 95\% CI: 0.49-0.96; $\mathrm{p}<0.05)$. However, this association lost significance after adjustment for age, gender, vascular risk factors and baseline WMH.

Table 5.4 Association between baseline ambulatory 24-hour blood pressure levels and progression of WMH by binary logistic regression analysis.

\begin{tabular}{|c|c|c|c|}
\hline & \multicolumn{3}{|c|}{$\begin{array}{l}\text { Progression of WMH } \\
\text { OR }(95 \% \mathrm{CI})\end{array}$} \\
\hline & unadjusted & model 1 & model 2 \\
\hline \multicolumn{4}{|c|}{ Ambulatory 24-h BP (mmHg) } \\
\hline SBP & $0.86(0.69-1.06)$ & $0.80(0.63-1.02)$ & $0.78(0.59-1.02)$ \\
\hline DBP & $0.83(0.49-0.96)^{*}$ & $0.89(0.55-1.14)$ & $0.81(0.43-1.04)$ \\
\hline
\end{tabular}

Results of binary logistic regression analysis presented as OR per $10 \mathrm{mmHg}$ increase in systolic blood pressure (SBP) or $5 \mathrm{mmHg}$ in diastolic blood pressure (DBP). Model 1 adjusted for age, gender and vascular risk factors (diabetes mellitus, hypercholesterolemia and smoking). Model 2 adjusted for age, gender and baseline white matter hyperintensities. OR: odds ratio; CI: confidence interval; WMH: white matter hyperintensities; 24-h BP: 24-hour ambulatory blood pressure; ${ }^{*} \mathrm{p}<0.05$.

\section{Discussion}

Our study shows that extensive basal ganglia PVS are associated with progression of WMH over two years of follow-up, independent of age, gender and vascular risk factors. However, this association was not independent of the presence of WMH at baseline. We did not find a positive association between centrum semiovale PVS and WMH 
progression and we did not find an association between 24-h SBP or 24-h DBP levels at baseline and WMH progression.

Studies with a cross sectional design showed that PVS, and in particular basal ganglia PVS, are associated with severity of other MRI markers of cSVD, including $\mathrm{WMH}^{3-4,16-}$ 17 and with increased BBB permeability ${ }^{21}$. Hypertension could lead to endothelial dysfunction and $\mathrm{BBB}$ breakdown ${ }^{2,7}$, which are considered to be the primary steps in the pathogenesis of $\mathrm{cSVD}^{4,6}$. Leakage of plasma components over the BBB leads to damage of the cerebral small vessel wall and enlargement of PVS ${ }^{6}$. Therefore, as PVS seem to appear early in the course of cSVD, the amount of PVS might be an early MRI marker of brain damage related to cSVD. In CADASIL, a genetic form of cSVD, severity of temporal PVS is strongly related with total WMH volume 22 and PVS in the temporal lobes have a pathological correlation with temporal $\mathrm{WMH}^{23}$. Our study shows that extensive basal ganglia PVS are associated with progression of WMH in lacunar stroke patients. Even though our results need to be confirmed in other cohorts, we suggest that basal ganglia PVS might be an early marker for progression of WMH in blood pressurerelated cSVD, although the presence of WMH still remains most important for further progression.

It has been suggested that WMH tend to form around PVS 6 , however we did not find an association between PVS in the white matter of the centrum semiovale and progression of WMH. However, we tested the association between overall severity of centrum semiovale PVS and general progression of WMH, which does not correlate them spatially. Another explanation could be that severity of centrum semiovale PVS is underestimated in those cases with overshadowing presence of extensive WMH. Finally, PVS in the centrum semiovale may have a different pathogenesis than basal ganglia PVS. They may be linked to cerebral amyloid angiopathy rather than blood pressure-related cSVD 5,24 .

We did not find a positive association between 24-hour ambulatory BP levels and progression of WMH after 2 years. Even though several other studies showed that high BP levels are associated with WMH progression ${ }^{14-15}$, this was not found by all25. The relationship between WMH and BP remains complex ${ }^{2}$. Previous studies have shown that cumulative, prior elevated BP levels are more associated with WMH compared to concurrent $\mathrm{BP}^{26-28}$. A J-curved relation between $\mathrm{BP}$ and $\mathrm{WMH}$ has also been shown ${ }^{29}$. We do not have data on severity and duration of hypertension, nor on previous treatment of elevated BP levels in our patients, and this may be important in the association between BP and progression of WMH. Furthermore, a substantial portion of our patients had anti-hypertensive treatment during the follow-up period and this may have influenced WMH progression. There is evidence that patients with untreated and uncontrolled hypertension have greater progression of WMH compared to patients with controlled or treated blood pressure levels ${ }^{15,30}$.

Our study has several limitations. First, not all patients were scanned at the same MRI field strength, which might have led to bias in grading lesions. However, analysis including only patients with the same field strength at baseline and follow up ( $n=98)$ did 
not change the results of our main analysis (results not shown). Second, we measured PVS and progression of WMH by using visual scales and not quantitative volumetric techniques. However, a quantitative method for counting PVS does not exist and visual semi-quantitative assessment is still the reference-standard method ${ }^{1}$. The modified Rotterdam Progression Scale is the most reliable visual assessment tool for WMH progression and correlates well with volumetrics ${ }^{20,31}$. Third, a cohort of lacunar stroke patients with advanced cSVD and a substantial amount of WMH at baseline, might not be ideal to test for an association between severity of PVS at baseline and progression of WMH. To confirm the predictive role of PVS as an early MRI marker of WMH progression, we suggest a study in a population at risk and in an early stage of cSVD (for example hypertensive patients) with a long follow-up time.

\section{Conclusion}

In conclusion, extensive basal ganglia PVS are associated with WMH progression after 2-year follow-up in lacunar stoke patients. However, this association was not independent of WMH at baseline. Therefore, baseline WMH still remain an important determinant of progression of WMH in cSVD. 


\section{References}

1. Wardlaw JM, Smith EE, Biessels GJ, Cordonnier C, Fazekas F, Frayne R,et al. Neuroimaging standards for research into small vessel disease and its contribution to ageing and neurodegeneration. Lancet Neurol 2013;12:822-838.

2. Wardlaw JM, Smith C, Dichgans M. Mechanisms of sporadic cerebral small vessel disease: insights from neuroimaging. Lancet Neurol 2013;12:483-497.

3. Klarenbeek P, van Oostenbrugge RJ, Lodder J, Rouhl RP, Knottnerus IL, Staals J. Higher ambulatory blood pressure relates to enlarged Virchow-Robin spaces in first-ever lacunar stroke patients. J Neurol 2013;260:115121.

4. Doubal FN, MacLullich AM, Ferguson KJ, Dennis MS, Wardlaw JM. Enlarged perivascular spaces on MRI are a feature of cerebral small vessel disease. Stroke 2010;41:450-454.

5. Yakushiji Y, Charidimou A, Hara M, Noguchi T, Nishihara M, Eriguchi M, et al. Topography and associations of perivascular spaces in healthy adults: the Kashima scan study. Neurology 2014;83:2116-2123.

6. Wardlaw JM. Blood-brain barrier and cerebral small vessel disease. J Neurol Sci 2010;15:66-71.

7. Dharmashankar K, Widlansky ME. Vascular endothelial function and hypertension: insights and directions. Curr Hypertens Rep 2010;12:448-455.

8. Vermeer SE, Longstreth WT Jr, Koudstaal PJ. Silent brain infarcts: a systematic review. Lancet Neurol 2007;6:611-619.

9. de Leeuw FE, de Groot JC, Oudkerk M, Witteman JC, Hofman A, van Gijn J, et al. Hypertension and cerebral white matter lesions in a prospective cohort study. Brain 2002;125:765-772.

10. Vermeer SE, Koudstaal PJ, Oudkerk M, Hofman A, Breteler MM. Prevalence and risk factors of silent brain infarcts in the population based Rotterdam Scan Study. Stroke 2002;33:21-25.

11. Schwartz GL, Bailey KR, Mosley T, Knopman DS, Jack CR Jr, Canzanello VJ, et al. Association of ambulatory blood pressure with ischemic brain injury. Hypertension 2007;49:1228-1234.

12. Staals J, van Oostenbrugge RJ, Knottnerus ILH, Rouhl RPW, Henkens LHG, Lodder J. Brain microbleeds relate to higher ambulatory blood pressure levels in first-ever lacunar stroke patients. Stroke 2009;40:32643268 .

13. Klarenbeek P, van Oostenbrugge RJ, Rouhl RP, Knottnerus IL, Staals J. Ambulatory blood pressure in patients with lacunar stroke: association with total MRI burden of cerebral small vessel disease. Stroke 2013;44:29952999.

14. Firbank MJ, Wiseman RM, Burton EJ, Saxby BK, O’Brien JT, Ford GA. Brain atrophy and white matter hyperintensity change in older adults and relationship to blood pressure. Brain atrophy, WMH change and blood pressure. J Neurol 2007;254:713-721.

15. Verhaaren BFJ, Vernooij MW, de Boer R, Hofman A, Niessen WJ, van der Lugt A, et al. High Blood Pressure and Cerebral White Matter Lesion Progression in the General Population. Hypertension 2013;61:1354-1359.

16. Rouhl RP, van Oostenbrugge RJ, Knottnerus IL, Staals JE, Lodder J. Virchow-Robin spaces relate to cerebral small vessel disease severity. J Neurol 2008;255:692-696.

17. Zhu Y, Tzourio C, Soumaré A, Mazoyer B, Dufouil C and Chabriat H. Severity of dilated Virchow-Robin spaces is associated with age, blood pressure, and MRI Markers of small vessel disease. A population-based study. Stroke 2010;41:2483-2490.

18. Donnan GA, Norrving B, Bamford J, Bogousslavsky J. Classification of subcortical infarcts. In: Donnan GA, Norrving B, Bamford J, Bogousslavsky J, eds. Subcortical stroke. New York: Oxford University Press Inc ;2002:27-34.

19. Fazekas F, Chawluk JB, Alavi A, Hurtig HI, Zimmerman RA. MR signal abnormalities at 1.5 T in Alzheimer's dementia and normal aging. Am J Roentgenol 1987;149:351-356.

20. Prins ND, van Straaten EC, van Dijk EJ, Simoni M, van Schijndel RA, Vrooman HA, et al. Measuring progression of cerebral white matter lesions on MRI: visual rating and volumetrics. Neurology 2004; 62:15331539 .

21. Wardlaw JM, Doubal F, Armitage P, Chappell F, Carpenter T, Muñoz Maniega S, et al. Lacunar stroke is associated with diffuse blood-brain barrier dysfunction. Ann Neurol 2009;65:194-202.

22. Yao M, Hervé D, Jouvent E, Duering M, Reyes S, Godin O, et al. Dilated perivascular spaces in small-vessel disease: a study in CADASIL. Cerebrovasc Dis 2014;37:155-163.

23. Yamamoto Y, Ihara M, Tham C, Low RW, Slade JY, Moss T, et al. Neuropathological correlates of temporal pole white matter hyperintensities in CADASIL. Stroke 2009;40:2004-2011. 


\section{Chapter 5}

24. Charidimou A, Hong YT, Jäger HR, Fox Z, Aigbirhio FI, Fryer TD, et al. White matter perivascular spaces on magnetic resonance imaging: marker of cerebrovascular amyloid burden? Stroke 2015;46:1707-1709.

25. Gouw AA, van der Flier WM, Fazekas F, van Straaten EC, Pantoni L, Poggesi A, et al. Progression of white matter hyperintensities and incidence of new lacunes over a 3-year period: the Leukoaraiosis and Disability study. Stroke 2008;39:1414-1420.

26. Guo X, Pantoni L, Simoni M, Bengtsson C, Björkelund C, Lissner L, et al. Blood pressure components and changes in relation to white matter lesions: a 32-year prospective population study. Hypertension 2009;54:5762.

27. Gottesman RF, Coresh J, Catellier DJ, Sharrett AR, Rose KM, Coker LH, et al. Blood pressure and whitematter disease progression in a biethnic cohort. Atherosclerosis Risk in Communities (ARIC) Study. Stroke 2010;41:3-8.

28. Marcus J, Gardener H, Rundek T, Elkind MS, Sacco RL, Decarli C, et al. Baseline and longitudinal increases in diastolic blood pressure are associated with greater white matter hyperintensity volume: the northern Manhattan study. Stroke 2011;42:2639-2641.

29. de Leeuw FE, de Groot JC, Oudkerk M, Witteman JC, Hofman A, van Gijn J, et al. A follow-up study of blood pressure and cerebral white matter lesions. Ann Neurol 1999;46:827-833.

30. Abraham HM, Wolfson L, Moscufo N, Guttmann CR, Kaplan RF, White WB. Cardiovascular risk factors and small vessel disease of the brain: blood pressure, white matter lesions, and functional decline in older persons. J Cereb Blood Flow Metab 2015;3 doi:10.1038/jcbfm.2015.121.

31. Gouw AA, van der Flier WM, van Straaten ECW, Pantoni L, Bastos-Leite AJ, Inzitari D, et al. Reliability and sensitivity of visual scales versus volumetry for evaluating white matter hyperintensity progression. Cerebrovasc Dis $2008 ; 25: 247-253$. 


\section{CHAPTER 6}

\section{The relation between total cerebral small vessel disease burden and gait impairment in patients with minor stroke.}

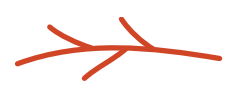

Loos CM, McHutchison C, Cvoro V, Staals J, Chappell F, van Oostenbrugge RJ, Wardlaw JM.

The relation between total cerebral small vessel disease burden and gait impairment in patients with minor stroke.

Int J Stroke 2017;1:1747493017730780. 


\section{Abstract}

Background Individual MRI markers of cSVD are associated with gait impairment. The impact of total cSVD-related brain damage, expressed by a cSVD MRI burden score, on mobility after stroke, has not been considered, although this score gives a better representation of the overall effect of cSVD on the brain. We determined if the total cSVD burden is associated with gait impairment three years after minor stroke.

Methods In total, 200 patients with minor lacunar or non-lacunar stroke (NIHSS $\leq 7$ ) underwent a brain MRI at presentation. Presence of lacunes, WMH, CMB and PVS were summed in a total cSVD MRI burden score (range 0-4). Gait disturbances, measured by timed-up-and-go test and self-reported Stroke Impact Scale mobility domain were assessed three years after stroke. We tested associations adjusted for key variables by linear regression analysis.

Results Total cSVD burden was not associated with gait impairment after minor stroke in all patients, nor in lacunar stroke patients $(n=87)$. In non-lacunar stroke patients $(n=113)$ the total cSVD burden was associated with lower Stroke Impact Scale mobility domain scores, independent of age, vascular risk factors and stroke severity (unstandardized B -4.61; 95\% CI -8.42;-0.79, $\mathrm{p}<0.05)$.

Conclusion Patients with non-lacunar stroke and a higher total cSVD burden have more subjective mobility impairment three years after stroke. The total cSVD MRI burden score is a possible marker to identify patients at risk for subjective gait impairment. These findings should be confirmed in larger studies. 


\section{Introduction}

Cerebral small vessel disease causes MRI visible brain damage, including WMH, lacunes, PVS and $\mathrm{CMB}^{1-2}$. The burden of cSVD on public health is substantial: cSVD is a leading cause of cognitive impairment, dementia and stroke ${ }^{3}$.

Less recognized, cSVD is also related to gait disturbances ${ }^{4-5}$ and worse functional outcome after stroke ${ }^{6-8}$. Several studies have demonstrated that individual MRI markers of cSVD, including WMH and CMB, are related to gait impairment ${ }^{4-5,9-10}$. However, most of these studies have focused on individual MRI features of cSVD rather than recognizing the impact of total cSVD-related brain damage. A total cSVD burden score, based on visual MRI feature recognition, might better capture the relation between risk factors and brain injury ${ }^{11-12}$ or the overall effect of cSVD on cognitive function ${ }^{13-14}$. Whether the total cSVD MRI burden score is associated with gait impairment after stroke is unknown.

We aimed to determine if overall cSVD-related brain damage, measured by a total cSVD MRI burden score, is associated with gait disturbances, objectively measured by the timed-up-and-go (TUG) test and subjectively assessed by self-reported Stroke Impact Scale (SIS) mobility domain score, three years after minor ischaemic stroke. In a secondary analysis, we also tested the association between the total cSVD burden scale and functional stroke outcome, measured by the modified Rankin Scale (mRS).

\section{Subjects and methods}

For a detailed description, see the Supplemental Data. In short, we used data from a prospective observational study in patients with minor ischaemic stroke (Mild Stroke Study-2 ${ }^{15-17}$. The study was approved by the Scotland and Lothian Research Ethics Committee (ref 09/S1101/54) and all patients gave written informed consent.

All patients underwent a $1.5 \mathrm{~T}$ brain MRI scan, which was assessed for presence of an acute symptomatic lacunar or non-lacunar infarct. Baseline MRI was also rated for presence of lacunes, WMH, CMB and basal ganglia PVS, all according to the STRIVE criteria for reporting studies in $\mathrm{cSVD}^{2}$. These MRI markers were summed in an ordinal "total cSVD burden score" (with a range of 0-4) by counting presence of each of these 4 MRI features ${ }^{12,14}$. Definition of MRI markers and details on cSVD burden score are in the Supplemental Data.

Three years after stroke, gait disturbances were objectively measured by TUG test and subjectively assessed by self-reported SIS mobility domain score. The TUG test measures time (in seconds) to get up from a chair, walk 3 meters, turn around, walk back, and sit back down ${ }^{18}$. The SIS is a stroke-specific, self-reported assessment questionnaire with 8 different domains, including mobility. The SIS mobility domain score (range 0100) was calculated from 9 mobility items by using a validated logarithm ${ }^{19}$. A low SIS mobility domain score reflects a high impact on health-related quality of life. Functional disability outcome was assessed by $\mathrm{mRS}$ at three years after stroke. We tested 


\section{Chapter 6}

associations adjusted for key variables (age, gender, vascular risk factors and stroke severity (NIHSS)) by linear regression analysis (log-transformed TUG, SIS) and by logistic regression analysis (mRS). Statistical significance was set at $\mathrm{p}<0.05$ (2-tailed).

\section{Results}

\section{Patients and Baseline Characteristics}

In total, 200 of 264 minor stroke patients had a three-year clinical follow-up (Figure 6.1). For a detailed description, see Supplemental Data. Baseline clinical and MRI characteristics are shown in Table 6.1.

Table 6.1 Characteristics of 200 minor stroke patients who had a three-year clinical follow-up.

\begin{tabular}{|c|c|c|c|}
\hline & $\begin{array}{l}\text { total stroke group } \\
\mathrm{N}=200\end{array}$ & $\begin{array}{l}\text { lacunar stroke } \\
\mathrm{N}=87\end{array}$ & $\begin{array}{l}\text { non-lacunar stroke } \\
\mathrm{N}=113\end{array}$ \\
\hline \multicolumn{4}{|l|}{ Demographics } \\
\hline Age (years; mean $\pm \mathrm{SD}$ ) & $67 \pm 11$ & $64 \pm 11$ & $689 \pm 11^{*}$ \\
\hline Male $(\%)$ & $112(56)$ & $49(56)$ & $63(56)$ \\
\hline NIHSS (range) & $1(0-7)$ & $1(0-7)$ & $1(0-5)^{*}$ \\
\hline Hypertension (\%) & $145(73)$ & $60(69)$ & $85(75)$ \\
\hline Diabetes mellitus (\%) & $20(10)$ & $7(8)$ & $13(12)$ \\
\hline Hyperlipidaemia (\%) & $126(63)$ & $56(64)$ & $70(62)$ \\
\hline Smoking $(\%)$ & $61(31)$ & $31(36)$ & $30(27)$ \\
\hline \multicolumn{4}{|l|}{ MR imaging } \\
\hline Presence of lacunes & $49(25)$ & $30(35)$ & $19(17)^{*}$ \\
\hline Presence of brain microbleeds & $33(17)$ & $18(21)$ & $15(13)$ \\
\hline Moderate-severe BG PVS (\%) & $100(50)$ & $48(55)$ & $52(46)$ \\
\hline \multicolumn{4}{|l|}{ Periventricular WMH Fazekas (\%) } \\
\hline 0 & $14(7)$ & $5(6)$ & $9(8)$ \\
\hline 1 & $89(44)$ & $40(46)$ & $49(43)$ \\
\hline 2 & $54(27)$ & $25(29)$ & $29(26)$ \\
\hline 3 & $43(22)$ & $17(20)$ & $26(23)$ \\
\hline \multicolumn{4}{|l|}{ Deep WMH Fazekas (\%) } \\
\hline 0 & $19(9)$ & $7(8)$ & $12(11)$ \\
\hline 1 & $96(48)$ & $42(48)$ & $54(48)$ \\
\hline 2 & $52(26)$ & $27(31)$ & $25(22)$ \\
\hline 3 & $33(17)$ & $11(13)$ & $22(19)$ \\
\hline Extensive WMH (\%) & $85(43)$ & $38(44)$ & $47(42)$ \\
\hline \multicolumn{4}{|l|}{ Total cSVD burden scale } \\
\hline 0 & $64(32)$ & $24(28)$ & $40(36)$ \\
\hline 1 & $52(26)$ & $20(23)$ & $32(28)$ \\
\hline 2 & $47(24)$ & $23(26)$ & $24(21)$ \\
\hline 3 & $27(13)$ & $12(14)$ & $15(13)$ \\
\hline 4 & $10(5)$ & $8(9)$ & $2(2)$ \\
\hline
\end{tabular}

${ }^{*} \mathrm{p}<0.05$. Lacunar stroke versus non-lacunar stroke patients. SD: standard deviation, BG: basal ganglia, PVS: perivascular spaces, WMH: white matter hyperintensities, cSVD: cerebral small vessel disease. 


\section{Association between total cSVD burden and (log-transformed) TUG test}

The TUG test was performed in 145 patients $(73 \%$ ) with a median time of 10.7 (range 3.2-38.6) seconds. Patients who completed the TUG test were significantly younger than patients who did not do the TUG test $(n=55)(65.5 \pm 11.0$ versus $70.2 \pm 11.8$ years, $\mathrm{p}<0.05)$; vascular risk factors and MRI characteristics did not differ between groups. The median time did not differ between lacunar stroke and non-lacunar stroke patients (10.9 (range 6.5-38.6) versus 10.6 (range 3.2-26.7) seconds, $\mathrm{p}=0.63$ ). The total cSVD burden was not associated with log-transformed TUG test (linear regression analysis; Table 6.2).

Table 6.2 Association between total cSVD burden and log-transformed timed-up-and-go test in minor stroke patients.

\begin{tabular}{|c|c|c|c|c|c|}
\hline \multirow[b]{2}{*}{ Total cSVD score } & \multicolumn{5}{|c|}{$\begin{array}{l}\text { log-transformed timed-up-and-go test } \\
\text { unstandardized B }(95 \% \mathrm{CI})\end{array}$} \\
\hline & $\mathrm{N}$ & unadjusted & model 1 & model 2 & model 3 \\
\hline Total minor stroke & 145 & $\begin{array}{l}0.02 \\
(-0.00 ; 0.04)\end{array}$ & $\begin{array}{l}0.01 \\
(-0.01 ; 0.03)\end{array}$ & $\begin{array}{l}0.01 \\
(-0.02 ; 0.03)\end{array}$ & $\begin{array}{l}0.00 \\
(-0.02 ; 0.02)\end{array}$ \\
\hline Lacunar stroke & 62 & $\begin{array}{l}0.00 \\
(-0.03 ; 0.03)\end{array}$ & $\begin{array}{l}0.00 \\
(-0.03 ; 0.04)\end{array}$ & $\begin{array}{l}0.00 \\
(-0.03 ; 0.04)\end{array}$ & $\begin{array}{l}-0.00 \\
(-0.04 ; 0.03)\end{array}$ \\
\hline Non-lacunar stroke & 83 & $\begin{array}{l}0.03^{*} \\
(0.00 ; 0.05)\end{array}$ & $\begin{array}{l}0.01 \\
(-0.02 ; 0.04)\end{array}$ & $\begin{array}{l}0.01 \\
(-0.02 ; 0.04)\end{array}$ & $\begin{array}{l}0.01 \\
(-0.02 ; 0.04)\end{array}$ \\
\hline
\end{tabular}

Multiple hierarchical linear regression analysis, ${ }^{*} \mathrm{p}<0.05$. cSVD: cerebral small vessel disease, CI: confidence interval. Model 1 adjusted for age and gender. Model 2 adjusted for age, gender and vascular risk factors (diabetes mellitus, hypertension, hypercholesterolemia and smoking). Model 3 adjusted for age, gender, vascular risk factors and NIHSS.

\section{Association between total cSVD burden and self-reported SIS mobility domain}

The self-reported SIS mobility domain questionnaire, completed in 165 patients (83\%), had a median score of 77.8 (range 22.2-100). The median SIS mobility score did not differ between the lacunar stroke and non-lacunar stroke group (both median of 77.8 (range 22.2-100), $\mathrm{p}=0.78$ ).

Table 6.3 shows associations between total cSVD burden and SIS mobility domain score. No association was found between total cSVD burden score and SIS mobility domain score in the total minor stroke group, nor in lacunar stroke patients. In nonlacunar stroke patients the total cSVD burden was associated with worse scores on the SIS mobility domain (unstandardized B -6.68, 95\% CI -9.96;-3.40, p<0.01). This association remained significant after adjustment for age, gender, vascular risk factors and stroke severity (unstandardized B -4.61; 95\% CI -8.42;-0.79, p<0.05). There was a strong correlation between objectively measured TUG test and subjectively assessed SIS mobility domain score: correlation coefficient $-0.58(\mathrm{n}=142 ; \mathrm{p}<0.01)$. 
Table 6.3 Association between total cSVD burden and Stroke Impact Scale mobility domain score in minor stroke patients.

\begin{tabular}{llllll}
\hline \multicolumn{5}{c}{ Stroke Impact Scale mobility domain score } \\
\hline unstandardized B (95\% CI) & model 2 & model 3 \\
\hline Total cSVD score & $\mathrm{N}$ & unadjusted & model & model & -0.95 \\
\hline Total minor stroke & 165 & $-3.05^{*}$ & -1.76 & -1.55 & $(-3.77 ; 1.86)$ \\
& & $(-5.65 ;-0.45)$ & $(-4.51 ; 1.00)$ & $(-4.35 ; 1.25)$ & 2.22 \\
Lacunar stroke & \multirow{2}{*}{0} & 0.50 & 1.40 & 1.20 & $(-2.15 ; 6.60)$ \\
Non-lacunar stroke & \multirow{2}{*}{92} & $(-3.71 ; 4.71)$ & $(-3.26 ; 6.06)$ & $(-3.43 ; 5.83)$ & $-4.61^{*}$ \\
& & $-6.68^{\dagger}$ & $-4.69^{*}$ & $-4.30^{*}$ & $(-8.42 ;-0.79)$ \\
\hline
\end{tabular}

Multiple hierarchical linear regression analysis, ${ }^{*} \mathrm{p}<0.05,{ }^{\dagger} \mathrm{p}<0.01$. cSVD: cerebral small vessel disease, CI: confidence interval. Model 1 adjusted for age and gender. Model 2 adjusted for age, gender and vascular risk factors (diabetes mellitus, hypertension, hypercholesterolemia and smoking). Model 3 adjusted for age, gender, vascular risk factors and NIHSS.

\section{Association between total cSVD burden and mRS}

At three years of follow-up, 200 patients had mRS measurement with a median mRS of 1 (range 0-5). One hundred seventy-four patients (87\%) were functionally independent $(\mathrm{mRS} \leq 2)$ and 26 patients $(13 \%)$ were functionally dependent (mRS 3-5). The total cSVD burden was associated with $\mathrm{mRS}>2$ in the total stroke group (OR 1.47; 95\% CI: 1.052.06; $\mathrm{p}<0.05)$. However, this association lost significance after adjusting for age, gender, vascular risk factors and baseline stroke severity (OR 1.21; 95\% CI 0.79-1.87, $\mathrm{p}=0.38$ ). No association was found between total cSVD burden and $\mathrm{mRS}$ in non-lacunar stroke patients $(n=113)$, nor in the lacunar stroke group $(n=87)$.

\section{Discussion}

Our study did not find an association between total cSVD burden and objectively measured gait disturbances, nor with subjectively assessed gait impairment in the total minor stroke group three years after stroke. However, in non-lacunar stroke patients the total cSVD burden score was associated with lower self-reported SIS mobility domain scores three years after stroke, independent of stroke severity.

Previous neuroimaging studies have consistently demonstrated that individual MRI markers of cSVD are related to gait impairment ${ }^{4-5,9-10,20}$, mainly in community-dwelling subjects rather than stroke patients. The Radboud University Nijmegen Diffusion Tensor and Magnetic Resonance Imaging Cohort (RUNDMC) study, which included patients with clinical cSVD (including stroke and gait impairment), showed that WMH, number of lacunes and $\mathrm{CMB}$ were associated with concurrent gait dysfunction, including impaired gait velocity and a prolonged TUG test ${ }^{5,9}$. The Leukoaraiosis and Disability (LADIS) study showed that WMH were associated with concurrent deterioration of gait function, especially at older age ${ }^{4,10}$. 
Although these studies have shown that individual MRI markers of cSVD are independently linked to concurrent gait impairment, these cSVD markers rarely occur in isolation on MRI. There is increasing evidence that a total cSVD MRI burden score, which summarizes individual cSVD markers in a compound scale, might better reflect the global overall effect of cSVD on the brain ${ }^{11-14,20-21}$. A study 22 in older subjects with vascular risk factors showed that concurrent gait function, measured by Unified Parkinson's Disease Rating Scale ${ }^{23}$, was associated with total cSVD burden. This was the first study looking at concurrent gait function and overall cSVD burden (but not after stroke), although the cSVD burden score was incomplete as they did not include PVS. Recently, a study ${ }^{20}$ in community-dwelling older subjects found that WMH and the total cSVD score were independently associated with slower gait speed assessed by a six-meter walk test.

Contrary to these positive results in larger studies, mostly in subjects without stroke, we did not find any association between total cSVD burden and gait disturbances, measured by TUG test. There are several differences between studies. Our sample size was smaller, although the direction of the effect was consistent with an association between total cSVD burden and slowing gait. Second, we used the TUG test, and did not perform functional gait analysis, which would be a more quantitative and more sensitive method in assessing (subtle) mobility impairment. However, the TUG test is a valid outcome measurement that assesses basic functional mobility in routine practice ${ }^{18}$, is representative of daily activities, also in stroke patients ${ }^{24}$ and is conceptually similar to the six-meter walk. Third, our minor stroke population was somewhat younger compared to several previous studies with community-dwelling subjects $4,10,20,22$. Last, the LADIS 4,10 and RUNDMC 5,9 study selected patients based on presence of WMH. This could have led to a higher WMH burden in these cohorts compared to ours. However, as the measurement methods were different (volumetric versus visual scales), it is difficult to compare. In our cohort, $43 \%$ had extensive WMH (represented by 1 point in cSVD burden score), while $54 \%$ had mild WMH and only 3\% had no WMH at all.

Subjectively measured mobility impairment was associated with the total cSVD burden score in non-lacunar stroke patients. The self-reported SIS mobility domain score was available for more patients and therefore increased power. The SIS is a valid and reliable comprehensive stroke-specific health outcome measurement, especially in minor strokes $^{19}$ and captures the impact of stroke on multiple domains, including mobility ${ }^{25}$. We found a strong correlation between TUG test and SIS mobility domain score, meaning that perceived mobility disturbances are relevant and furthermore, mobility is a broader function than what is measured by the TUG test. The associations we found were present in non-lacunar stroke patients, but not in lacunar stroke patients. A possible explanation could be that stroke subtype is a moderator of the effect of cSVD on outcome; a non-lacunar ischemic stroke could make the brain more vulnerable to the impact of cSVD. Furthermore, as we did not find an association between the total cSVD burden score and mRS three years after minor stroke, it should be noted that any association between the total cSVD burden score and mobility impairment is not simply because of 
a co-association with worse functional stroke outcome after minor stroke. Therefore, our results indicate that minor non-lacunar stroke patients with a high total cSVD load on MRI are prone to report more often subjective mobility disturbances three years after minor stroke, independent of stroke severity.

Our study has several limitations. Although this is the first study which investigates if the total cSVD burden score could be a possible marker in predicting gait impairment in patients with minor stroke, our sample is small for a common disease like stroke. A larger study is warranted to confirm if the association between gait speed and total cSVD burden reaches significance in a larger sample. We measured gait function at three years after stroke onset, so it could be that significant disabled patients may not have participated in clinical follow-up, leading to selection bias. We did not have gait function at baseline, so we could not explore gait decline, nor correct for pre-existing gait disturbances.

A strength of our study is that it was prospective, systematic and assessments were blinded. We used standardized international consensus criteria ${ }^{2}$ to describe cSVD imaging findings and provide predictive rather than just concurrent mobility data. Furthermore, we used an overall cSVD-related brain damage score. The total cSVD burden score is a pragmatic and simple visual score, which gives a more comprehensive view of the impact of cSVD on the brain ${ }^{12}$. Patients with minor (non-disabling) stroke are an ideal stroke subgroup for exploring the relationship between cSVD burden and gait disturbances, as the impact of stroke itself on outcome measurements is probably reduced.

\section{Conclusion}

The total cSVD burden was not associated with objectively measured gait impairment, nor with subjectively assessed gait disturbances in minor stroke patients, nor in lacunar stroke patients. As patients with non-lacunar stroke and a higher total cSVD burden report more often subjective mobility impairment three years after stroke, the total cSVD burden score is a possible marker to identify non-lacunar stroke patients at risk for subjective gait impairment. These findings should be confirmed in a larger study.

\section{Funding}

The Mild Stroke Study-2 follow up study at 3 years was funded by Chest Heart Stroke Scotland. The original MSS-2 study was funded by the Wellcome Trust (ref. 088134/Z/09/A) and Row Fogo Charitable Trust. The imaging was performed at the Brain Research Imaging Centre Edinburgh, which is supported by the SINAPSE collaboration and the Chief Scientist Office of the Scottish Government (http://www.bric.ed.ac.uk/). The work was supported by European Union Horizon 2020 (EU H2020), PHC-03-15, project No 666881, 'SVDs@Target', and the Fondation Leducq Transatlantic Network of Excellence for Study of Perivascular Spaces in Small 
Vessel Disease, ref no. 16 CVD 05. The work reflects the views of the authors and not of the funders. CMJL was supported by the Dutch Alzheimer Foundation and VC holds a NHS Research Scotland Fellowship. The work was performed in the Edinburgh Dementia Research Centre in the UK Dementia Research Initiative. 


\section{References}

1. Wardlaw JM, Smith C, Dichgans M. Mechanisms of sporadic cerebral small vessel disease: insights from neuroimaging. Lancet Neurol 2013;12:483-497.

2. Wardlaw JM, Smith EE, Biessels GJ, et al. Neuroimaging standards for research into small vessel disease and its contribution to ageing and neurodegeneration. Lancet Neurol 2013;12:822-838.

3. Debette S, Markus HS. The clinical importance of white matter hyperintensities on brain magnetic resonance imaging: systematic review and meta-analysis. BMJ 2010;341:c3666.

4. Baezner H, Blahak C, Poggesi A, et al. Association of gait and balance disorders with age-related white matter changes: the LADIS study. Neurology 2008;70:935-942.

5. de Laat KF, van Norden AG, Gons RA, et al. Gait in elderly with cerebral small vessel disease. Stroke 2010;41:1652-1658.

6. Leonards CO, Ipsen N, Malzahn U, Fiebach JB, Endres M, Ebinger M. White matter lesion severity in mild acute ischemic stroke patients and functional outcome after 1 year. Stroke 2012;43:3046-3051.

7. Kim BJ, Leeb SH. Prognostic Impact of Cerebral Small Vessel Disease on Stroke Outcome. J Stroke 2015;17:101-110.

8. The IST-3 collaborative group. Association between brain imaging signs, early and late outcomes, and response to intravenous alteplase after acute ischaemic stroke in the third International Stroke Trial (IST-3): secondary analysis of a randomised controlled trial. Lancet Neurol 2015;14:485-496.

9. de Laat KF, van den Berg HA, van Norden AG, Gons RA, Olde Rikkert MG, de Leeuw FE. Microbleeds are independently related to gait disturbances in elderly individuals with cerebral small vessel disease Stroke 2011;42:494-497.

10. Kreisel SH, Blahak C, Bäzner H, et al. Deterioration of gait and balance over time: the effects of age-related white matter change--the LADIS study. Cerebrovasc Dis 2013;35:544-553.

11. Klarenbeek P, Van Oostenbrugge RJ, Rouhl, RP, Knottnerus ILH, Staals J. Ambulatory blood pressure in patients with lacunar stroke: association with total MRI burden of cerebral small vessel disease. Stroke 2013;44:2995-2999.

12. Staals J, Makin S, Doubal F, Dennis M, Wardlaw JM. Stroke subtype, vascular risk factors and total MRI brain small-vessel disease burden. Neurology 2014;83:1228-1234.

13. Huijts M, Duits A, van Oostenbrugge RJ, Kroon AA, de Leeuw PW, Staals J. Accumulation of MRI markers of cerebral small vessel disease is associated with decreased cognitive function. A study in first-ever lacunar stroke and hypertensive patients. Front Aging Neurosci 2013;5:72.

14. Staals J, Booth T, Morris Z, et al. Total MRI load of cerebral small vessel disease and cognitive ability in older people. Neurobiology of Aging 2015;36:2806-2811.

15. Makin SD, Doubal FN, Dennis MS, Wardlaw JM. Clinically Confirmed Stroke With Negative DiffusionWeighted Imaging Magnetic Resonance Imaging: Longitudinal Study of Clinical Outcomes, Stroke Recurrence, and Systematic Review. Stroke 2015;46:3142-3148.

16. Valdés Hernández M del C, Armitage PA, Thrippleton MJ, et al. Rationale, design and methodology of the image analysis protocol for studies of patients with cerebral small vessel disease and mild stroke. Brain Behav 2015;5:e00415.

17. Wardlaw JM, Makin S, Valdés Hernández MC, et al. Blood-brain barrier failure as a core mechanism in cerebral small vessel disease and dementia: evidence from a cohort study. Alzheimers Dement 2017;13:634-643.

18. Podsiadlo D, Richardson S. The timed "Up \& Go": a test of basic functional mobility for frail elderly persons. J Am Geriatr Soc 1991;39:142-148.

19. Duncan PW, Wallace D, Lai SM, Johnson D, Embretson S, Laster U. The stroke impact scale version 2.0. Evaluation of reliability, validity, and sensitivity to change. Stroke 1999;30:2131-2140.

20. Pinter D, Ritchie SJ, Doubal F, et al. Impact of small vessel disease in the brain on gait and balance. Sci Rep 2017;7:41637.

21. Field TS, Doubal FN, Johnson W, et al. Early life characteristics and late life burden of cerebral small vessel disease in the Lothian Birth Cohort 1936. Aging 2016;8:2039-2061.

22. Hatate J, Miwa K, Matsumoto M, et al. Association between cerebral small vessel diseases and mild parkinsonian signs in the elderly with vascular risk factors. Parkinsonism Relat Disord 2016;26:29-34.

23. Fahn S, Elton RL, Members of the UPDRS Development Committee. in: Fahn S, et al. (Eds.), Recent Developments in Parkinson's Disease, vol. 2, Macmillan Health Care Information, Florham Park, New Jersey, 1987,153-163. 
24. Hershkovitz A, Gottlieb D, Beloosesky Y, Brill S. Assessing the potential for functional improvement of stroke patients attending a geriatric day hospital. Arch Gerontol Geriatr 2006;43:243-248.

25. Lai SM, Studenski S, Duncan PW and Perera S. Persisting Consequences of Stroke Measured by the Stroke Impact Scale. Stroke 2002;33:1840-1844. 


\section{Supplemental data}

\section{Study Population and Recruitment}

We used data from a prospective observational study in patients with minor stroke (Mild Stroke Study-2). The methods have been described in detail before ${ }^{1-3}$. Briefly, this study recruited stroke patients who presented with minor lacunar or non-lacunar (i.e. large artery cortical or subcortical) ischaemic stroke to the Lothian regional stroke service (Western General Hospital, Edinburgh, UK) from May 2010 to May 2012. Patients with contra-indications for MRI, unstable medical conditions and with a severe (NIHSS>7) and disabling stroke were excluded. The study was approved by the Scotland and Lothian Research Ethics Committee (ref 09/S1101/54) and all patients gave written informed consent.

\section{Baseline clinical Data}

Baseline demographics, clinical features and vascular risk factors were recorded at baseline: age, gender, hypertension (blood pressure $\geq 140 / 90 \mathrm{mmHg}$ or a previous diagnosis), diabetes mellitus (fasting blood glucose $\geq 6.1 \mathrm{mmol} / \mathrm{L}$ or a previous diagnosis), hypercholesterolemia (total cholesterol $>5.0 \mathrm{mmol} / \mathrm{L}$ or a previous diagnosis) and smoking status. The stroke severity was determined by the NIHSS.

\section{MR imaging}

All patients underwent a 1.5 Tesla brain MRI scan (median onset-to-MRI time was 7 days with a range of 0-142 days) on a research-dedicated 1.5 T MR scanner (Signa LX; General Electric, Milwaukee, WI). Sequences included axial DWI, FLAIR, T2-weighted imaging, GRE and sagittal T1-weighted sequences. Details were described elsewhere 1-3. $^{-3}$ An experienced neuroradiologist assessed MR images, blinded to clinical information, for presence and location of an acute symptomatic infarct. An acute infarct was defined as a hyperintense area on DWI with corresponding reduced signal on apparent diffusion coefficient imaging, with or without an increased signal on FLAIR or T2-weighted imaging and a reduced signal on T1-weighted imaging 4 . We defined a recent lacunar infarct as a round or ovoid lesion, with axial diameter $<20 \mathrm{~mm}$, in the basal ganglia, internal capsule, centrum semiovale or brainstem, with similar signal characteristics as described above, and carefully distinguished from $\mathrm{WMH}^{5}$. Cortical infarcts were defined as infarcts involving cortical tissue (including adjacent subcortical tissue), or large ( $>20 \mathrm{~mm}$ axial diameter) striatocapsular or subcortical lesions ${ }^{6}$. MRI was also rated for presence of lacunes, WMH, CMB and basal ganglia PVS, all according to the STRIVE criteria for reporting studies in $\mathrm{CSVD}^{6}$. Lacunes were defined as round or ovoid lesions $(<20 \mathrm{~mm}$ axial diameter) of CSF signal intensity on T2 and FLAIR, generally with a hyperintense rim on FLAIR and no increased signal on DWI, in the basal ganglia, internal capsule, centrum semiovale or brainstem ${ }^{6}$. The intra-rater kappa for lacunes was $0.85^{7}$. Cerebral 
microbleeds were defined as small homogeneous, round foci of low signal intensity on GRE in the white matter, basal ganglia, brainstem, cerebellum or cortico-subcortical junction, with a diameter $<5 \mathrm{~mm}$, and differentiated from vessel flow voids and mineral depositions in the basal ganglia ${ }^{6}$. The interclass correlation coefficient for $\mathrm{CMB}$ was 0.68 to $0.78^{8}$. We graded deep and periventricular WMH according to Fazekas' scale? . The intra-class correlation coefficient for WMH intra-observer rating was $0.96^{7}$. Perivascular spaces were defined as round, oval or linear-shaped lesions with a smooth margin, absence of mass effect and with CSF signal intensity on T2-weighted images, and (if visible) hypointense on FLAIR images without a hyperintense rim to distinguish them from old lacunar infarcts ${ }^{6}$. Basal ganglia PVS were rated on a previously described, validated semiquantitative scale from 0 to $4^{10}$. The intra-rater kappa for basal ganglia PVS was 0.80 to $0.90^{7}$.

These MRI markers were summed in an ordinal "total cSVD burden score" (with a range of 0-4) by counting presence of each of these 4 MRI features as described earlier $^{7,11}$. One point on the total cSVD burden scale was awarded when one or more lacunes were present. Presence of one or more CMB gave one point on the total cSVD burden scale. One point was awarded on the total cSVD burden scale in case of (early) confluent deep WMH (Fazekas' score 2 or 3) and/or irregular periventricular WMH extending into the deep white matter (Fazekas' score 3). Presence of moderate to severe PVS at the basal ganglia (grade 2 to 4 ) gave one point on the total cSVD burden scale. The cut-off points of the total cSVD burden scale were tested and validated earlier $7,12-$ 13 .

\section{Stroke Subtype Classification}

We classified clinical stroke subtype into lacunar or non-lacunar stroke syndromes according to the Oxfordshire Community Stroke Project Classification"14. For "final diagnosis" the clinical and radiological subtype was considered and where these differed, the radiologic classification was used ${ }^{15}$. If no recent ischemic lesion corresponding with presenting symptoms was visible on MRI, the clinical classification was used ${ }^{14}$.

\section{Gait}

Three years after stroke, patients were contacted by post with a follow-up questionnaire, including the self-reported SIS, and were invited to attend for a follow-up with a faceto-face assessment (in hospital or through a home-visit), which included functional tests (including TUG test). The TUG test measures time (in seconds) to get up from a chair, walk 3 meters, turn around, walk back, and sit back down ${ }^{16}$. The SIS (version 3.0) is a stroke-specific, self-reported, health status assessment questionnaire with 59 items ${ }^{17}$ and includes 8 different domains, including mobility. We calculated the SIS mobility domain score (range 0-100) from 9 mobility items by using a validated domain score logarithm ${ }^{17}$. A low SIS mobility domain score reflects a high impact on health-related quality of life. 
The mRS is an ordinal scale ranging from 0 (no disability) to 6 (death), was available at three years after stroke and measures functional disability outcome after stroke ${ }^{18-19}$.

\section{Statistical Analysis}

Data were presented as mean \pm standard deviation for normally distributed data and as medians with range for nonparametric data. Categorical variables are presented as numbers $(\mathrm{N})$ with frequencies (\%). Differences between groups were tested by using independent samples t-test for normally distributed variables and Mann-Whitney $U$ test for variables with skewed distributions. Categorical variables were explored by Pearson $\chi^{2}$ and Fisher test. For our primary analyses, we analyzed TUG test as a log-transformed continuous variable: $\ln (T U G)$. We determined the association between $\ln (T U G)$ (dependent variable) and the total cSVD burden scale (as predictor variable) and the SIS mobility domain score (dependent variable) and the total cSVD burden scale (as predictor variable) by using a hierarchical linear multiple regression analysis. All analyses were performed with the total cSVD burden scale as a continuous variable. The regression analysis included 3 different models, in which we first corrected for age and gender (model 1), second for age, gender and vascular risk factors, including diabetes mellitus, hypertension, hypercholesterolemia and smoking (model 2) and model 3 was adjusted for age, gender, vascular risk factors and stroke severity (NIHSS at baseline, as a continuous variable). These regression analyses were performed in the total stroke group, but also separately in lacunar stroke and non-lacunar stroke patients. The results of linear regression analysis were presented as unstandardized B-values with 95\% confidence intervals $(95 \% \mathrm{CI})$. The relationship between TUG test and SIS mobility domain score was investigated by using Spearman's correlation coefficient. We also performed a secondary logistic regression analysis between the total cSVD burden score and mRS (dichotomized: 0-2 versus 3-5) at three years after minor stroke. Statistical significance was set at $\mathrm{p}<0.05$ (2-tailed). Analyses were performed using SPSS statistical software package (SPSS version 23.0; SPSS Inc, Chicago, IL).

\section{Patients Characteristics}

In total 264 patients with minor stroke were recruited at baseline ${ }^{1}$. At three years, 200 of these patients had a clinical follow-up (22 patients died, 16 patients declined and 26 patients were not contactable) and mRS available at three years after stroke (0-5). Of these, 157/200 patients completed an in-person follow-up and 43 patients declined a visit, but provided some follow-up data. In total, 165 follow-up patients completed the mobility domain questionnaire of the SIS and 145 patients had a TUG test (4 patients refused TUG test, 1 patient used a wheelchair, 1 patient had a leg amputation and 6 patients had unsafe mobility). 


\section{References}

1. Makin SD, Doubal FN, Dennis MS, Wardlaw JM. Clinically Confirmed Stroke With Negative DiffusionWeighted Imaging Magnetic Resonance Imaging: Longitudinal Study of Clinical Outcomes, Stroke Recurrence, and Systematic Review. Stroke 2015;46:3142-3148.

2. Valdés Hernández Mdel C, Armitage PA, Thrippleton MJ, et al. Rationale, design and methodology of the image analysis protocol for studies of patients with cerebral small vessel disease and mild stroke. Brain Behav 2015;5:e00415.

3. Wardlaw JM, Makin S, Valdés Hernández MC, et al. Blood-brain barrier failure as a core mechanism in cerebral small vessel disease and dementia: evidence from a cohort study. Alzheimers Dement 2017;13:634-643.

4. Warlow C, van Gijn J, Dennis M, et al. Is it a vascular event and where is the lesion? Identifying and interpreting the symptoms and signs of cerebrovascular disease. In: Warlow C, van Gijn J, Dennis M, et al. Stroke: Practical Management, 3rd ed. Malden, MA: Blackwell Publishing; 2008:35-130.

5. Wang X, Valdés Hernández MC, Doubal F, Chappell FM, Wardlaw JM. How much do focal infarcts distort white matter lesions and global cerebral atrophy measures? Cerebrovasc Dis 2012;34:336-342.

6. Wardlaw JM, Smith EE, Biessels GJ, et al. Neuroimaging standards for research into small vessel disease and its contribution to ageing and neurodegeneration. Lancet Neurol 2013;12:822-838.

7. Staals J, Makin S, Doubal F, Dennis M, Wardlaw JM. Stroke subtype, vascular risk factors and total MRI brain small-vessel disease burden. Neurology 2014;83:1228-1234.

8. Cordonnier C, Potter GM, Jackson CA, et al. Improving interrater agreement about brain microbleeds: development of the Brain Observer MicroBleed Scale (BOMBS). Stroke 2009;40:94-99.

9. Fazekas F, Chawluk JB, Alavi A, Hurtig HI, Zimmerman RA. MR signal abnormalities at 1.5 T in Alzheimer's dementia and normal aging. Am J Roentgenol 1987;149:351-356.

10. Doubal FN, MacLullich AM, Ferguson KJ, Dennis MS, Wardlaw JM. Enlarged perivascular spaces on MRI are a feature of cerebral small vessel disease. Stroke 2010;41:450-454.

11. Staals J, Booth T, Morris Z, et al. Total MRI load of cerebral small vessel disease and cognitive ability in older people. Neurobiology of Aging 2015;36:2806-2811.

12. Huijts M, Duits A, van Oostenbrugge RJ, Kroon AA, de Leeuw PW, Staals J. Accumulation of MRI markers of cerebral small vessel disease is associated with decreased cognitive function. A study in first-ever lacunar stroke and hypertensive patients. Front. Aging Neurosci 2013;5:72.

13. Klarenbeek P, Van Oostenbrugge RJ, Rouhl RP, Knottnerus ILH, Staals J. Ambulatory blood pressure in patients with lacunar stroke: association with total MRI burden of cerebral small vessel disease. Stroke 2013;44:2995-2999.

14. Bamford J, Sandercock P, Dennis M, Burn J, Warlow C. Classification and natural history of clinically identifiable subtypes of cerebral infarction. Lancet 1991;337:1521-1526.

15. Potter G, Doubal F, Jackson C, Sudlow C, Dennis M, Wardlaw J. Associations of clinical stroke misclassification ("clinical-imaging dissociation") in acute ischemic stroke. Cerebrovasc Dis 2010;29:395-402.

16. Podsiadlo D, Richardson S. The timed "Up \& Go": a test of basic functional mobility for frail elderly persons. J Am Geriatr Soc 1991;39:142-148.

17. Duncan PW, Wallace D, Lai SM, Johnson D, Embretson S, Laster U. The stroke impact scale version 2.0. Evaluation of reliability, validity, and sensitivity to change. Stroke 1999;30:2131-2140.

18. Rankin J. Cerebral vascular accidents in patients over the age of 60. II. Prognosis. Scott Med J 1957;2:200-215.

19. Quinn TJ, Dawson J, Walters MR, Lees KR. Reliability of the modified Rankin Scale: a systematic review. Stroke 2009;40:3393-3395 



\section{CHAPTER 7}

General discussion and future perspectives. 



\section{General discussion and future perspectives}

\section{Introduction}

Cerebral small vessel disease (cSVD) encompasses all pathological processes of small perforating brain vessels ${ }^{1}$. The incidence increases with age and in the presence of common vascular risk factors. It is related to cognitive impairment and dementia, lacunar stroke, gait impairment and general functional disability ${ }^{2-4}$. The burden on public health is substantial. The pathogenesis is largely unknown and ways to slow down the progression of consequences of cSVD are still lacking. Comprehension of the course of structural brain changes seen in cSVD might result in better understanding of both aetiology and consequences of cSVD, and eventually will lead to specific treatment options.

Conventional MRI plays an essential role in the diagnosis, evaluation of severity and progression of cSVD". Cerebral SVD causes "silent" brain damage that is visible on conventional MRI, including white matter hyperintensities (WMH), lacunes, cerebral microbleeds (CMB) and perivascular spaces (PVS). These MRI features of cSVD often exist long before clinical symptoms occur. MRI markers have a faster progression rate than clinical outcome measurements and thus, longitudinal studies are more suitable when imaging outcome markers are used as markers for disease evolution ${ }^{6}$. This is further supported by the difficulty to measure (subtle) changes in clinical outcomes, such as cognitive decline or gait disturbances, as these are often determined by several more factors than just cSVD. Also, sample size estimates to detect treatment effects in clinical trials are much smaller when using MRI markers as endpoints ${ }^{6}$. Consequently, MRI features of cSVD seem to be ideal surrogate markers for clinical trials in which novel treatments can be evaluated, even before clinical endpoints are reached. Besides, MRI features might also be used to define patients at risk for cognitive decline and gait impairment, and thus for selection of patients in trials. Eventually, this would lead to more personalized treatment approaches in cSVD to prevent disease progression.

The general aim of this thesis was to gain more insights into the course of structural brain changes seen in cSVD by assessing the radiological evolution of different MRI features of cSVD. This led to new insights on cavitation, development of WMH "caps", WMH "track" degeneration and progression of WMH. Reviewing the results of our studies and the evolving literature on CSVD, some questions and discussion points remain, which are:

I. What has imaging learned us about the natural disease course of cSVD?

II. Is it possible to design an overall cSVD progression score?

III. What are perspectives for future research?

\section{What has imaging learned us about the natural course of cSVD?}

If imaging features are used as surrogate markers for presence, severity and progression of cSVD, it is crucial to comprehend the natural evolution of these MRI features. In chapter 2 and 4, we described the radiological evolution of symptomatic lacunar infarcts. 
We found that most sporadic symptomatic lacunar infarcts cavitate over time. Longer time interval between stroke onset and imaging is the sole predictor of cavitation (chapter 2). Therefore, it seems that a symptomatic lacunar infarct undergoes a dynamic morphological process that, via cavitation, eventually results in a lacune. However, we also found that a portion of symptomatic lacunar infarcts disappears. Although it may be that the brain tissue healed without the formation of a lacune ("real" regression of cSVD), it seems more likely that these lacunar infarcts have progressed into small collapsed lacunes or micro-infarcts that are indiscernible at conventional MRI. This implies that conventional MRI could underestimate disease progression of cSVD.

Besides long-term morphological changes of the symptomatic lacunar infarct itself, we found that surrounding brain tissue undergoes secondary changes over time. We observed occurrence of WMH "caps" distally from symptomatic lacunar infarcts during follow-up (chapter 3 and 4). Based on appearance and location, we postulate that WMH "caps" might be the consequence of regionally impaired vascular autoregulation and chronic hypoperfusion in the internal border zone, at the end of the vascular territory of the deep perforator. This is consistent with the concept of a WMH "penumbra" . It has been suggested that the WMH "penumbra" is a predilection site for brain tissue at risk for deterioration, leading to a more severe lesion or new ischaemic lesions ${ }^{7-8}$.

We also found secondary changes of the descending white matter (WMH "track"), adjacent to the symptomatic lacunar infarct (chapter 4). Based on their location and radiological characteristics, it is plausible that these WMH "tracks" are the end stage of Wallerian degeneration. The presence of these secondary white matter abnormalities confirms the idea that symptomatic lacunar infarcts have a widespread effect on the surrounding brain tissue. Longitudinal MRI studies with tractography and diffusion tensor imaging have shown secondary white matter tract degeneration ${ }^{9}$ and atrophy of the overlying cortex ${ }^{10-11}$. Additionally, these secondary changes have been associated with impaired clinical outcome and cognitive decline?

The natural evolution of symptomatic lacunar infarcts and secondary changes of adjacent white matter reflect an accumulating and neurodegenerative disease course and indicate that cSVD lesions are intimately connected ${ }^{12}$. In chapter 5 , we found that extensive basal ganglia PVS were associated with progression of WMH, which supports the idea that cSVD MRI markers are intimately connected to each other during disease progression.

The dynamic evolution of cSVD has also been described in other studies. Both hospital and population based studies showed that WMH volume, lacunes and cerebral microbleeds increase over time ${ }^{13}$. Predictors of cSVD progression are baseline WMH severity, high lesion load at baseline and presence of vascular risk factors, including age, hypertension and current smoking ${ }^{13}$. In general, it was thought that this evolution of cSVD was linear and continuously progressive. However, recent studies suggest that cSVD might be a non-linear and highly dynamic process ${ }^{14}$. Progression of cSVD markers show accelerations over time that are associated with increasing age ${ }^{14}$. Besides progression, stationary phases and even regression of MRI features are seen in cSVD 
patients during follow-up ${ }^{13,15}$. Regression of WMH has long been overlooked and only recently gained attention. At this moment, it is unknown if regression of cSVD is accompanied by improvement of clinical outcome. It could be that regression of WMH is accompanied by atrophy of white matter tracts, which could mean that reduction of cSVD markers leads to clinical decline ${ }^{13-14}$. However, reduction of WMH volume might also reflect a reversible component. One study showed that a decrease of WMH was associated with blood pressure reduction and less recurrent cerebrovascular events ${ }^{15}$. This might imply that better vascular risk factor management could limit or even prevent progressive cSVD-related brain damage, which eventually leads to a better clinical outcome.

In conclusion, the radiological evolution of cSVD is best regarded as a highly dynamic process with phases of increase of cSVD-related lesions, formation of new lesions, but also regression, cavitation, disappearance of lesions, secondary changes in surrounding brain tissue and even distant (cortical) degenerative changes. The dynamics of the individual MRI features seem to be inter-related. This means that the use of MRI features as surrogate markers for cSVD progression is not straight forward.

\section{Is it possible to design an overall cSVD progression score?}

Most cSVD research focused on individual MRI markers, although a total cSVD burden score, composed of four MRI markers, gives a more comprehensive view of the overall impact of cSVD on the brain ${ }^{16}$. The total MRI burden score has been associated with age, vascular risk factors, including hypertension ${ }^{16-17}$, and cognitive function and decline ${ }^{18-20}$. This compound cSVD burden score is easy applicable in clinical practice as it is a visual rating scale of conventional MRI sequences.

Although cognitive decline is the most studied clinical consequence of cSVD-related brain damage, cSVD is also associated with gait impairment ${ }^{3}$. The total cSVD burden score has been associated with slower gait speed in community-dwelling older subjects ${ }^{21-}$ 22. We could not establish an association between the total cSVD burden score and speed of gait in minor stroke patients (chapter 6), although the direction of effect was consistent with a possible association. Nevertheless, we found that non-lacunar stroke patients with a high total cSVD burden score report more often subjective mobility impairment (chapter 6). This might imply that the total MRI burden score could be used as a neuroimaging marker of "brain frailty", which gives rise to vulnerability, and identify non-lacunar stroke patients at risk for (subjective) gait impairment related to cSVD (independent of the stroke itself). Larger studies are needed to confirm our results and to determine if the association between gait and total cSVD burden also exists in lacunar stroke patients.

Next to a baseline total cSVD burden score, a compound score for severity of cSVDrelated brain damage, a score that encompasses the progression of individual MRI markers in one measure, could add value in identifying patients at risk for further disease progression and worse clinical outcome. Taken the accumulating and dynamic nature of cSVD in consideration, a total cSVD progression score might give a more accurate 
estimation of the structural consequences of cSVD-related brain damage over time. This novel score should estimate severity of disease progression in a pragmatic way, such that it would be a practical surrogate outcome measure for clinical trials in which novel treatments are tested. This score has not been designed yet, and several requirements have to be fulfilled. First, the total cSVD progression score has to include all four MRI features, as they are all independently related with disease progression ${ }^{13}$. However, as we showed in chapter 5 , they are closely connected and to include them in one progression scoring method will be complicated. Second, this score should include secondary neurodegenerative changes of surrounding brain tissue, like WMH "tracks" and overlying cortical atrophy, as they are separate imaging features of disease progression related to clinical deterioration. Finally, different degrees of cSVD progression have to be included, and not just dichotomization of progression (yes/no) of each MRI marker, because progression is non-linear and very dynamic as discussed before.

In conclusion, a total cSVD burden score gives a more comprehensive estimation of the impact of cSVD on the brain and could possibly identify patients at risk for worse clinical outcome, including cognitive decline and gait impairment. As progression of cSVD seems to be highly dynamic and non-linear, progression scores of individual MRI markers are insufficient to predict the overall impact of cSVD on the brain. Future research should focus on the development of a pragmatic compound cSVD progression score, which is easy to apply in clinical practice. However, due to the highly dynamic natural evolution of cSVD, such a progression score will be challenging to develop. Furthermore, interpretation will be difficult, as stationary, regression and disappearance of cSVD lesions are part of the natural disease course.

\section{What are perspectives for future research?}

Although this thesis has led to new insights in the radiological evolution of cSVD, our studies also give rise to new research objectives.

If symptomatic lacunar infarcts form a cavity over time, this could result in loss of white matter connectivity, which eventually could impair clinical outcome. Therefore, it would be interesting to evaluate the connectivity of white matter tracts and their microstructural integrity in lacunar infarcts that have cavitated versus non-cavitated lesions with MRI techniques, such as DTI or MRI tractography.

Second, the prognostic value of secondary white matter changes for the impairment of cognition, gait and general functional outcome needs to be studied further. As cognitive functions depend on efficient functioning and integrity of complex cortical-subcortical networks ${ }^{23}$, it is plausible that these secondary white matter changes might cause (further) cognitive decline and gait impairment. Moreover, larger studies are warranted to identify risk factors or predictors of these secondary neurodegenerative changes, in order to prevent these. As not all symptomatic lacunar stroke patients show these secondary white matter changes, it is likely that (accumulation of) specific risk factors makes the brain vulnerable for these changes. We also hypothesized that WMH "caps" might be the consequence of regionally impaired vascular autoregulation and chronic 
hypoperfusion in of the vascular territory of the deep perforator (chapter 3). Therefore, it could be interesting to study longitudinally (regional) cerebral perfusion at the vicinity of a lacunar infarct, for example with advanced MRI imaging methods, to ground this hypothesis.

Most longitudinal studies, including ours, have assessed evolution of cSVD on MRI at two different time points (baseline and one follow-up). However, a longitudinal study with multiple time points, over a longer period of time, might give more insights in the temporal dynamics of symptomatic lacunar infarcts and secondary changes. A recent substudy of the RUNDMC assessed progression of individual cSVD markers at three time points over nine years and showed that progression of these MRI features cSVD is highly variable ${ }^{14}$.

Last, high resolution MRI techniques, including 7T MRI, have become more available for research. These techniques provide more detailed anatomical information of the small perforating vessels and cSVD-related brain damage. It would be interesting to study long-term morphological changes of symptomatic lacunar infarcts and surrounding brain tissue on 7T MR imaging. Besides visualizing structural changes of perforating vessels, 7T MR might also have the opportunity to view hemodynamic changes and reactivity in cSVD, by measuring blood flow velocity and pulsatility ${ }^{24-25}$. Even though it is unlikely that 7T MRI will be used routinely in clinical practice, it could be used in cSVD research to provide additional information on cSVD-related brain damage and neurodegeneration.

\section{Conclusion}

In conclusion, cSVD is not an innocent, slowly progressive disease, but should be seen as a neurological disorder with a highly dynamic, accumulating, and neurodegenerative nature. Further research on progression of cSVD should focus on the temporal dynamics of cSVD and on the development of a compound cSVD progression score, which could define more accurate patients at risk for the long-term clinical consequences of cSVD. If better vascular risk factor management could limit or even prevent progressive cSVD-related brain damage in the future, personalized treatment approaches will eventually improve clinical outcome, including gait function and general functional dependence. 


\section{References}

1. Wardlaw JM, Smith C, Dichgans M: Mechanisms of sporadic cerebral small vessel disease: insights from neuroimaging. Lancet Neurol 2013;12:483-497.

2. Pantoni L. Cerebral small vessel disease: from pathogenesis and clinical characteristics to therapeutic challenges. Lancet Neurol 2010;9:689-701.

3. de Laat KF, van Norden AG, Gons RA, van Oudheusden LJ, van Uden IW, Bloem BR, et al. Gait in elderly with cerebral small vessel disease. Stroke 2010;41:1652-1658.

4. Kim BJ, Leeb SH. Prognostic Impact of Cerebral Small Vessel Disease on Stroke Outcome. J Stroke 2015;17:101-110.

5. Wardlaw JM, Smith EE, Biessels GJ, Cordonnier C, Fazekas F, Frayne R, et al. Neuroimaging standards for research into small vessel disease and its contribution to ageing and neurodegeneration. Lancet Neurol 2013;12:822-838.

6. Benjamin P, Zeestraten E, Lambert C, Ster IC, Williams OA, Lawrence AJ, et al. Progression of MRI markers in cerebral small vessel disease: Sample size considerations for clinical trials. J Cereb Blood Flow Metab 2016;36:228-240.

7. Maillard P, Fletcher E, Harvey E, Carmichael O, Reed B, Mungas D, et al. White Matter Hyperintensity penumbra. Stroke 2011;42:1917-1922.

8. Duering M, Csanadi E, Gesierich B, Jouvent E, Hervé D, Seiler S, et al. Incident lacunes preferentially localize to the edge of white matter hyperintensities: insights into the pathophysiology of cerebral small vessel disease. Brain 2013; 136:2717-2726.

9. Reijmer YD, Freeze WM, Leemans A, Biessels GJ; Utrecht Vascular Cognitive Impairment Study Group. The effect of lacunar infarcts on white matter tract integrity. Stroke 2013;44:2019-2021.

10. Duering M, Righart R, Csanadi E, Jouvent E, Hervé D, Chabriat H, et al. Incident subcortical infarcts induce focal thinning in connected cortical regions. Neurology 2012;79:2025-2028.

11. Duering M, Righart R, Wollenweber FA, Zietemann V, Gesierich B, Dichgans M. Acute infarcts cause focal thinning in remote cortex via degeneration of connecting fiber tracts. Neurology 2015;84:1685-1692.

12. Wardlaw JM, Valdés Hernández MC1, Muñoz-Maniega S. What are white matter hyperintensities made of? Relevance to vascular cognitive impairment. J Am Heart Assoc 2015;4:001140.

13. van Leijsen EMC, de Leeuw FE, Tuladhar AM. Disease progression and regression in sporadic small vessel disease-insights from neuroimaging. Clinical Science 2017;131:1191-1206.

14. van Leijsen EMC, van Uden IWM, Ghafoorian M, Bergkamp MI, Lohner V, Kooijmans ECM, et al. Nonlinear temporal dynamics of cerebral small vessel disease: The RUN DMC study. Neurology 2017;10:1569-1577.

15. Wardlaw JM, Chappell FM, Valdés Hernández MDC, Makin SDJ, Staals J, Shuler K, et al. White matter hyperintensity reduction and outcomes after minor stroke. Neurology 2017;89:1003-1010.

16. Staals J, Makin S, Doubal F, Dennis M, Wardlaw JM. Stroke subtype, vascular risk factors and total MRI brain small-vessel disease burden. Neurology 2014;83:1228-1234.

17. Klarenbeek P, Van Oostenbrugge RJ, Rouhl, RP, Knottnerus ILH, Staals J. Ambulatory blood pressure in patients with lacunar stroke: association with total MRI burden of cerebral small vessel disease. Stroke 2013;44:2995-2999.

18. Huijts M, Duits A, van Oostenbrugge RJ, Kroon AA, de Leeuw PW, Staals J. Accumulation of MRI markers of cerebral small vessel disease is associated with decreased cognitive function. A study in first-ever lacunar stroke and hypertensive patients. Front. Aging Neurosci 2013;5:72.

19. Staals J, Booth T, Morris Z, et al. Total MRI load of cerebral small vessel disease and cognitive ability in older people. Neurobiology of Aging 2015;36:2806-2811.

20. Uiterwijk R, van Oostenbrugge RJ, Huijts M, De Leeuw PW, Kroon AA, Staals J. Total Cerebral Small Vessel Disease MRI Score Is Associated with Cognitive Decline in Executive Function in Patients with Hypertension. Front Aging Neurosci 2016;8:301.

21. Pinter D, Ritchie SJ, Doubal F, et al. Impact of small vessel disease in the brain on gait and balance. Sci Rep 2017;7:41637.

22. Hatate J, Miwa K, Matsumoto M, et al. Association between cerebral small vessel diseases and mild parkinsonian signs in the elderly with vascular risk factors. Parkinsonism Relat Disord 2016;26:29-34.

23. Lawrence AJ, Chung AW, Morris RG, Markus HS, Barrick TR. Structural network efficiency is associated with cognitive impairment in small-vessel disease. Neurology 2014:83;304-311. 
24. Bouvy WH, Geurts LJ, Kuijf HJ, Luijten PR, Kapelle LJ, Biessels GK et al. Assessment of blood flow velocity and pulsatility in cerebral perforating arteries with 7-T quantitative flow MRI. NMR Biomed 2016;29:12951304.

25. Schnerr RS, Jansen JFA, Uludag K, Hofman PAM, Wilberger JE, van Oostenbrugge RJ, et al. Pulsatility of Lenticulostriate Arteries Assessed by 7 Tesla Flow MRI-Measurement, Reproducibility, and Applicability to Aging Effect. Frontiers in Physiology 2017:8;961. 

Summary. 



\section{Summary}

Cerebral small vessel disease (cSVD) is an umbrella term that encompasses all pathological processes of the small brain vessels. The incidence of cSVD increases with age and presence of vascular risk factors, such as hypertension, diabetes mellitus and smoking. It is related to acute lacunar stroke, but also to chronic slowly progressive symptoms, such as cognitive impairment and dementia, as well as gait disturbances and general functional disability. The pathogenesis of cerebral SVD is still largely unknown. Therefore, specific prevention and treatment are suboptimal. As these small perforating vessels are difficult to visualize in vivo by standard imaging methods, most research has been focusing on brain parenchyma lesions which are associated with cSVD and which are visible on magnetic resonance imaging (MRI). These MRI markers are white matter hyperintensities (WMH), lacunes, cerebral microbleeds (CMB) and perivascular spaces (PVS).

Cerebral SVD is a progressive neurological disease. However, radiological patterns of disease progression have been studied little, and ways to slow down or prevent progression are consequently lacking. The general aim of this thesis was to gain more insights into the natural course of cSVD by assessing the radiological evolution of different MRI features of cSVD.

In chapter 2, we assessed the evolution of symptomatic lacunar infarcts over two years of follow-up in a first-ever lacunar stroke population. We included 82 first-ever stroke patients with a lacunar infarct in the deep brain regions. We performed a brain MRI at presentation and 2 years later, which was visually assessed on size of the lacunar infarct and presence of cavitation. We showed that most symptomatic infarcts had reduced in diameter and that the majority became partly or completely cavitated on follow-up imaging. A small portion disappeared, probably these small infarcts collapsed and were therefore not visible on MRI. Longer time interval between stroke onset and imaging was the sole predictor of cavitation. We concluded that cavitation seems to be a dynamic process, with a reduction in size over time, and with a definitive lacune as final result.

During the assessment of these imaging results, we noticed the occurrence of new WMH "capped" on the symptomatic lacunar lesion on several follow-up MR scans. We described our thoughts on this observation in chapter 3. In 15 of 82 first-ever lacunar stroke patients, we observed on 2-year follow-up MRI a new WMH in the zone adjacent to and just distal from the old lacunar infarct (WMH "caps"). The presence of these WMH "caps" was not associated with vascular risk factors, nor with presence of WMH at baseline, nor with progression of diffuse WMH. As the mean ambulatory blood pressure at baseline was significantly lower in those with a WMH "cap", we hypothesized that the distal zone adjacent to the lacunar infarct, might be vulnerable for regionally impaired vascular autoregulation and chronic hypoperfusion, resulting in a new, single WMH. 
To confirm our results from chapter 2 and 3, we investigated the long-term changes in imaging appearance of symptomatic lacunar infarcts and the adjacent white matter, in a (different) lacunar stroke cohort. In chapter 4, we selected, from two nonoverlapping single centre stroke studies, 79 lacunar stroke patients with a recent small subcortical (lacunar) infarct on baseline structural MRI (capsula interna, basal ganglia, centrum semiovale or brainstem) and with follow-up MRI available at one to five years later. We assessed changes in imaging characteristics of symptomatic lacunar infarcts and surrounding white matter. We found that most lacunar infarcts were cavitated on follow-up imaging. Besides WMH "caps", we also observed new WMH inferior from the index lacunar lesion, which seemed to be following a descending white matter tract similar to Wallerian degeneration. We called these WMH "tracks". We concluded that WMH "caps" and "tracks" may reflect another aspect of cSVD-related disease evolution. The clinical and prognostic value remains to be determined.

Perivascular spaces are considered to be an early MRI marker of cSVD, and are associated with other MRI markers of cSVD, including WMH. In chapter 5, we determined the association between severity of PVS and progression of WMH after 2-year followup in lacunar stroke patients. In 118 first-ever lacunar stroke patients we obtained brain MRI and a follow-up brain MRI 2 years later. We visually graded presence of PVS and WMH at baseline and progression of WMH on follow-up MRI. We showed that extensive basal ganglia PVS are associated with progression of WMH. As this association was not independent of baseline WMH, we concluded that presence of WMH at baseline remains an important determinant of further progression of WMH.

There is increasing evidence that a total cSVD MRI burden score, which encaptures the presence of the individual cSVD markers in one measure, might better reflect the overall effect of cSVD on the brain. In chapter 6 , we determined if the total burden of cSVD is related with mobility impairment in minor stroke patients 3 years after stroke. For this study, we included 200 patients with minor lacunar or non-lacunar stroke. Baseline MRI was visually rated for presence of lacunes, WMH, CMB and PVS, and summed in a total cSVD MRI burden score (range 0-4). Gait disturbances, measured by timed-up-and-go test and self-reported Stroke Impact Scale mobility domain were assessed three years after stroke. We found that the total cSVD burden score was not associated with gait impairment after minor stroke. However, patients with non-lacunar stroke and a higher total cSVD burden reported more subjective mobility impairment three years after stroke. We concluded that the total cSVD MRI burden score could be a possible marker to identify patients at risk for subjective gait impairment.

In chapter 7, we discussed the findings of this thesis and three important overarching questions that emerged from our results. First, we addressed the question what imaging has learned us about the natural disease course of cSVD. We substantiated why MRI markers are ideal surrogate markers in studies of cSVD. Besides long-term morphological changes of the symptomatic lacunar infarct itself (cavitation and micro-infarcts), we also found that surrounding brain tissue undergoes secondary changes (WMH "caps" 
and Wallerian degeneration) over time. Based on our findings, and recent literature, we concluded that radiological evolution of cSVD is a highly dynamic and non-linear process. Besides increase or stabilization of cSVD-related lesions, studies also show evidence for lesion regression. Individual MRI features also seem to be inter-related during disease progression and there are other imaging features of disease evolution, such as cavitation, WMH "caps" and "tracks". This means that the use of MRI features as surrogate markers for cSVD progression is not straight forward.

Second, we asked ourselves if it is possible to design an overall progression score. As mentioned earlier, a total cSVD burden score could give a more comprehensive view of the overall impact of cSVD on the brain, and could possibly identify patients at risk for worse clinical outcome. An ideal cSVD progression score should include, next to the 4 MRI markers of cSVD, secondary neurodegenerative features, such as WMH "tracks". However, such total cSVD progression score will be challenging to develop, due to the highly dynamic natural evolution of cSVD.

Thirdly, we discussed future perspectives for cSVD research. We think that it could be worthwhile to evaluate the connectivity of white matter tracts in cavitated versus noncavitated lesions, and to determine the clinical value of secondary white matter changes. A longitudinal study, over a longer period of time, and with multiple time points might give more insights in the dynamics of cSVD progression. Lastly, high resolution MRI techniques, including high field MRI, could provide additional information on CSVDrelated brain damage, neurodegeneration and hemodynamic changes in cSVD. 

Nederlandse samenvatting. 



\section{Nederlandse samenvatting}

Cerebrale small vessel disease (cSVD) of "ziekte van de kleine hersenbloedvaten" is een cluster van verschillende pathologische processen die de perforerende vaten van de hersenen aantasten. Deze aandoening is geassocieerd met toenemende leeftijd en de aanwezigheid van de klassieke risicofactoren voor hart- en vaatziekten, zoals hoge bloeddruk, suikerziekte en roken. Cerebrale SVD kan zich acuut, en meer chronisch progressief presenteren. De acute presentatie bestaat uit een lacunair herseninfarct, en de chronische presentatie bestaat uit geheugenstoornissen en dementie. Daarnaast is de chronische presentatie van cSVD ook geassocieerd met loopstoornissen en algemene achteruitgang in functioneren. Hoe cSVD exact ontstaat, is nog grotendeels onbekend. Daardoor is preventie en behandeling tot op heden niet optimaal. Omdat de perforerende bloedvaten in de hersenen zelf moeilijk in beeld gebracht kunnen worden, richten de meeste onderzoeken naar cSVD zich op de gevolgen in het hersenparenchym, die op een magnetische resonantie (MRI) hersenscan zichtbaar zijn. Deze MRI-kenmerken of "radiologische markers" van cSVD zijn lacunaire herseninfarcten, witte stof hyperintensiteiten (WMH), microbloedingen en perivasculaire ruimtes.

Cerebrale SVD is een langzaam voortschrijdend ziekteproces. Desalniettemin zijn radiologische patronen van ontwikkeling en progressie van cSVD nog maar weinig bestudeerd, terwijl dit mogelijk een veel beter beeld kan geven over het natuurlijke beloop van de ziekte en de eventuele relatie met de klinische verschijnselen. Het doel van dit proefschrift is om meer inzicht te krijgen in het natuurlijke beloop van cSVD door het bestuderen van de evolutie van de verschillende MRI-kenmerken bij patiënten met cSVD.

In hoofdstuk 2 hebben we de natuurlijke evolutie van symptomatische lacunaire herseninfarcten onderzocht bij een populatie met een eerste doorgemaakt lacunaire hersenberoerte. We includeerden 82 patiënten met een eerste lacunair herseninfarct. Allen kregen een MRI-hersenscan bij presentatie in het ziekenhuis en een vervolg MRI-scan 2 jaar later. Op beide MRI-scans werd de grootte van het lacunair infarct gemeten en werd de mate van "cavitatie" ("holtevorming") van het lacunair infarct bepaald. We lieten zien dat, na 2 jaar opvolging, 94\% van de diep gelegen symptomatische lacunaire herseninfarcten volledige of gedeeltelijke "cavitatie" toonden en dat de meeste lacunaire infarcten kleiner werden. Opvallend was dat een klein deel van de lacunaire infarcten niet meer zichtbaar was tijdens de opvolging, vermoedelijk doordat deze te klein waren geworden om nog met een MRI te detecteren. Een langer tijdsinterval tussen beide hersenscans was de enige voorspeller voor "cavitatie". We concludeerden dan ook dat "cavitatie" van lacunaire herseninfarcten een dynamisch proces lijkt te zijn, waarbij het infarct krimpt en er uiteindelijk een "lacune" wordt gevormd.

Bij de beoordeling van de MRI-hersenscans zagen we dat een deel van de patiënten op de vervolg MRI een nieuwe WMH naast het lacunaire herseninfarct ontwikkeld had. In hoofdstuk 3 beschrijven we deze nieuwe radiologische bevinding. In 15 van de 82 
geïncludeerde patiënten zagen we een dergelijk nieuwe, geïsoleerde WMH, meestal rond of ovaal van vorm, telkens aansluitend en distaal gelegen van het lacunaire infarct. Gezien deze WMH een soort kap over het infarct vormden, hebben we deze laesies WMH "caps" genoemd. We konden geen relatie vinden tussen WMH "caps" en aanwezigheid van vasculaire risicofactoren, noch met toename van WMH in het algemeen. Wel vonden we een relatie tussen het ontstaan van WMH “caps" en een lagere gemiddelde bloeddruk, en we veronderstellen dat de regio distaal van het lacunair herseninfarct gevoelig is voor veranderingen in autoregulatie en chronisch verminderde perfusie, welke uiteindelijk leidt tot het ontstaan van deze geïsoleerde WMH.

Om onze bevindingen (hoofdstuk 2 en hoofdstuk 3) te bevestigen, hebben we de radiologische verandering van symptomatische lacunaire herseninfarcten verder in kaart gebracht in een andere studiepopulatie. In hoofdstuk 4 hebben we de lange termijn veranderingen van symptomatische lacunaire herseninfarcten en omgevende witte stof op MRI-hersenscans onderzocht in 79 patiënten met een licht herseninfarct uit twee prospectieve, observationele studies. Allen hadden een lacunair herseninfarct doorgemaakt en hadden tevens een opvolging met een MRI-hersenscan, gemiddeld 1 tot 5 jaar na het herseninfarct. We vonden dat bijna alle lacunaire herseninfarcten gedeeltelijke of volledige "cavitatie" vertoonden op de vervolg MRI. Buiten de eerder beschreven WMH "caps" (hoofdstuk 3), observeerden we in deze studie bij een deel van de patiënten ook een nieuwe geïsoleerde WMH, die onder het lacunaire herseninfarct gelegen was. Dit was meestal zichtbaar op meerdere MRI sneden en we noemde dit WMH "tracks". Gezien deze WMH “tracks" dalende witte stof banen lijken te volgen, zijn deze vermoedelijk het radiologisch equivalent van Walleriaanse degeneratie. We concludeerden dat zowel WMH "caps" als "tracks" aparte fenomenen zijn van ziekte-evolutie, en dat hun klinische en prognostische waarde nog verder bepaald zal moeten worden.

Naast lacunaire herseninfarcten en WMH zijn perivasculaire ruimten een andere MRImarker van cSVD. Perivasculaire ruimten zijn met cerebrospinaal vocht gevulde ruimten rondom de kleine bloedvaten in de basale kernen en het centrum semiovale en worden gezien als een vroege uiting van cSVD. Deze zijn geassocieerd met andere MRI-markers van cSVD, en meer specifiek met uitgebreide WMH. In hoofdstuk 5 onderzochten we of de aanwezigheid van perivasculaire ruimten geassocieerd is met progressie van WMH. In deze studie werden 118 patiënten met een eerste lacunaire hersenberoerte geïncludeerd. Alle patiënten hadden een baseline MRI-hersenscan en een vervolg MRI-hersenscan na 2 jaar. Deze scans werden visueel beoordeeld, zowel op aanwezigheid van perivasculaire ruimten en WMH, als op toename van WMH. We vonden een relatie tussen de aanwezigheid van perivasculaire ruimten in de basale kernen en toename van WMH na 2 jaar. Deze relatie was onafhankelijk van leeftijd, geslacht en vasculaire risicofactoren. De aanwezigheid van WMH op de baseline MRI-hersenscan bleek echter de belangrijkste voorspeller voor toename van WMH te zijn.

De meeste studies naar cSVD onderzoeken de afzonderlijke MRI-kenmerken van cSVD, terwijl de verschillende radiologische merkers in werkelijkheid gecombineerd 
voorkomen. Een totale cSVD score, welke een samengestelde score is bestaande uit de 4 belangrijkste MRI-markers van cSVD, geeft een beter beeld van de ernst van de onderliggende ziekte en de totale impact van cSVD op de hersenen. In hoofdstuk 6 onderzochten we of de totale cSVD score gerelateerd is aan loopstoornissen en algemene functionele achteruitgang, 3 jaar na het doorgemaakte herseninfarct. In deze studie werden 200 patiënten met een lichte beroerte, zowel lacunair als niet-lacunair, geïncludeerd. Alle patiënten kregen een MRI-hersenscan op baseline, welke gescoord werd op aanwezigheid van de verschillende MRI-merkers. Deze werden opgeteld in een totale cSVD score. Drie jaar na de beroerte werden patiënten uitgenodigd voor een klinische opvolging met een functionele gangtest (timed-up-and-go test), functionele uitkomst score (gemodoficeerde Rankin Scale score) en zelf-rapportage vragenlijst over de impact van de beroerte op motorisch, sociaal en functioneel vlak (Stroke Impact Scale). We konden geen relatie aantonen tussen de totale cSVD score en objectief gemeten loopstoornissen (timed-up-and-go test). Patiënten met een niet-lacunair herseninfarct rapporteerden echter meer mobiliteitsklachten op de Stroke Impact Scale vragenlijst, onafhankelijk van de ernst van het herseninfarct. We concludeerden dan ook dat de totale cSVD score een merker kan zijn voor het identificeren van patiënten die een verhoogd risico hebben op subjectieve mobiliteitsproblemen.

In hoofdstuk 7 discussieerden we over de resultaten van de verschillende studies van het proefschrift en over drie belangrijke vragen, die ontstonden naar aanleiding van de resultaten van onze studies en eerdere studies. Als eerste gingen we in op de vraag wat de studie van de MRI-markers ons geleerd heeft over het natuurlijk beloop van de ziekte. We beargumenteerden waarom MRI-markers de ideale ziektemerkers zijn voor cSVD. We rapporteerden over de morfologische veranderingen van het lacunaire herseninfarct zelf ("cavitatie"), maar ook over de veranderingen van de omgeving, en meer specifiek de veranderingen van de omgevende witte stof rondom het lacunaire herseninfarct (WMH “caps" en Walleriaanse degeneratie). Uit dit alles, samen met recente literatuur, blijkt het natuurlijke beloop van cSVD radiologisch een niet-lineair en zeer dynamisch proces te zijn. Naast toename of stabilisatie van de bekende MRI-markers, wordt er ook soms een afname van MRI-kenmerken beschreven tijdens de opvolging. De verschillende MRI-kenmerken van cSVD lijken ook onderling verbonden te zijn tijdens ziekteprogressie, en zijn er nog andere kenmerken, zoals cavitatie, WMH “caps" en "tracks". Dit heeft als gevolg dat, het gebruik van individuele MRI-markers om ziekteprogressie in te schatten, nog niet volledig opgeklaard is.

Daarnaast stelden we ons ook de vraag of het mogelijk is een totale cSVD progressie score te ontwikkelen. Zoals eerder aangegeven, geeft een totale cSVD score een beter beeld van de totale impact van cSVD op de hersenen. Een totale cSVD progressie score zou idealiter patiënten kunnen identificeren die een verhoogde kans hebben op klinische achteruitgang en een slechtere uitkomst. Een ideale progressie score zou, naast de klassieke MRI-markers, ook andere neurodegeneratieve veranderingen, zoals WMH "tracks", moeten omvatten. Toch zal de ontwikkeling en het gebruik van zulk een cSVD 
progressie score niet evident zijn, rekening houdend met de dynamiek van ziekteprogressie.

Als derde en laatste punt gingen we in op de toekomstperspectieven voor verder cSVD onderzoek. Het zou interessant zijn om de connectiviteit van witte stofbanen bij lacunaire infarcten met en zonder "cavitatie" te vergelijken, of te kijken of de veranderingen in de witte stof gerelateerd zijn met een slechtere klinische uitkomst. Een longitudinale studie over een langere periode, met verschillende interval MRI-scans, zou een beter beeld kunnen geven van de dynamiek van cSVD. Daarnaast zouden nieuwe MRItechnieken, zoals hoge veldsterkte MRI, een beter beeld kunnen geven over de structurele veranderingen in de perforerende vaten, cSVD-gerelateerde neurodegeneratie en hemodynamische veranderingen in cSVD. 


\section{Valorisation.}





\section{Valorisation}

"Valorisation is the process of creating value from knowledge, by making knowledge suitable and/or available for social and/or economic exploitation and to translate this knowledge into competitive products, services, processes and new commercial activities." (adapted definition based on the National Valorisation Committee 2011:8). In other words, it is the important translation of scientific knowledge to social, financial and economical relevance.

\section{Economic and social burden of cSVD}

Stroke is one of the leading causes of long-term disability worldwide. In the Netherlands, approximately 41,000 people are yearly admitted to a hospital due to a stroke ${ }^{1}$. Further, the estimated number of patients who are living in the Netherlands with the consequences of a stroke is nearly 310,000 people ${ }^{1}$. The medical costs of stroke are substantial, accounting for $2.5 \%$ of the total medical costs in the Netherlands ${ }^{2}$. Therefore, stroke puts a major burden on the healthcare system and society in general. It is expected that that these numbers will increase over the years, as the mean age of the population will rise and the incidence of stroke increases with age.

Lacunar stroke accounts for $25 \%$ of all ischemic strokes and is in general caused by cerebral small vessel disease (cSVD), which is an umbrella term for all pathologies affecting small vessels of the brain. Besides stroke, cSVD also causes cognitive impairment, dementia and gait disturbances. These consequences increase the social burden of cSVD far beyond the negative consequences of stroke.

The pathogenesis of cSVD is largely unknown and ways to slow down the progression of cSVD are still lacking. Comprehension of the natural course and progression of structural brain changes seen in cSVD, results in better understanding of both pathogenesis and consequences of cSVD, and eventually will lead to specific treatment and prevention options. This thesis aids in understanding the natural disease course of cSVD and shows that the radiological evolution of cSVD is a highly dynamic process with progression, stability, regression and disappearance of cSVD lesions. These findings implicate that some cSVD lesions might be reversible and imply that better vascular risk factor management could limit or even prevent progressive cSVD-related brain damage, which eventually could lead to a better clinical outcome. It is expected that total healthcare costs will decrease by preventing progressive cSVD-related brain damage.

\section{Lacunar stroke}

Lacunar stroke is generally thought to be a "minor" stroke. However, a sporadic symptomatic lacunar stroke should not be seen as an isolated "minor" clinical event. A lacunar stroke is just one of the several clinical expressions of an underlying small vessel vasculopathy with a progressive and highly dynamic course. The dynamics of cSVD seems to be more complex than we thought. A symptomatic lacunar infarct shows morphological 
changes on the long term, but also shows that the surrounding brain tissue undergoes secondary neurodegenerative changes over time.

Valorisation of this scientific knowledge to clinical practice needs to be done. We have to assess the prognostic value of these secondary white matter changes on cognition, gait and general functional outcome. However, the most important start of knowledge valorisation is its publication. We made the knowledge of this thesis available for other researchers, (healthcare) organizations and the general public in multiple, scientific publications.

\section{Total SVD burden score}

As different MRI markers of cSVD often co-occur, it is thought that the presence of these MRI markers together, represents the severity of brain-related damage of cSVD. Earlier, our research group proposed the "total cSVD score", which combines all individual MRI markers of cSVD into one measure. This total cSVD burden score is easily applicable in clinical practice as it is a visual rating scale of conventional MRI sequences and does not need computer software. Further, a total cSVD burden score gives a more comprehensive view of the overall impact of cSVD on the brain. This thesis includes the first longitudinal study to determine the possible association between total cSVD burden and gait impairment after minor stroke. The results of this study imply that the total MRI burden score could be used as a neuroimaging marker of "brain frailty", which identifies stroke patients at risk for (subjective) gait impairment related to cSVD, independent of the incident stroke. Gait disturbances are common in the elderly and are related to functional disability, institutionalization, and death ${ }^{3-4}$.

Last years, the interest in this compound cSVD burden score has grown and other research groups have adopted the concept and also studied the predictive role of total cSVD score on clinical outcome measures. Recent studies showed that the total cSVD burden could predict mortality ${ }^{5}$, unfavourable functional outcome ${ }^{6}$ and worse quality of life after stroke ${ }^{7}$. Therefore, the evaluation of total cSVD burden could facilitate developing individual treatment and rehabilitation strategies in patients with cSVD, which eventually leads to a better functional outcome.

A similar concept for a compound cSVD progression score is needed. However, the development will be a challenge due to the dynamic nature of cSVD. As we showed, the natural evolution of cSVD is not just a simple disease progression.

\section{Conclusion}

This thesis helps neurologists and stroke clinicians to better understand the natural disease course of cSVD. Its seems that cSVD is not an innocent, slowly progressive disease, but rather a highly dynamic, accumulating, and neurodegenerative neurological disorder.

By preventing progressive cSVD-related brain damage in the future, personalized treatment approaches will eventually improve clinical outcome, including gait function 
and general functional independence. This will eventually unburden the healthcare system and society in the future. 


\section{References}

1. Buddeke J, van Dis I, Visseren FLJ, Vaartjes I, Bots ML. Hart- En Vaatziekten in Nederland 2017, Cijfers over Heden, Verleden En Toekomst. Hartstichting 2017.

2. RIVM. Kosten Van Ziekten. 2011.

3. Guralnik JM, Ferrucci L, Simonsick EM, Salive ME, Wallace RB. Lower-extremity function in persons over the age of 70 years as a predictor of subsequent disability. N Engl J Med 1995; 332: 556-561.

4. Verghese J, LeValley A, Hall CB, Katz MJ, Ambrose AF, Lipton RB. Epidemiology of gait disorders in community-residing older adults. J Am Geriatr Soc 2006;54:255-261.

5. Song TJ, Kim J, Song D, Yoo J, Lee HS, KimYJ, et al. Total cerebral small-vessel disease score is associated with mortality during follow-up after acute ischemic stroke. J. Clin. Neurol 2017;13:187-195.

6. Arba F, Inzitari D, Ali M, Warach SJ, Luby M and Lees KR. Small vessel disease and clinical outcomes after IV rt-PA treatment. Acta Neurol. Scand. 2017;136:72-77.

7. Liang Y, Chen YK, Deng M, Mok VCT, Wang DF, Ungvari GS, et al. Association of Cerebral Small Vessel Disease Burden and Health-Related Quality of Life after Acute Ischemic Stroke. Front Aging Neurosci. 2017;9:372. 
Dankwoord.

$>1$ 



\section{DANKWOORD}

Bloed, zweet, en tranen, maar dan... opeens, is het af! Zeven jaar geleden kreeg ik de kans om aan dit avontuur te beginnen. Vol enthousiasme ben aan mijn reis begonnen. Dat het een dynamisch avontuur werd, waarbij mijn boekje uiteindelijk een hele andere richting zou inslaan, had ik niet geheel verwacht. Maar dat is ook wetenschappelijk onderzoek doen... Natuurlijk zou dit boekje nooit tot stand gekomen zijn zonder de hulp en steun van vele mensen rondom mij. Mensen die me hebben bijgestaan, me hebben geïnspireerd, me hebben laten lachen, me moed hebben ingepraat en vooral van wie ik ook veel heb geleerd. Mijn dank hiervoor is groot. Enkele personen wil ik in het bijzonder danken, te beginnen met mijn promotoren.

Beste Prof. dr. RJ van Oostenbrugge, beste Robert. Als een soort vader heb je gewaakt over mij tijdens dit avontuur, zowel over mijn opleiding tot neuroloog, als over dit promotietraject. Je wist meermaals mijn (soms te) gevoelige snaar te raken met een gevatte (soms wat ongepaste) opmerking, maar toch wist je me steeds te stimuleren op die manier en het beste uit mij naar boven te halen. In het begin moest ik nogal wennen aan jouw "eigen" manier van denken (welke meestal enkele sprongen lijkt over te slaan) en communiceren (of beter gezegd: antwoorden met twee woorden op een - voor mij meestal erg doordachte - mail), toch ga ik onze gesprekken en (mail)conversaties missen. Ik zal je eeuwig dankbaar zijn dat je "iets" zag in dat Belgische meisje!

Beste dr. J Staals, beste Julie. Jij hebt een buitengewone grote bijdrage geleverd aan dit boekje. Eerlijk, zonder jou, was dit boekje er nooit gekomen. Jouw begeleiding, kritische blik en vooral geduld, werkten voor mij stimulerend. Meer dan eens heeft één enkele opmerking van jou me op het rechte pad gebracht. Daarnaast was je "mijn handleiding" als ik (weer) niet begreep wat Robert juist bedoelde. Daarnaast ben ik blij dat ik je afgelopen jaren, ook als "Julie" heb leren kennen (zoals tijdens een etentje in Chateau Neercanne). Hoe jij klinische taken, onderwijsmomenten en vasculair onderzoek combineert, is voor mij een voorbeeld! Dank om zo inspirerend te zijn.

Dear Prof. dr. JM Wardlaw, dear Joanna, I am so grateful that you gave me the opportunity to learn from you, and your research group at the Brain Research Imaging Centre in Edinburgh! Thanks for a lovely time in Scotland and I am honoured that you found time in your busy schedule to discuss my research in our weekly meetings during my stay in Edinburgh. Your critical point of view made every manuscript better! You have an amazing research team, which helped me in every way. Special thanks to Caroline, Vera, Stephen, Gordon, Mat, Francesca, Moira, Kirsten, and Brittany. Rozanna, ook al was onze tijd in Edinburgh samen kort, toch was mijn verblijf niet hetzelfde geweest zonder onze kleine onderonsjes. Ik wens je veel liefde en succes toe op jouw nieuw Edinburgh avontuur!

Beste Prof. dr. HJM Smeets, beste Bert. Ook al is het boekje uiteindelijk een hele andere richting uitgegaan, toch wil ik je langs deze weg bedanken voor jouw input en visie op 
genetisch onderzoek. Altijd enthousiast en optimistisch, ook al vielen de resultaten tegen. Ik ben nog steeds overtuigd dat er iets in zit, maar denk dat de tijd nog niet rijp is. Een stelling had ik je beloofd. Eveline, Mike en Ellen, dank om geduldig te zijn, en me alles op "dummy" formaat uit te leggen.

Ik wil de beoordelingscommissie, bestaande uit Prof. dr. WH Mess, Prof. dr. PAM Hofman, Prof. dr. CJM Klijn, Dr. ML Kuijf en Prof. dr. PM Parizel, hartelijk danken voor hun tijd en kritische beoordeling van mijn manuscript.

Ik wil alle neurologen, inclusief klinisch neurofysiologen, van het MUMC+ te Maastricht, Catharina ziekenhuis te Eindhoven en Epilepsiecentrum Kempenhaeghe te Heeze danken voor hun bijdrage, ieder op geheel eigen wijze, aan mijn opleiding tot neuroloog.

Ik dank de volledige vakgroep neurologie en het "neurovasculaire team", inclusief neurochirurgen, intensivisten en interventionele radiologen van het Universitair Ziekenhuis Antwerpen om me met open armen te ontvangen. Laetitia en Peter, dank om mijn start zo vlot te laten verlopen. Het voelt bijna als "thuis" komen. Ik kijk er erg naar uit om jullie persoonlijk beter te leren kennen, samen te werken en samen de beroertezorg naar een nog hoger niveau te tillen.

Mijn paranimfjes, Tine en Kim. Tine, hoewel we elkaar afgelopen jaren minder zagen door drukte en de afstand, toch was je mijn trouwste supporter in alles wat ik deed! Wat ben ik blij dat we weer wat dichter bij elkaar wonen en vooral dat Emma en Jules samen kunnen opgroeien. Kim, mijn steun en toeverlaat van de laatste jaren... Je bent een toparts, een topvrouw en een topmama. Laat je vooral niets anders wijsmaken. Dank dat je er steeds was voor mij. Ik ben zo trots dat jullie beide aan mijn zijde staan!

Assistenten van de vakgroep neurologie Maastricht, wat zijn jullie een fantastische groep! Blijf de groep die jullie nu zijn: vol enthousiasme, en met de nodige humor. Met spijt heb ik jullie uitgezwaaid. Rik, ik ben blij dat ik je voor altijd mijn "poulain" mag noemen! Je kan het, heb gewoon vertrouwen.

Assistenten van de vakgroep neurologie Antwerpen, wat is het leuk om enthousiasme te zien in alles wat jullie doen. Ik hoop dat ik een stimulerende factor binnen jullie opleiding mag zijn.

Lieve onderzoekers en collega's van de neurovasculaire onderzoeksgroep, wat hebben we lol gehad op de verschillende congressen en uitjes! Els en Marjolein, de "halve" Nederlanders of beter gezegd de "halve" Belgen,... hoewel we de laatste jaren elkaar wat uit het oog zijn verloren, toch ben ik dankbaar dat jullie er waren voor mij! Ellen, wat ben ik blij dat we samen de laatste loodjes hebben gehaald! Super veel succes met het afronden van jouw eigen boekje. Dank, Christa en Astrid, voor het faciliteren van alles. De polidames en de volledige afdeling neurologie (C5 en medium care C5), dank voor jullie interesse in alles wat ik deed.

Natuurlijk kan ik niet anders dan mijn "jonkies” nog eens extra te bedanken voor alle steun, de leuke jaarcursussen, borrels, lekkere etentjes, maar vooral voor de vriendschap! Martijn en Tom, "the original jonkies", samen aan de opleiding begonnen en samen de 
opleiding met fierheid beëindigd. Charlotte, Kim, Martine en Mark, dit geldt ook voor jullie. Wat ben ik blij dat ik jullie aan mijn zijde had afgelopen 6 jaar. Al zien we elkaar nu minder vaak, toch ben ik blij dat ik jullie nog dicht bij mij heb dankzij de moderne technologische wereld ( $6^{\mathrm{e}}$ jaars 4 life $(\dot{)})$ !

Moemoe, jij bent de reden, waarom ik ben, wie ik ben en waarom ik doe, wat ik doe. Ik sta hier vandaag onder jouw motto: “Als je iets doet, doe het dan met stijl!".

Kiki, je kan de golven niet stoppen, maar je kan wel leren surfen! Als je me iets hebt geleerd de laatste jaren, is het dat wel. Soms ben ik jaloers op jou... hoe jij in het leven staat en de vreugde die jij uit kleine dingen haalt. Wat ben ik blij dat jij mijn zus bent en dat jij dit boekje nog persoonlijker hebt gemaakt.

Arlette, dank voor al je hulp bij het corrigeren van sommige (dyslectische) teksten.

Lieve mama en papa, zonder jullie hulp, steun en toeverlaat, was ik nooit zover gekomen. Dank dat jullie me een veilig nest hebben gegeven, maar ook dat jullie me vrij hebben gelaten om te zijn wie ik ben, om me te laten doen wat ik wou en vooral om me aan te moedigen om steeds nog een stapje verder te gaan. Nooit heb ik me alleen of "dom" gevoeld en altijd heb ik op jullie kunnen rekenen, voor alles. Ik zal altijd van jullie blijven houden en draag dit boekje dan ook met veel trots aan jullie op.

Tenslotte, mijn 2 lieve prinsen... Jules, mijn engel, maar ook mijn bengel. Jij bent het beste van mij! Wat geniet ik elke dag van jouw lach, jouw ontdekkingstocht, jouw streken en deugnieterij, en vooral jouw liefde. Jij hebt me als persoon beter gemaakt. Wat kijk ik uit naar alles wat je nog zal bereiken in het leven!

En dan ten slotte, Maarten, zoetje, jouw liefde (al dan niet uitgesproken), jouw steun (welke soms gewoon jouw aanwezigheid is), jouw aanmoediging (vaak kort en krachtig) en jouw vertrouwen (in alles wat ik doe) zijn mijn drijfveer. Door jou kan ik de wereld aan! Kus. 

List of publications. 



\section{List of publications}

Loos CMJ, Staals J, Wardlaw JM. Response by Loos et al. to letter regarding article, "Long-term morphological changes of symptomatic lacunar infarcts and surrounding white matter on structural MRI". Stroke 2018;49:e269.

Loos CMJ, Stephen MDJ, Staals J, Dennis MS, van Oostenbrugge RJ, Wardlaw JM. Long-term morphological changes of symptomatic lacunar infarcts and surrounding white matter on structural MRI. Stroke 2018;49:1183-1188.

van Montfort L, Loos CMJ, Anten M, Jansen RLH. Herpes Encephalitis: A Mortal Complication in a Patient Treated with Immunosuppressive Drugs because of ImmuneRelated Adverse Events after Ipilimumab Treatment. Case Rep Oncol 2017;10:11121115.

Loos CMJ, McHutchison C, Cvoro V, Staals J, Chappell F, van Oostenbrugge RJ, Wardlaw JM. The relation between total cerebral small vessel disease burden and gait impairment in patients with minor stroke. Int J Stroke 2017;1:1747493017730780.

Loos CMJ, Klarenbeek P, van Oostenbrugge RJ, Staals J. Association between basal ganglia perivascular spaces and progression of white matter hyperintensities in lacunar stroke patients. PLoS One 2015;10:e0137323.

Nederkoorn PJ, van Dijk EJ, Koudstaal PJ, Luijckx GJ, van Oostenbrugge RJ, Visser MC, Wermer MJ, Ruigrok YM, Algra A, Kappelle LJ; Dutch String-of-Pearls Stroke Study-Group. Luitse M, Zweedijk B, Kappelle L, Rinkel GJ, Ruigrok YM, Algra A, Nederkoorn PJ, Baharoglu I, Ek-Post M, Luijckx GJ, Messchendorp G, van de Minne F, Oostenbrugge RJ, Loos CM, Lindl A, Koudstaal PJ, Fonville S, Scheele M, Wermer MJ, Hamming AM, Janssen K, van Dijk EJ, Wilbers J. The Dutch String-of-Pearls Stroke Study: protocol of a large prospective multicenter genetic cohort study. Int J Stroke 2015;10:120-122.

Loos CMJ, van Oostenbrugge RJ, Staals J. The appearance of a new white matter lesion adjacent to the old infarct in first-ever lacunar stroke patients: a two-year follow-up study with MRI. Cerebrovasc Dis 2012;34:443-445.

Loos CMJ, Staals J, Wardlaw JM, van Oostenbrugge RJ. Cavitation of deep lacunar infarcts in first ever lacunar stroke patients: a two year follow-up study with MR. Stroke 2012;43:2245-2247.

Loos CMJ, Achten E, Santens P. Proton magnetic resonance spectroscopy in Alzheimer's disease. Acta Neurol Belg 2010;110:291-298. 



\section{Curriculum Vitae.}

Caroline Maria Jozef Loos was born on the $4^{\text {th }}$ of June 1985 in Turnhout, Belgium. She is the second child and daughter of Renaat Achille Paulina Loos, married with Anna Maria Cecilia Raymond Adriaensens. She grew up, together with her sister Christine, in the Belgian "Kempen". In 1988, she went to primary school "Maria Goretti" in Herselt. From 1997-2003, she followed her education at "Sint-Lambertus" school, Westerlo. She opted for the study direction Latin-Mathematics and Science-Mathematics. In 2003, 18 years old, she moved to Ghent and started her medical study at Ghent University, Belgium. On 24th of June 2010 she received her master degree of medicine and spoke the Hippocratic Oath.

During her medical study, she became fascinated by neurology and research and wrote her first manuscript on Alzheimer's disease and spectroscopy, under supervision of Prof. dr. P Santens (University Ghent). In 2010, she started working as a resident at the department of neurology of Maastricht University Medical Centre (MUMC+), the Netherlands, and began her doctoral research on cerebral small vessel disease (which resulted in this thesis), under supervision of Prof. dr. RJ van Oostenbrugge and Dr. J Staals. (MUMC+). From 2010 to 2012 she was the local coordinator of the String of Pearls Initiative, Stroke pearl. She married Maarten Trossaert in 2014, in Hoegaarden, Belgium. In 2016, she went to Edinburgh for 3 months to do research at the Brain Research Imaging Centre, University Edinburgh, UK, supervised by Prof. dr. JM Wardlaw. In August 2016, she became mother of Jules Maria Polydor Trossaert, her first son. On $13^{\text {th }}$ of December 2017, she finished her neurology training (MUMC+). She started working as a neurologist with neurovascular focus at Antwerp University Hospital (UZA), Belgium. As a member of the NeuroVascular Center Antwerp (NVCA), she combines clinical work and research in an academic setting with the focus on neurovascular diseases.

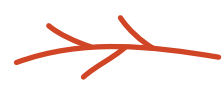




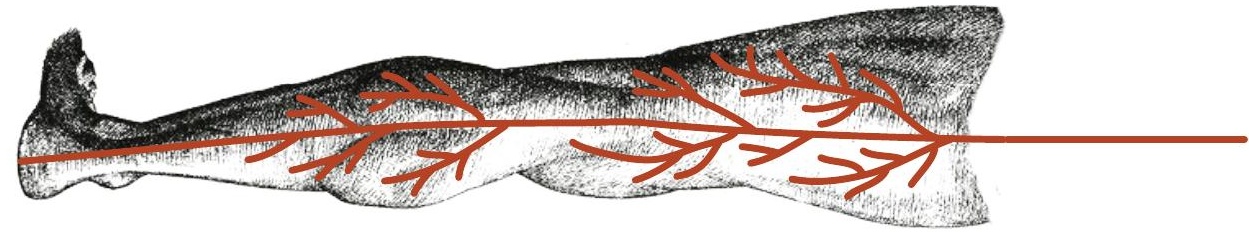

CAROLINE M.J. LOOS

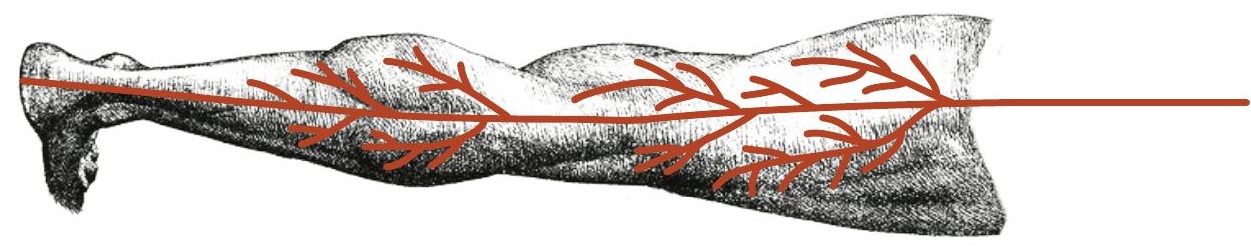

